Portland State University

PDXScholar

$11-4-1993$

\title{
The Voices I Never Hear: Communication Apprehension and Associated Nonverbal Behaviors in the Primary School Child
}

Linda Dunn

Portland State University

Follow this and additional works at: https://pdxscholar.library.pdx.edu/open_access_etds

Part of the Speech and Rhetorical Studies Commons

Let us know how access to this document benefits you.

Recommended Citation

Dunn, Linda, "The Voices I Never Hear: Communication Apprehension and Associated Nonverbal Behaviors in the Primary School Child" (1993). Dissertations and Theses. Paper 4656.

https://doi.org/10.15760/etd.6540

This Thesis is brought to you for free and open access. It has been accepted for inclusion in Dissertations and Theses by an authorized administrator of PDXScholar. Please contact us if we can make this document more accessible: pdxscholar@pdx.edu. 
AN ABSTRACT OF THE THESIS OF Linda Dunn for the Master of Science in Speech Communication presented November 4, 1993 .

TITLE: The Voices I Never Hear: Communication

Apprehension and Associated Nonverbal Behaviors in the Primary School Child

APPROVED BY MEMBERS OF THE THESIS COMMITTEE:
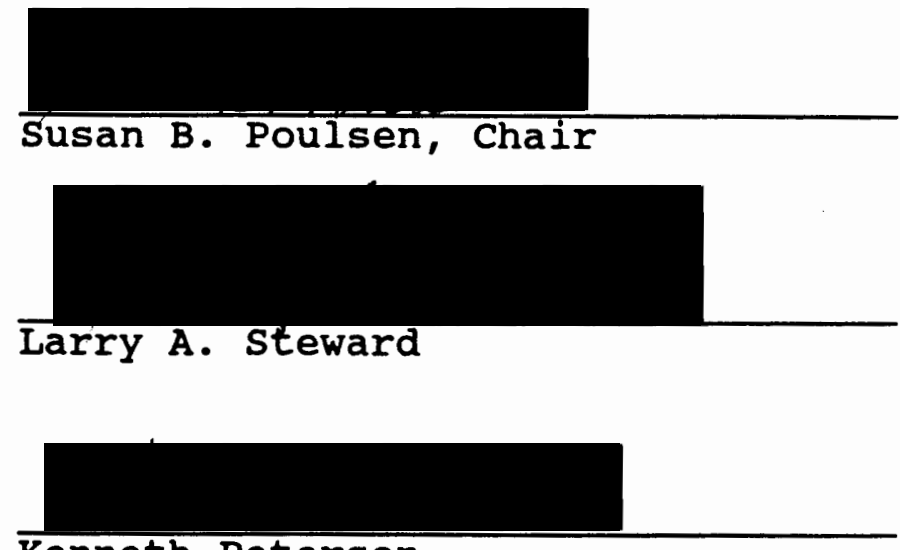

The confidence to communicate orally with others is the first requisite for verbal interaction. Anxiety which occurs in anticipation of speaking with others or while engaged in speaking hinders interaction, and is referred to as communication apprehension. This study examines levels of communication apprehension among a sample primary school population and the possible relationship between such levels and frequencies of nonverbal behaviors called self-adaptors that may be associated with the anxiety. Greater awareness 
of communication apprehension in children is justified in light of research that suggests it is negatively related to academic achievement in elementary school students.

A four-month field'study was conducted in a Northwestern suburban elementary school by the researcher who had taught in the school for the previous seven years. The hypothesis tested was that a positive correlation exists between levels of communication apprehension and displayed self-adaptor behaviors. The study employed methodological triangulation, using both quantitative and qualitative data. An established self-report measure (MECA) consisting of a 20-item questionnaire suggesting various communication situations was administered to 42 third grade students and analyzed using descriptive statistics. Students scoring one standard deviation above the mean were identified as communication apprehensive (CA). Nervous behaviors called self-adaptors were tallied using a researcher developed measurement tool (UBSSF), and the frequencies of these behaviors correlated with the results of the self-report measure to find the predicted association. The hypothesis was not supported in this study.

Complementary qualitative information also provided substantial data. This included classroom observations and videotapings of students in small group work sessions, individual recorded interviews of the $C A$ students using film elicitation and interviews with their classroom teachers, 
field notes (general notations, oral data from teaching specialists, and additional demographic information), and continuing information from the apprehensive students following the conduct of the study. All qualitative data was examined for cross-situational consistency thought to be associated with communication apprehension.

significant evidence for a correlation between levels of communication apprehension and frequency of self-adaptor behaviors was not found. However, this study contributed to a greater understanding of $\mathrm{CA}$ by challenging currently held views on communication apprehension. Also, through the use of method triangulation, quantitative and qualitative forms of self report provided some evidence for the crosssituational consistency of $\mathrm{CA}$. Communication apprehensive students were found to be aware of their anxieties and able to verbally address their fears. The phenomenological interpretation of $\mathrm{CA}$ student and teacher interview texts facilitated the reconstruction of the participants' perspectives. Finally, suggestions by the researcher addressed the training of teachers to raise their awareness of communication apprehension and to provide needed accommodation of $\mathrm{CA}$ students in the classroom. 
THE VOICES I NEVER HEAR: COMMUNICATION APPREHENSION AND ASSOCIATED NONVERBAL BEHAVIORS

IN THE PRIMARY SCHOOL CHILD

by

LINDA DUNN

A thesis submitted in partial fulfillment of the requirement for the degree of

\author{
MASTER OF SCIENCE \\ in \\ SPEECH COMMUNICATION
}

Portland State University

1993 
TO THE OFFICE OF GRADUATE STUDIES:

The members of the Committee approve the thesis of Linda Dunn presented November 4, 1993.

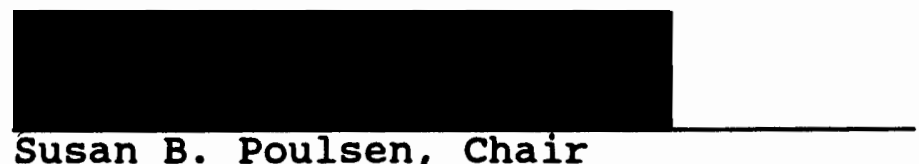

Susan B. Poulsen, Chair

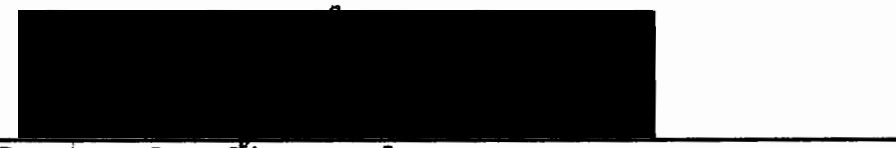

Larry A. Steward

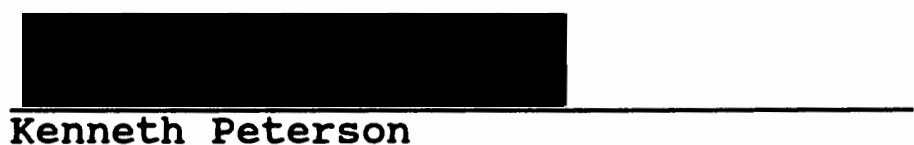

APPROVED:

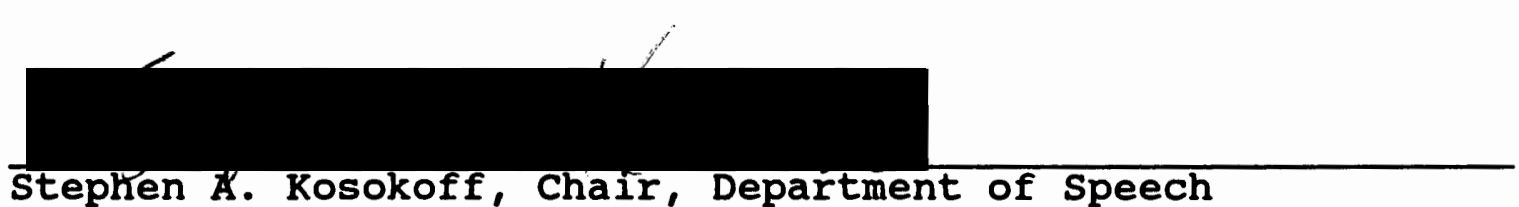

Communication

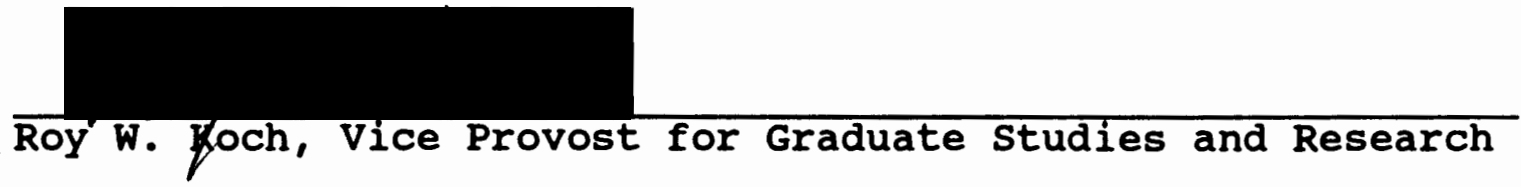




\section{ACKNOWLEDGEMENTS}

The conduct of research is facilitated by people as much as the written word, and inspiration is found in many places. I would like to thank my thesis committee--Larry Steward, Ken Peterson, and especially Dr. Susan Poulsen, who, with my mentors, Shirley Gidley, Doug Smith and Bev Hobson, have held out new challenges and provided the support I needed to meet them.

I am also thankful to my children for their examples: Sheila, who is Life's brave warrior, and Brian, who is finding his own strong voice in scholarship.

Finally, thank you to all other family and friends, especially Duane, who have encouraged and tolerated yet another project of mine. Without your patience I could not have accomplished this work. 
TABLE OF CONTENTS

PAGE

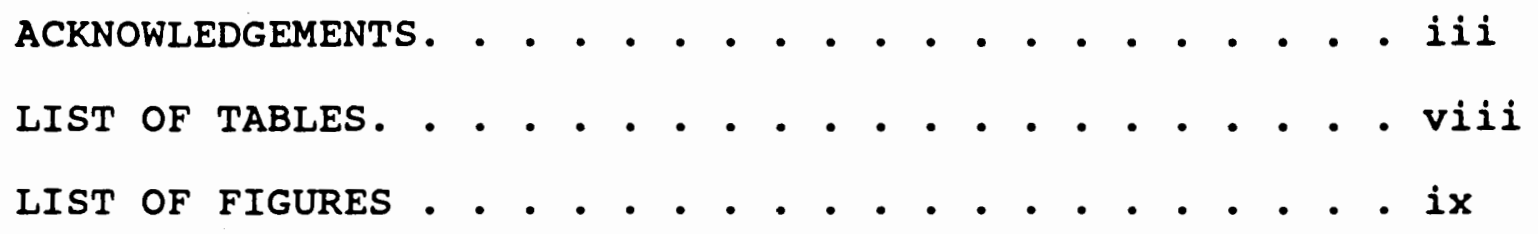

CHAPTER

I

INTRODUCTION. . . . . . . . . . . . 1

Statement of the Problem. . . . . . . 2

The Purpose of the Study. . . . . . . 2

Background of the Problem . . . . . 3

Definition of concepts. . . . . . . . 4

Significance of the Investigation . . . 6

The Research Questions and Hypothesis . 9

Hypothes is

Overview of the study . . . . . . . 10

II REVIEW OF THE LITERATURE. . . . . . . . . 11

Aspects and Etiology of Communication

Apprehension. . . . . . . . . . 12

CA Types, Symptoms, and Consequences. . 15

Internal

External/Verbal

External/Nonverbal

Academic/Social Effects of CA

Constructs Related to Communication

Apprehension. . . . . . . . . 28

Treatment and/or Accommodation. . . . 33 
The Phenomenological Perspective. . . . 36

Summary • • • • • • . • • • • • • 38

Endnotes. . . . . . . . . . . . 41

III RESEARCH METHODS AND DATA COLLECTION

PROCEDURES. •. . . . . . . . . . . . 42 42

Method. . . . . . . . . . . 43

Research Design--Quantitative

and Qualitative Methods

Sampling Procedures

Unit of Analysis

Quantitative Measurement

Instruments

Qualitative Methods

Validity and Reliability

of the study

Procedure

Initial Processes

The Pilot study

Resolution of Procedural Problems and

Recommendations for the Main study. . 78

Prepartion and conduct of the Main

study . . . . . . . . . . . 79

Endnotes. . . . . . . . . . . 84

RESULTS . . • . • . . . • • • • • • • 87

Test of the Hypothesis. . . . . . . 87

MECA and Self-Adaptor scoring and Analysis. . . . . . . . . . 88

Recording of Self-Adaptor scores

Through Use of the Upper

Body Self-Adaptor Scoring Form

Initial Data Analysis and Assignment of Cell Means

Within-Class same-Sex

Comparisons of MECA

Scores and Self-Adaptors

Analysis of Variance Tests

(ANOVA) 
Final Procedures

Videotaped Classroom observations . . . 102

Four Classroom Observations

Interviews. . . . . . . . . . 106

Student Interviews

Teacher Profiles and

Interviews

Summary . . . . . . . . . . . 132

Endnote . . . . . . . . . . . 134

$\mathrm{V} \quad$ DISCUSSION AND CONCLUSIONS. . . . . . . 135

Discussion. . . . . . . . . . 136

Quantitative Data

Qualitative Data

CA student Interviews

Teacher Interviews

Summary of Findings . . . . . . . 169

Limitations of the study. . . . . . 171

strengths of the study. . . . . . . 177

Recommendations for Future Research . . 182

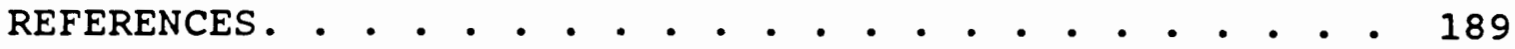

APPENDICES

A MEASURE OF ELEMENTARY COMMUNICATION

APPREHENSION--MECA. . . . . . . . 201

B UPPER BODY SELF-ADAPTOR SCORING FORM (UBSSF) . . . . . . . . . . . . . 204

C DIRECTIONS FOR USE OF THE UPPER BODY SELF-ADAPTOR SCORING FORM (UBSSF) • • . 206

D LETTER OF EXPLANATION TO PARENTS--PILOT STUDY . . . . . . . . . . . . 209

E INFORMED CONSENT 
vii

F LETTER OF EXPLANATION TO PARENTS--MAIN STUDY . . . . . . . . . . . . . 213

G MECA SCORES/FREQUENCY COUNTS OF SELF-ADAPTORS--STUDY SAMPLE . . . . . 215

H DEMOGRAPHIC INFORMATION FOR STUDY SAMPLE. • . 218

I FOLLOW UP INFORMATION ON STUDY SAMPLE CA

STUDENTS. . . . . . . . . . . . 221 


\section{LIST OF TABLES}

TABLE

PAGE

I Categories of Manifestations: Reticence, Communication Apprehension, and

Shyness . . . . . . . . . . . . 32

II Time 1 and Time 2 MECA Scores by Class. . . 90

III MECA Scores of High CA Students . . . . . . 91

IV. Three-Way Analysis of Variance for all MECA Scores . . . . . . . . . 95

$V$ Three-Way Analysis of Variance for all Self-Adaptor Scores . . . . . . . . 96

VI Two-Way Analysis of Variance for all Self-Adaptor Scores . . . . . . . . 97

VII I Tests Comparing Class $A$ and $B$ MECA and Self-Adaptor Mean Scores . . . . 98

VIII $\underline{T}$ Tests Comparing Class $A$ and $B$ MECA and Self-Adaptor Scores by Gender . . . . . 99

IX Typology of Fears . . . . . . . . . . 146 


\section{LIST OF FIGURES}

\section{FIGURE}

PAGE

1. Hypothesis . . . . . . . . . . . 10

2. Modified MECA Instrument (Hoffman, 1990) . . 51

3. Modified Upper Body Self-Adaptor Scoring 
To the "quiet" ones 


\section{CHAPTER I}

\section{INTRODUCTION}

In my teaching experience of the last 25 years at kindergarten through tenth grade levels, I have been concerned about certain students who seemed anxious when asked to read aloud, give an oral report, or participate in a discussion. I have also noticed some children who appeared nervous, exhibiting far more kinesthetic movement than other students. I considered that those behaviors that teachers like myself continually notice, sometimes criticize, and many times try to "erase," may actually be indicators of an anxiety state that could impact students' social and academic development. Also, when evaluating student participation at the end of each term, I realized that some of these children had not spoken enough for me to recall their voices.

oral participation within a group structure has been increasing in importance as some educational teaching strategies shift from the traditional lecture/question model to small group work (Johnson, Johnson, \& Holubec, 1988). I have wondered whether the needs of the apprehensive child have been perceived by teachers and addressed within these changing classroom structures. 


\section{STATEMENT OF THE PROBLEM}

What are the emotional, social, and educational implications for the identified communication apprehensive child in small group learning structures as perceived by apprehensive students and their teachers?

THE PURPOSE OF THE STUDY

This exploratory study was conducted in order to identify primary school children who tested as communication apprehensive ( $C A)$, and determine a possible relationship between $C A$ and a set of nonverbal kinesic behaviors known as self-adaptors. This research responded to a call for studies among young students in the natural elementary classroom setting since levels of $\mathrm{CA}$ appear to increase during the third and fourth grades and may be negatively related to academic achievement (Bourhis \& Allen, 1992; Comadena \& Prusank, 1988; Garrison \& Garrison, 1979a; Hoffman, 1990, 1992; Hurt \& Preiss, 1978; Mccroskey, 1976, 1977b; McCroskey, Andersen, Richmond, \& Wheeless, 1981; Mccroskey \& Richmond, 1987; Prusank \& Comadena, 1987; Wheeless, 1971).

Behaviors of identified apprehensive students within small group learning structures were examined, as well as teacher and student perceptions of communication apprehension and the children's classroom preferences for learning. The study also addressed the issue of 
cross-situational consistency believed to be associated with the enduring quality of communication apprehension (McCroskey, 1982).

A triangulated method was used to examine communication apprehension in this study (Albrecht \& Ropp, 1982; Denzin, 1989; Sevigny, 1981). This approach provides complementary use of perspectives that are both qualitative (observations, field notes, videotaping, film elicitation, and interviews) and quantitative (statistical analysis of self-report test results and observational data of nonverbal self-adaptors).

\section{BACKGROUND OF THE PROBLEM}

Richmond and Mccroskey (1985) suggest that as much as 20 of the adult population suffers from communication apprehension, that is, anxiety about talking with others. since much of learning is verbal and communicative, a person without access to communication experiences and the active involvement required may suffer deficits in social as well as educational learning (Bourhis \& Allen, 1992; Comadena \& Prusank, 1988; Garrison \& Garrison, 1979a; Hurt \& Preiss, 1978). Most research in this area has concerned students attending secondary and college level classes in public speaking and communication. Less work has been done to identify and examine the construct in children who also experience this internal affective state. For exceptions, 
see Comadena and Prusank (1989), Garrison and Garrison (1979a, 1979b), Harris (1980), Hoffman (1990, 1992), Mccroskey (1984), Mccroskey et al. (1981), Mccroskey and Daly (1976), and watson and Monroe (1990).

Communication apprehension appears to be negatively related to academic achievement in high school and college students (Davis \& Scott, 1978; McCroskey, 1977a, 1977b; Mccroskey \& Andersen, 1976; Mccroskey, Booth-Butterfield, \& Paynes, 1989; Scott \& Wheeless, 1977), and some studies have found a similar negative effect for elementary school children (Bourhis \& Allen, 1992; Comadena \& Prusank, 1988; Garrison \& Garrison, 1979a; Mccroskey \& Richmond, 1987; Prusank \& Comadena, 1987).

\section{DEFINITION OF CONCEPTS}

Certain terms used within the fields of education and speech communication will be found throughout this study. Definitions and background information for these terms are provided here.

McCroskey (1977b) defines communication apprehension as "an individual level of fear or anxiety associated with either real or anticipated communication with another person or persons" (p. 78). In a later definition, he defines "trait-like CA . . a relatively-enduring personality-type orientation toward a given mode of communication across a variety of settings" (McCroskey, 1982, p. 147). While CA 
may be either temporary or situational, or a relatively enduring condition, it is the cross-situational, relatively enduring form that was examined in this study. Though other forms of communication apprehension have been identified, such as fear of writing or singing (Andersen, Andersen, \& Garrison, 1978; Daly \& Miller, 1975), most research, including the present study, continues to focus upon fear of speaking (McCroskey, 1984).

Littlejohn (1989) describes communication apprehension as a possible outcome of cognitive processing, and Mccroskey (1976) suggests that it may be associated with certain kinesic nonverbal behaviors. Self-adaptors constitute a particular kinesic or movement form of nonverbal behavior that is thought (at times) to be adaptive in its response to an anxiety condition, and as such, may be associated with CA (Comadena \& Andersen, 1978; McCroskey, 1976). In this study, self-adaptors are either continuous, lasting a few seconds and possibly involving an object such as the touching of clothing or jewelry, or discrete--a brief touching of an object or self, such as a momentary touch on the face.

References to elementary school children in this research are to students attending kindergarten through the sixth grade, while references to primary school children are to those students in kindergarten through grade three. Cooperative learning is defined as an instructional 
technique which facilitates student-to-student interaction as an important part of learning, and usually takes place in small groups of four or five students (Kagan, 1990). This method is in contrast to the traditional lecture/question approach used in many classrooms.

\section{SIGNIFICANCE OF THE INVESTIGATION}

First, this study responds to continuing calls in the literature for studies of CA among young children, including observations of nonverbal behaviors in the natural learning context of the elementary classroom (McCroskey, 1976, 1977b; McCroskey et al., 1981). The available research is, unfortunately, rather limited (Comadena \& Andersen, 1978; Comadena \& Prusank, 1988; Hoffman, 1990, 1992; Wheeless, 1971). As Wheeless (1971) states:

the problem [communication apprehension] has not been attacked at its root in the early years. Undoubtedly, concern must now focus on the communication apprehensive in the elementary school. (p. 299)

second, only one reported study has examined CA in young children through observations within the natural classroom setting (Hoffman, 1990, 1992). If communication apprehension develops early in life, studies should focus on $C A$ that is present in the first few years of school including observations for certain nonverbal behaviors that might serve as indicators of the condition (Comadena \& 
Andersen, 1978; Comadena \& Prusank, 1988). As Comadena and Prusank (1989) clearly indicate:

- . we believe that systematic observational studies of the classroom behaviors of low and high communication apprehensive students would be very informative . . and would enhance our understanding of the relationship between $C A$ and student learning. (p. 89)

This is the first reported study to examine the relationship between communication apprehension in young children and their displayed self-adaptor behaviors. It also examines the relationship between qualitative data and results of a self-report measure of $C A$ and the presence of self-adaptor behaviors.

The results of this study have important implications for areas of research and education. First, the use of method triangulation provided for data gathering and analysis from quantitative and qualitative perspectives. second, a nonverbal tool was developed and used by the researcher to record self-adaptor behaviors of $\mathrm{CA}$ children within the classroom setting. Third, young CA students discussed the content of their videotaped classroom observations, related perceptions of their communication apprehension, and shared their preferred form of classroom learning structure in interviews with the researcher. Fourth, the findings of this study raise questions about prevailing views that $C A$ children are quiet and avoid interaction (Comadena \& Prusank, 1988, 1989; Garrison \& Garrison, 1979b; Harris, 1980; Hittleman, 1988; Hurt \& 
Preiss, 1978; McCroskey, 1980; McCroskey \& Daly, 1976; Mccroskey et al., 1981; Wheeless, 1971).

Last, there is disagreement in extant literature whether teachers can (Garrison \& Garrison, 1979b) or cannot (McCroskey, 1980) identify CA children. Based on inservice work with more than 5,000 educators, McCroskey (1980) states that when teachers try to assist quiet students, the results of their efforts are sometimes more harmful than helpful. According to steward's (1968) study of reticent college students, many teachers believe that more practice will necessarily provide a better performance, when in fact, the opposite might be true. On occasion, I have given my own quiet students additional opportunities for oral presentation with resulting resistance, accompanied by agitation, tears or other signs of distress. In light of these misunderstandings, I believe that teachers may benefit from an awareness of communication apprehension and the difficulties experienced by $C A$ children in the classroom which my study addresses among a sample of third grade children. Recommendations for teacher training that will prepare educators to acknowledge and assist children with $\mathrm{CA}$ are addressed in Chapter $\mathrm{V}$. 
THE RESEARCH QUESTIONS

AND HYPOTHESIS

The research questions enumerate the concerns and scope of the study from the qualitative perspective. The conduct of the research specifically addressed these concerns.

The first research question ( $R Q$ ) addresses a previously untested relationship between communication apprehension and certain nonverbal kinesic behaviors among elementary school students.

RQ1: Is self-reported communication apprehension related to the display of self-adaptor behaviors within the interview situation?

The second research question also addresses related data from the qualitative perspective.

RQ2: To what extent does the phenomenological interpretation of data confirm the results of a self-report measure and the existence of accompanying self-adaptor behaviors?

The third and fourth research questions address identification and description of the CA child, class participation and learning structures.

RQ3: Are classroom teachers able to identify and describe their communication apprehensive students?

RQ4: Are CA students aware of their apprehension, and will they participate within a small group learning structure? 
Hypothesis

This study tested the following hypothesis: a positive correlation exists between levels of $\mathrm{CA}$ and displayed self-adaptor behaviors.

Levels of $\mathrm{CA}$ in Children

(Identified by self-report measure) kinesic self-adeptors displayed

(Identified by observation)

Figure 1. Hypothesis.

OVERVIEW OF THE STUDY

The thesis is divided into five chapters. Chapter I has introduced the concept of communication apprehension and the purpose of the study. Chapter II reviews related literature which includes aspects and etiology of $C A$, types, symptoms and consequences, related constructs, treatment and/or accommodation, and the phenomenological perspective. Chapter III, Research Methods and Data Collection Procedures, describes the research design, the study sample, unit of analysis, validity and reliability, and data collection instruments, methods, and procedures for the pilot study including recommendations, and a brief summary of the main study. Chapter IV describes the data analysis procedures and findings. Finally, Chapter V, Discussion and Conclusions, addresses the analysis of the quantitative and qualitative data, summary of findings, strengths and limitations of the study, and implications and recommendations for future research. 
CHAPTER II

REVIEW OF THE LITERATURE

This chapter discusses communication apprehension within a larger treatment of issues surrounding the construct. The first section, Aspects and Etiology of Communication Apprehension, discusses the cognitive foundations of communication apprehension and its location within a certain view of knowledge and reality. It also addresses the need to understand the etiology and development of communication apprehension as determined by heredity, modeling, school environment, or as a learned response to certain types of reinforcement.

The second section, CA Types, symptoms, and Consequences, concerns communication apprehension that is enduring and possibly negatively related to academic achievement compared to that which is more transient and situational. Internal and external symptoms and academic and social consequences which might alert educators to the learning and socialization needs of the anxious child are also considered in this section. External symptoms may include certain nonverbal behaviors called self-adaptors which may be considered indicative of the presence of $C A$. 
In the current study, these behaviors were observed and recorded for comparisons with CA self-reports.

The third section, Constructs Related to Communication Apprehension, addresses constructs of reticence and shyness and the organization of $\mathrm{CA}$ and other communication problems as global concepts. The fourth section, Treatment and/or Accommodation, discusses therapy treatment and/or accommodation of communication apprehension within the classroom. The final section, The Phenomenological Perspective, considers the concept of phenomenology as a framework for the interpretation of teacher and student views of $C A$ that were shared with the researcher.

\section{ASPECTS AND ETIOLOGY OF COMMUNICATION APPREHENSION}

The CA construct exists within a cognitive theoretical perspective of reality (Greene \& Sparks, 1983b; Littlejohn, 1989). The foundations of reticent behavior are also found within this perspective (Clevenger, 1984). Littlejohn describes this as the World View I perspective which assumes the existence of a free and knowing being able to evaluate experiences and organize and act upon information by choosing from available alternatives. According to Littlejohn, this view presupposes a reality that is accessible though apart from the human being, and communication apprehension is an outgrowth of this cognitive processing that results in anxiety based upon previous 
communication experiences. Mccroskey and Richmond (1987) and Littlejohn state that repeated expectations for communication that continually result in negative outcomes lead to learned helplessness in which no expectations of adequacy can be developed. McCroskey and Richmond maintain that this condition forms the basis for communication apprehension, and McCroskey (1976) suggests that the resulting apprehension may have behavioral manifestations.

Two models have been offered to explain the cognitive processes that result in CA. Greene and Sparks (1983a) explain the construct within the framework of an action assembly in which memories are activated and arranged on the interactional (interaction goal identified), ideational (semantic content brought together), utterance (syntax in use) and sensorimotor (motor commands assembled and enacted) levels. It is at the interactional level that the authors suggest an individual may be unable to choose appropriate communication behaviors that lead to a positive interaction goal. An assimilation perspective of $C A$ is given by Beatty and Behnke (1980) who state that the intensity of communication apprehension changes due to the influence of accumulated state anxiety experiences which are taken into a person's cognition.

Heredity of social temperament has been identified as a possible cause of communication apprehension (Kagan \& Reznick, 1986). However, it has also been suggested that 
modeling the behavior of uncommunicative parents or family members could influence the development of $C A$ in children, although more than the modeling effect is probably involved (McCroskey \& Richmond, 1980).

Mccroskey et al. (1981) state that the school environment also might contribute to the development of communication apprehension:

Children in lower elementary school (K-3) report lower levels of $C A$ than do children in upper elementary school (4-6), junior high school (7-9) or high school (10-12). The biggest change appears to occur in kindergarten . . Another substantial increase appears to occur during grades 3 and 4 . Thus, before puberty, CA norms are achieved that remain relatively stable through all subsequent age groups. (p. 128)

The authors suggest that "we should continue to suspect the school environment as a potential causal agent for increased levels of CA in children" (p. 129). Concern is expressed by Mccroskey et al. for the physical facilities, the peer environment and even the teachers, as the authors find that teachers of grades 1-4 themselves exhibit higher levels of CA than teachers of any other grade level although no claim is made that teacher $C A$ affects children's feelings toward communication (1981).

Comadena and Prusank (1988) also found that CA seems to increase as the child proceeds through the grade levels. Hurt and Preiss (1978) refer to an increase in CA among seventh, eighth and ninth graders, but do not suggest a possible connection with the onset of puberty. Though 
occurrence of increase in CA at different grade levels appears to differ somewhat, all sources discussed here suggest relatively early indications of the anxiety.

Some researchers place importance on the way a possible predisposition to anxiety develops through inconsistent or negative reinforcement that encourages communication at times, and at other times discourages it (Richmond \& Mccroskey, 1985). The authors also discuss how CA may possibly be reversed by continual positive reinforcement of communication, and others concur that if speaking is positively rewarded by reinforcement, more oral communication results (Daly \& Friedrich, 1981; Wells, 1986). In their discussion of $C A$ in elementary and secondary students, Mccroskey et al. (1981) expressed greatest support for a reinforcement explanation of $C A$ in the young child, while recognizing the possibilities of a heredity factor or the contribution of highly apprehensive teachers to the development of $\mathrm{CA}$ in children. While reinforcement of student $C A$ by apprehensive teachers was not a focus of this study, the implications of differing teaching styles and various social problems encountered by $C A$ students were considered.

CA TYPES, SYMPTOMS, AND CONSEQUENCES

Temporary or situational CA which occurs only within a certain time or circumstance and the more continuous 
condition of communication apprehension are discussed by Clevenger (1984), and Mccroskey and Richmond (1987). However confusion occurs when Mccroskey (1984) uses the term "traitlike CA" to describe communication apprehension as an enduring aspect of personality that differs from "a true trait. . an invariant characteristic of an individual, such as eye color and height" (p. 16). The author has borrowed the term "trait" from the psychological theories of personality that do not include physical characteristics in the definition of the term (Allport, 1968; Mehrabian, 1968; Smith \& Smith, 1958). The word has also been appropriated by Mccroskey from the field of genetics which considers physical characteristics of individuals. In an effort to describe communication apprehension that appears cross-situational, Mccroskey has used the term "trait" inappropriately. Also, a traitlike aspect of personality suggests a state of semi-permanence that I find unsuitable for the proposed study of CA in primary school children, since they seem to experience such marked personal, academic, and social growth when they first enter school. I have never thought of my youngest students as "unchanging" in any way.

However, I believe communication apprehension that is an abiding anxiety can be harmful to young children, as it may effect them in all aspects of their lives. That is, their anxiety may trouble them in all situations with others 
as they work or play within the home, school, or neighborhood environments. Therefore, it is the cross-situational, enduring form of communication apprehension I have chosen to examine because this more serious form may negatively impact academic and social development of school children (Bourhis \& Allen, 1992; Comadena \& Prusank, 1988, 1989; Garrison \& Garrison, 1979a; Hoffman, 1990, 1992; Hurt \& Preiss, 1978; Mccroskey \& Daly, 1976; McCroskey \& Richmond, 1987; Prusank \& Comadena, 1987; Richmond, Beatty, \& Dyba, 1985; scott \& wheeless, 1977). Since this anxiety is an internal experience, self-report was seen as the best way to verify its existence. Strong support for teacher perception of $C A$ through observation of behaviors has not been found (Garrison \& Garrison, 1979b; Watson, 1989; Watson \& Monroe, 1990). One of the first ways of measuring the relatively constant condition of $C A$ by self-report was through the use of a scale called the Personal Report of Communication Apprehension (PRCA) (McCroskey, 1970). Other instruments addressed desires to communicate or reports of communication behavior, but only the PRCA appeared to "specifically relate to fear or anxiety about communication . . " (Mccroskey, 1977b). A derivation of the PRCA that is appropriate for children was used in the current study, and levels of student communication apprehension are discussed in this study without reference to trait or state comparisons. 
Communication apprehension may exert a strong influence over the lives of those who have developed this anxiety. Particular internal and external effects of $C A$ are noted in apprehensive individuals, and McCroskey (1984) indicates that certain kinds of avoidance probably occur as a result of varying levels of communication apprehension.

\section{Internal}

Certain personality correlates may be present in those identified as communication apprehensive: a more constant general anxiety, low tolerance for doubt and dispute, less control over feelings, a lessened sense of adventure, a low level of self esteem and assertiveness, and an immaturity of emotions (Richmond \& McCroskey, 1985). Further, the authors note that the person with high $C A$ is not considered to be very creative and takes less risks than someone with a low level of communication apprehension. Butler (1986) finds that $C A$ individuals are more emotionally unstable, restrained, submissive, fearful, and experience less self-confidence and more tension than those with little anxiety.

\section{External/Verbal}

Mccroskey (1984) indicates that if avoidance is not an option, the $C A$ individual may attempt to withdraw verbally from the communication situation by participating as little as possible or not at all. Such a student might 
deliberately give wrong answers or continually say "I don't know" in the hopes of not being asked further questions. Mccroskey, on the other hand, indicates that an inability to express oneself appropriately because of anxiety might result in over-communication or "nervous chatter," a relatively rare response to $\mathrm{CA}$. This represents an attempt to compensate for communication apprehension and can also be disruptive to the communication process.

Jordan and Powers (1978) found that the language of apprehensive individuals was characterized by more descriptors and inappropriate word usage, shorter words, and more repetitious use of words and phrases than the language of non-CA persons. Burgoon and Hale (1983) found that the language of apprehensive individuals consisted of weaker descriptors and shorter words and phrases, but these individuals wrote more words and used more word variety than those who were not apprehensive. Those with communication apprehension also showed less ability to adapt to change in the communication context.

\section{External/Nonverbal}

Physical withdrawal associated with or indicative of communication apprehension is discussed by Hurt and Preiss $(1978):$

The most obvious socially maladaptive behavior of the communication apprehensive student is withdrawal. High communication apprehensives exhibit a strong desire to avoid interaction with others. (p. 315) 
The authors discuss social and occupational choices made by apprehensive adults that remove them physically from others. According to Richmond and Mccroskey (1985), students with communication apprehension also make behavioral choices accordingly, especially in a traditional classroom in which desks are arranged in rows. Apprehensive students select seats in areas along the side and in the back of a classroom if possible, and ignore the areas of high interaction in the front and center of the room (McCroskey, 1977a; Richmond \& Mccroskey, 1985)

Communication is not restricted to speech alone, but includes the nonverbal communication channels as well:

We consider nonverbal communication to be those attributes or actions of humans, other than the use of words themselves, which have socially shared meaning, are intentionally sent or interpreted as intentional, are consciously sent or consciously received, and have the potential for feedback from the receiver. (Burgoon \& Saine, 1978, p. 9)

Burgoon's 1989 study on nonverbal manifestations of arousal offers support for the existence of nonverbal indications of anxiety, and Burgoon and Koper (1984) also state that such a relationship may exist between nonverbal behaviors and reticence. In their discussion of immediacy behaviors, actions that signal the desire to be with or avoid others, Richmond and Mccroskey (1985) suggest that touch and gestures as well as other nonverbal behaviors signal the communicative intent of the user. Cardot (1982) found that when they are close to others, those who are communication 
apprehensive use more arm-blocking behaviors which are believed to lessen anxiety. Mccroskey (1976) also suggests that research needs to be done in proxemics (use of personal space). However, the studies of proxemics that I found used stationary dyads, a structure not available in the natural classroom setting. In addition, Mccroskey states that more constrained kinesic or movement behaviors will be exhibited by $C A$ individuals, and advises further research in the area of kinesics as well. For the purposes of this study, kinesic behavior remained the best choice for classroom observation of nonverbal behaviors in CA students, though McCroskey (1984) cautioned that behavioral indicators alone cannot confirm the existence of communication apprehension. Knapp (1980) discussed five categories of nonverbal kinesic behavior: emblems (having a direct verbal "translation," like the gesture for "OK"), illustrators (illustrative and directly connected to speech, like pointing to present objects), affect displays (usually facial indicators of emotions), regulators (like turn-taking cues), and adaptors (usually touches that are early-developing "adaptive efforts to satisfy needs, perform actions, manage emotions . . ." (p. 8). In their 1978 study of college students during interview situations, Comadena and Andersen examined the possible relationship between emblem, illustrator and adaptor hand movements and communication apprehension. 
Ekman and Friesen (1969) indicate that adaptors are behaviors that might give information about the user, but are not used for communication purposes. Leathers (1978) states that:

As a potential source of information about an individual's attitudes, level of anxiety, and self-confidence, bodily cues in the form of adaptors are apt to be more useful than emblems, illustrators, affect displays, or regulators. ( $p$. 57)

Harrison (1974) finds that ". - . for the observer, the adaptor may have sign value; it may be an informative indicator of the performer's inner state" (p. 101).

According to Ekman and Friesen (1969), adaptors are acquired to manage emotions as well as relate to others and care for physical and/or personal needs. As the person matures, the actions are shortened until their performance is no longer closely related to the need they once satisfied, but a certain situation might trigger the use of an adaptor that was learned in earlier years. Leathers (1978) describes these actions as: "types of nonverbal behavior which show how the communicator has adapted or adjusted to previous conditions or environments in his life" (p. 206). There is some agreement that these behaviors indicate negative feelings (Knapp, 1980). Freedman, o'Hanlon, Oltman, and witkin (1972) found that the use of adaptors during interviews of college students reflected an anxiety condition when the interviewee perceived a "cold" interview or a "rejecting interviewer." In their coding, 
the nonverbal adaptors are iconic or similar to the action that is being symbolized, or intrinsic as in waving a fist while in the act of fighting (Littlejohn, 1989).

Three types of adaptors have been identified by Ekman and Friesen (1969): object-adaptors, alter-directed adaptors, and self-adaptors. Object-adaptors involve the use of an instrument or tool and can be connected to speech as in the punctuation movement made with a pencil by a speaker. The authors state that these behaviors are often consciously performed but not usually acquired during childhood. Alter-directed adaptors are interpersonal behaviors which signify connection (giving or taking from someone) or defense/withdrawal (a "fight or flight" response), and involve changes in proxemics or use of personal space.

According to Ekman and Friesen (1969), the third type, self-adaptors, are kinesic behaviors acquired in managing basic needs such as scratching an irritation on the skin or grooming or are initially associated with certain emotional states, settings or events with other individuals. These include "self-touch, soothing, scratching, biting, cradling some part of the body" (Harrison, 1974, p. 137), "moving into a more comfortable position" (Mehrabian, 1972, p. 3), "head-scratching, licking the lips, rubbing hands" (Harper, Wiens, \& Matarazzo, 1978, p. 138), "holding, squeezing, pinching" (Knapp, 1980, p. 8). As the child matures, 
self-adaptors may still fulfill a function or simply consist of what Ekman and Friesen call "the adaptive habit" (p. 86). Freedman (1976) cites the use of self-adaptors when the individual's attention is distracted. The author states that an individual may have little awareness of these behaviors which are not connected to speaking in any way though they may be caused by topics that are being discussed. Self-adaptors are included in Clevenger's (1961) discussion of visible symptoms in reticent college students: "(Fidgetiness)--shuffles feet, sways, swings arms . . . (Autonomia)--moistens lips, plays with something . . ." (p. 298) •

Freedman et al. (1972) discuss two kinds of self-adaptors: those that are continuous and distinguished by direction or focus and may employ an object without the object-focused connection to speech, such as touching clothes or jewelry; and discrete or non-continuous self-adaptors that are brief, like touching the eye or chin once:

Twiddling, fiddling, and fidgeting all suggest that a person is becoming more nervous. Tugging at clothing and ears . . . are among the many bodily movements that quite clearly suggest "I am nervous." (Leathers, 1986, pp. 62-63)

Self-adaptors have been measured in twenty one studies of nonverbal behaviors (Baesler \& Burgoon, 1987). Only one of the studies involved children (Siegelman, Adams, Meeks, \& Purcell, 1986), and the focus of the research appeared to be 
unrelated to the purpose of the current study. Comadena and Andersen (1978) found no relationship between certain self-adaptors and communication apprehension in college students in an interview setting. I did not receive information from this study until after the research for the current study had been conducted. However, two of the self-adaptors considered by the authors had been included in the current study (e.g. grooming hair and scratching self). An additional study by Barraso, Freedman, and Grand (1980) involved self-adaptors used by children. Here again, the focus of the study was attentional processes involved in performing tasks and unrelated to $C A$ or the natural classroom environment. However, the authors stated that the presence of self-adaptors (called body-focused movements) are not only indicative of attentional difficulties, but may signal the presence of other problems as well. I adopted the study's tally method for scoring self-adaptors which is explained in Chapter III.

To summarize, communication apprehension or anxiety about talking with others appears to exist as an internal state. A type of nonverbal behavior called a self-adaptor is thought at times to indicate an internal state of anxiety. This would suggest that the condition of anxiety (in this case, communication apprehension) and certain behaviors (self-adaptors) may be co-present. 
Academic/Social Effects of $C A$

Teachers of communication apprehensive students appear to hold certain negative expectations for such students' academic and social success. In two studies in which teachers were asked to predict possible academic and social success for $C A$ and non-CA students, fearful students were not expected to be as successful as their more confident peers (McCroskey \& Daly, 1976; Smythe \& Powers, 1978). In an additional study, teachers' expectations of students' academic abilities were predictive for the level of student success experienced, and when this occurs, the expected results are called the "Pygmalion effect" (Rosenthal \& Jacobson, 1968).

In a recent study Hoffman (1990) reviewed research on relationships among level of $C A$, teacher expectations and student achievement: "These studies suggested that high levels of $C A$ were perceived by teachers and translated into lower expectancies for future performance" (p. 3). In discussing the nine correlations of her study, Hoffman concluded that the data did not support a direct effect for CA on teacher expectations or student achievement, though a connection was suggested between restricted student initiated communication which may influence expectations and result in lower achievement scores. Hoffman (1992) found no relationship between academic achievement scores and $C A$. 
Though Mccroskey (1980) found no connection between communication apprehension and intelligence, Mccroskey and Richmond (1987) cite a negative effect for three measures of student achievement, and in an examination of mathematics, language and reading scores, Comadena and Prusank (1988) found that elementary and middle school students who had high levels of CA showed lower achievement scores compared to students who had low and medium levels of CA. Little research regarding academic achievement has been conducted with large populations at the elementary level, but one that has been done yielded similar results (Prusank \& Comadena, 1987). In this study, direct causality between CA and lower achievement scores is not indicated, but a connection of some type is strongly suggested. However, recent studies of much smaller elementary populations showed little or no correlation between levels of $C A$ and measures of academic achievement (Hoffman, 1990; Watson \& Monroe, 1990).

Communication apprehensive students do appear to have difficulties socializing with their peers (Hurt \& Preiss, 1978; Richmond, Beatty, \& Dyba, 1985). The authors point out that students high in CA may be disliked or ignored by their peers, thus causing socialization difficulties that may lead to a loss of self esteem. The difficulties that a CA individual might have interacting within a social setting may result in fewer relationships and friends since avoidance precludes social interaction. Richmond, Beatty, 
and Dyba found that children experiencing $C A$ had trouble initiating relationships with other students, and students who were more talkative were seen by their peers to be more intelligent and approachable. McCroskey and Daly (1976) found that this negative view toward others with CA was shared by teachers as well as peers.

\section{CONSTRUCTS RELATED TO COMMUNICATION APPREHENSION}

Other communication problems have been identified that are similar to $C A$ and also have negative consequences. Discussion of these related constructs is necessary to identify major differences, similarities, overlaps among them and suggestions for treatment. Some authors have attempted to establish categories of constructs in order to identify a general concept or an inclusive term which stands for all constructs in the group,' and adding to the confusing array of constructs, Daly and stafford (1984) found 30 self-report measures that claim to reflect different constructs within the concept of social-communicative anxiety. Using a different perspective, clevenger (1984) offered a way of categorizing similar constructs according to the responses generated by the communication problems.

clevenger (1984) notes the lack of theoretical clarity that 15 years of study of the constructs had not resolved. 
Finding differences among related constructs that seem to coincide, overlap, and/or contradict each other is an ongoing endeavor, but is not the direct concern of this study (Kelly \& Keaten, 1992; Richmond \& Roach, 1992). Therefore, instead of examining each construct within many categories, I believe that describing and comparing the major, specific constructs of reticence, communication apprehension and shyness may be most helpful in understanding how communication apprehension relates to other similar communication problems.

Phillips (1968) identifies reticence as a condition in which an individual perceives their own inability to communicate, and the cost of revealing this inability is seen to outweigh the possible benefits of communicating with others, resulting in the choice of reticent or quiet behavior. According to steward (1968) a reticent person is also someone one who exhibits anxiety in communicative situations because of this negative self perception, though Phillips (1968) states that a reticent individual may not always experience fear in a social situation. In another study, Phillips (1984) suggests that the reticent person overemphasizes other peoples' reactions to their inability to communicate. Reticence is viewed by clevenger (1984) as a behavioral condition with cognitive foundations. Kelly (1982) states that a reticent individual may perform poorly either because of deficient skills or anxiety, a 
differentiation that the author indicates cannot be empirically measured.

Although communication apprehension could lead to reticent or quiet behavior, the interior experience of anxiety about communication, without the self perception of skill deficit, is distinct from the concept of reticence (McCroskey, 1977b). Communication apprehension may or may not have a resulting negative effect on communication skills, but a poor communication performance could result from the experienced anxiety of a cognitive state (Kelly, 1982; Leary, 1983). Communication apprehension is seen as a cognitive anxiety response rather than one that is physiological such as sweating when one is nervous, or behavioral such as stuttering (Clevenger, 1984). However, the author suggests that physiological reactions or certain behaviors may suggest the presence of the cognitive condition of $C A$, though such reactions or behaviors are not a substitute for self-report measures that directly address the cognitive condition.

Shyness appears to range from a preference to be alone to almost total avoidance of others because of the extreme anxiety caused by social interaction (Kelly, 1982). It appears to consist of a fear of people which results from cultural pressures placed upon the individual (zimbardo, 1977). Zimbardo, Pilkonis, and Norwood (1975) state:

our highly competitive, individualistic, egocentric culture puts a person on the spot dozens of times 
each day. Most of us . . react appropriately and without shyness to the demands of the social environment. The shy person, however... becomes a super-sensitive individual and overreacts. ( $p$. 71)

The authors indicate that around others, the shy person is almost always silent. However, Pilkonis (1977) suggests that there may be public and private shyness. That is, a person may feel shy but not appear shy. Communication apprehension and shyness seem to share the internal experience of anxiety, and these internal feelings may or may not lead to an effect on communication skills (Kelly, 1982). Kelly also states that what may be called "shy behavior" could actually be caused by reticence or communication apprehension.

sorting out the similarities and differences among the constructs of reticence, communication apprehension and shyness remains a confusing process. An alternate form of explanation might prove more helpful (see Table I).

The meaning of communication apprehension as a cognitive condition and an enduring, internal, affective state which is cross-situational was used in this study. CA is the most appropriate choice of construct in addressing young students' anxiety about communication because of its possible serious ramifications for the academic and social development of the child (Comadena \& Prusank, 1988; Hurt \& Preiss, 1978), and because it has been identified in 
children through use of a reliable measure (Garrison \& Garrison, 1979a).

TABLE I
CATEGORIES OF MANIFESTATIONS: RETICENCE, COMMUNICATION APPREHENSION, AND SHYNESS ${ }^{1}$

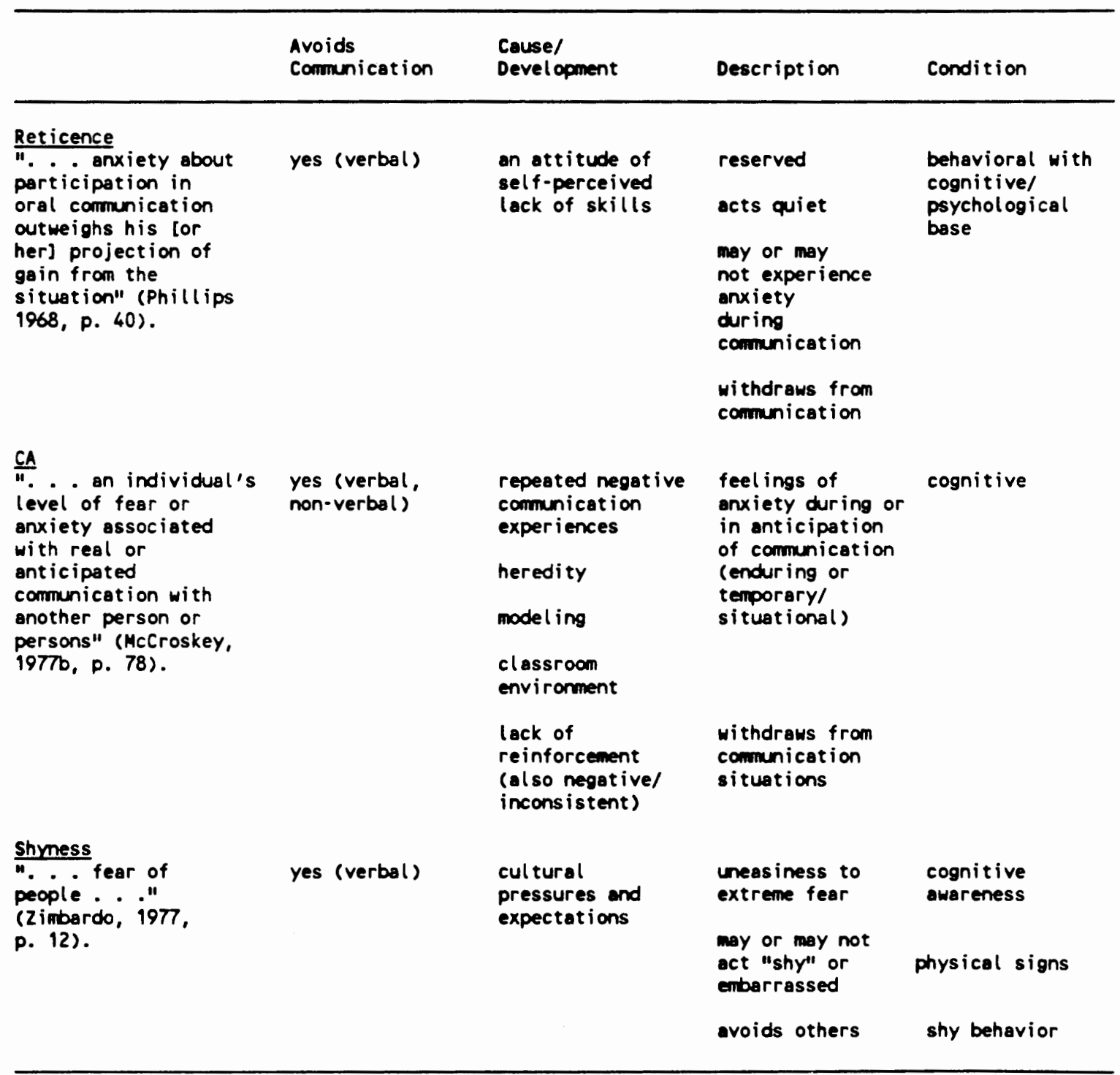




\section{TREATMENT AND/OR ACCOMMODATION}

Many methods attempt to address the problems presented by communication apprehension and its related constructs. Two perspectives are available: a therapeutic or treatment approach and/or an educationally oriented accommodation approach. Therapy or treatment has as its goal the extinction of the anxiety experienced when anticipating communication with others. It generally falls into three main categories which may or may not relate to certain constructs: cognitive modification emphasizing the individual's response to irrational thoughts about communication (Fremouw, 1984; Fremouw \& Scott, 1979; Fremouw \& Zitter, 1978; Hurt \& Preiss, 1978), systematic desensitization or extinction of $\mathrm{CA}$ through repeated introduction of anxiety-producing stimuli (Friedrich \& Goss, 1984; Mccroskey, 1972), and skills training (Kelly, 1984). A more recent visualization treatment approach by Ayres \& Hopf (1990) uses scripts to reinforce positive thinking prior to a speech performance. ${ }^{2}$

An educationally oriented approach for accommodation of students who are communicatively apprehensive may take place through the use of instructional strategies and might include manipulation of the environment to help the $C A$ student; it does not seek to "cure" the individual of apprehension. In relation to the school setting, four 
studies suggest accommodation of the communication apprehensive student. The first study includes Mccroskey's (1980) recommendations: development of a communicationpermissive classroom; encouragement (not requirement) of oral participation; use of alternate ways of participation and evaluation; and support for student choice of seating. In the second study, watson (1989) suggests that involvement in a supportive environment might encourage oral participation in apprehensive students. Hittleman (1988) encourages alternative ways to let the quiet student respond in the classroom including use of a system of signals. In the last study, Booth-Butterfield (1986) suggests flexible assignments and work in dyads and small groups for highly apprehensive students.

Sources in the field of education also propose that small group work will have a positive effect on anxious children and encourage them to participate. An application of small group work, cooperative learning groups, proposes to address the needs of these students:

In the traditional classroom almost all content related student talk occurs in one situation: students respond to a teacher's question, speaking with the whole class as an audience. In this situation there is usually a strong competitive element: . . a wrong answer is met with the waving of hands of other students more than ready to prove their ability by correcting the mistake.

In the cooperative classroom most content related student talk occurs either in pairs within teams or in the small group. Team members are supportive - . If there is correction, it is in the process of negotiation of meaning, not in the process of 
evaluation. In such a situation, talking is adaptive--it leads to content and language acquisition. And to the thing which means most to most students--peer support and recognition. (Kagan, 1990, pp. 3:6-3:7)

The idea of joint effort in small classroom groups is not a new one (Johnson, Johnson, \& Holubec, 1988). Cooperative learning was first established in the United States in 1806 when a school based upon this concept was started in New York City. It gained acceptance under the leadership of Colonel Francis Parker in the last 30 years of the 19th century (Patridge, 1883). The one-room school house functioned in this way out of necessity.

John Dewey (1915) championed this cooperative method of learning as part of his project method of instruction. In the late 1940's, Deutsch (cited in Johnson, Johnson, \& Holubec, 1988) added the component of small group or team competition to the existing structures of cooperative learning. He was responsible for the modern version of the method in which team members are taught to work together, help each other and be supportive in order to achieve the team goal.

Cooperative learning is a way of accomplishing an educational task through joint effort, and has been used and taught to other teachers by this researcher. Children's communication activities involving the assigned task are carried out through their explaining, problem solving, negotiating, disagreeing and resolving differences in small 
student groups. A related form, learning centers, involves student communication during separate and simultaneous small group activities. According to steward (1968), it is this sharing of the communication responsibility and the focus of attention on a specific activity that may assist a student who is nervous about communication. Kagan (1990) suggests that with his form of the method which minimizes competition, these groupings facilitate learning and enable all students to experience greater socialization. It is this kind of learning environment in which the observations of the current study took place.

on the other hand, according to Richmond and McCroskey (1985), CA's feel pressure to communicate when assigned to small groups, even though this environment is considered less anxiety producing for most people. When high CA's do talk in small groups, what they say is not usually as relevant to the group discussion as what others may contribute. Because these comments do not assist in achieving the group goal, the authors believe that such a behavior may deflect further questions from the CA individual.

THE PHENOMENOLOGICAL PERSPECTIVE

Finally, interviews with $C A$ children and their teachers were conducted during this study. The interpretation of the interview text was carried out using 
the phenomenological approach. According to Frey, Botan, Friedman, and Kreps (1991), "Phenomenology . . . is based on the belief that what people do depends on what they perceive . . " (p. 9), and the goal of this method of research is to describe how people interpret their lived experience. Qualitative study data were analyzed using the world view II perspective that knowledge is created in social interaction and includes how people view events and derive meaning from them (Littlejohn, 1989). The importance of interpretation from the subject's point of view arises from the nature and experiences of each individual, and these influence the way life events are interpreted (Patton, 1980; Schutz, 1967).

Since communication apprehension is experienced as an interior, individual response to communication situations, the phenomenological approach was appropriate for the examination and analysis of the interview texts. This approach adopted the perspectives of the students to find emergent themes. The children were able to "speak" through the interview text in acknowledging and explaining their fears, thus providing a sense of what it means to be a communication apprehensive child.

In the same way, common themes were identified in the teachers' interview texts. The teachers' perspectives were re-created in order to discover their awareness and understanding of the $\mathrm{CA}$ children in their classrooms. 
SUMMARY

$\mathrm{CA}$ is an anxiety about talking with others. It is an internal cognitive condition that may result from heredity of temperament, modeling of uncommunicative family members, inadequate reinforcement in home and/or school settings or repeated unsuccessful communication events.

I chose to study communication apprehension because this enduring anxiety appears to negatively impact the social and academic development of anxious children. Many people experience communication anxiety at times but still appear to enjoy talking with others. However, the high CA child who is the main focus of this research, finds talking with others a more difficult experience. This study acknowledges self-report as the primary evidence of the cross-situational and enduring condition of communication apprehension. Certain verbal and nonverbal effects and academic/social consequences may follow from the $C A$ condition. Self-adaptors are nonverbal kinesic behaviors that are thought to be associated with levels of communication apprehension and indicate its presence, and were observed in CA children in the present study. Both brief and longer lasting self-adaptors were analyzed in this study.

Communication apprehension is related to other similar constructs such as reticence and shyness, and to more global categories of related constructs as well. However, 
available literature does not clearly distinguish among the various constructs as to prior conditions, simultaneous occurrences or different causes and effects. To date, researchers do not agree as to the level of distinction that should exist among the constructs.

Therapy or treatment for communication apprehension has been recommended in the literature as well as specific teaching strategies which employ cooperative learning activities within small group structures. However, the use of cooperative learning activities may or may not relieve anxiety through shared communication responsibility and concentration on the group learning task.

The study hypothesis predicted a positive correlation between self-reported communication apprehension, through use of the Measure of Elementary Communication Apprehension or MECA (Garrison \& Garrison, 1979a), and certain nonverbal self-adaptor behaviors, as recorded on the researcher-developed Upper Body Self-Adaptor Scoring Form or UBSSF. This data were used to ascertain cross-situational consistency of $C A$ and as a further test for the enduring quality of the anxiety. Qualitative data were collected as well through observation and analysis of self-adaptors, use of field notes, and interviews with $C A$ students (using film elicitation technique) as well as interviews with their teachers. The phenomenological perspective was taken reflecting the views of the participants by identifying 
emergent categories of meaning through an interpretation of interview texts. By identifying $C A$ in children and bringing their perspectives to light, this study seeks to raise teacher awareness of and knowledge about what constitutes a $C A$ child, so that the instructional and social needs of the apprehensive young child might be accommodated through appropriate teaching strategies in the classroom setting. 


\section{ENDNOTES}

1 other singular and global definitions and descriptions are given for the constructs of reticence, communication apprehension, and shyness, as well as other related constructs. Interested readers may see Burgoon (1976); Clevenger (1984); Daly (1978); Daly and McCroskey (1984); Burgoon and Koper (1984); Kelly (1982); McCroskey and Richmond (1987); McCroskey et al. (1981); Mortensen, Arnston, and Lustig (1977).

2 The extinction of $C A$ through repeated introduction of anxiety-producing stimuli during systematic desensitization has been suggested for use with students (Friedrich \& Goss, 1984; McCroskey, 1972). However, I have found no current applications to the elementary school setting. Social skills training for reticence does not refer to the internal anxious affective state which is addressed in this study (Kelly, 1984). Visualization techniques are not generally advocated for use in the elementary classroom in the school district in which this study was conducted. 


\section{CHAPTER III}

\section{RESEARCH METHODS AND DATA COLLECTION PROCEDURES}

This chapter presents the methods and procedures used in this study. The first section, Method, describes the design, participants, unit of analysis, measurement instruments, other forms of data collection, and validity and reliability of the study. Procedure, the second section, describes the research processes of the pilot study. The third section, Recommendations for the Main study, contains additions or deletions of procedures based on pilot study results. The final section, conducting the Main study, presents a brief, initial summary of the study procedures and results.

The purpose of this exploratory study was to identify primary school children who tested as communication apprehensive and determine a possible relationship between communication apprehension (CA) and a set of nonverbal kinesic behaviors known as self-adaptors. Significant increases in $C A$ levels during the third and fourth grades have been noted (Comadena \& Prusank, 1988; Mccroskey et al., 1981; Wheeless, 1971). These findings suggest that the problem of communication apprehension should be examined at early grade levels, and call for studies in the actual 
classroom setting. This study addressed four research questions (see Chapter I) and tested the following hypothesis: a positive correlation exists between levels of communication apprehension and displayed self-adaptor behaviors.

METHOD

Research Design--ouantitative and Qualitative Methods

The research questions and hypothesis were addressed in two ways. One approach utilized an experimental field research design in which statistical procedures were used to establish levels of $C A$ among a sample of primary school children and test the predicted relationship between $C A$ and self-adaptors. Additional data were gathered and analyzed using a qualitative approach which, together with the statistical procedures helped determine the possible enduring nature and cross-situational consistency of $\mathrm{CA}$. Participants' perspectives and additional data were analyzed to obtain further corroboration of the MECA results.

Applying both research approaches in a multiple-method approach is called method triangulation--"the incorporation of field survey instruments with on-site observation" (Albrecht \& Ropp, 1982, p. 163). The benefits of this approach are stated by the authors:

In effect, triangulation can result in maximizing a single method's benefits while "neutralizing" its drawbacks. For example, observational methods may 
aid survey analysis in the validation of results and interpretation of statistical findings. (p. 170)

Also, Sevigny (1981) states that:

Triangulated inquiry offers stronger potential for generalization through built-in mechanisms which rule out rival hypotheses. . . The triangulated approach asks whether other plausible interpretations are allowed from differing participant perspectives, while allowing for cross-validation measurement. (p. 73)

Both quantitative and qualitative data are used in the present study to achieve the benefits of this multi-method approach .

According to McCracken (1988),

the [quantitative] goal is to isolate and define categories as precisely as possible before the study is undertaken, and then to determine, again with great precision, the relationship between them. (p. 16)

In this study, Time 1 and Time 2 administrations of a self-report measure of CA (MECA) were given to primary school children in their classrooms to identify levels of communication apprehension (Garrison \& Garrison, 1979a). Nonverbal self-adaptor behaviors were observed and their frequency recorded through use of an instrument developed by the researcher (The Upper Body Self-Adaptor Scoring Form) . While self-adaptors in children have not previously been examined as in the present study, the MECA has been administered to other larger student populations. Correlations were performed between identified levels of $C A$ and the frequency of self-adaptors to discover the positive relationship predicted in the hypothesis. 
The qualitative method differs in that its goal is: - . to capture what people say and do as a product of how they interpret the complexity of their world. In order to grasp the meaning of a person's behavior, the qualitative researcher seeks to understand social events from the person's point of view . . (Sevigny, 1981, p. 68)

Qualitative study data included classroom observations, videotapings, interviews with $C A$ students using film elicitation, interviews with their teachers, and field notes (including general notations, oral data from teaching specialists and additional demographic information). Through use of the phenomenological perspective in which the individual's lived experience is the focus of knowledge (Littlejohn, 1989), the researcher attempted to reconstruct the reality of the study subjects. This is known as an emic approach (Sevigny, 1981). Mccracken (1988) indicates that - . qualitative research normally looks for patterns of interrelationship between many categories rather than the sharply delineated relationship between a limited set of them. (p. 16)

This qualitative data combined with the quantitative information which constitutes the etic approach (external or coming from "outer" constructs and theories [Sevigny, 1981]) to provide a holistic view of the participants (Patton, $1980)$.

\section{Sampling Procedures}

population. The sample was drawn from a population of primary school children in a Northwestern suburban elementary school. The actual sample consisted of 42 
students from two third grade classes (24 boys and 18 girls), hereafter referred to as Class $A$ and class $B$.

The participants were 9 or 10 years old. Thirty-two of the students were Caucasian, and the study sample also included five Hispanic, two Korean, and one each of Black, Chinese, and Cambodian students. Sixteen of the 42 students had attended the school since kindergarten. The subjects constituted a purposive sample in that they were not picked by random (Frey et al., 1991). Rather, they were the only available subjects that met the criteria of being enrolled in the third grade.

\section{Unit of Analysis}

The present study required a shift in the unit of analysis from the examination of individual apprehensive third grade students to the investigation of differences between the two classes in the main study. This occurred as a result of statistical analysis which found two different populations within the study, and qualitative analysis indicating different teaching/learning environments. As discussed by Patton (1980):

These different units of analysis are not mutually exclusive. However, each unit of analysis implies a different kind of data collection, a different focus for the analysis of data, and a different level at which statements about findings and conclusions would be made. (p. 167)

These differences are addressed in Chapters IV and V. 
Quantitative Measurement

Instruments

One measurement tool was used in the study to measure student levels of $\mathrm{CA}$, the Measure of Elementary Communication Apprehension (MECA) (Garrison \& Garrison, 1979a). A second instrument developed by this researcher, The Upper Body Self-Adaptor Scoring Form (UBSSF), was used to measure frequency and duration of certain nonverbal self-adaptor behaviors.

Measure of Elementary Communication Apprehension. Since $C A$, or anxiety about talking with others, is taken to be an internal cognitive experience, self-report remains the preferred form of measurement, according to Mccroskey (1984). Mccroskey maintains that other measures such as behavioral observations may indicate or support the existence of $\mathrm{CA}$ but cannot prove its occurrence as a cognitive condition within the individual. He acknowledges the problems encountered in using self-report measures to determine factual matters, but indicates that self-report appears suitable to measure areas of affect and/or perceptions.

Three derivations of McCroskey's Personal Report of Communication Apprehension (PRCA) have been developed (McCroskey \& Richmond, 1987). The first two questionnaires included items concerned with fear of public speaking, while 
the PRCA-24 measured items in different contexts and therefore seems a more adequate reflection of communication apprehension that is enduring and cross-situational. Levine and Mccroskey (1990) reviewed similar tests and found their results agreed with and supported the PRCA-24 as a reliable test of communication apprehension.

Another instrument, the Personal Report of Communication Fear (PRCF), measures $C A$ in children, and employs a smaller vocabulary than the PRCA-24. However, some choices may confuse children by asking them to disagree with a negatively-worded item (McCroskey, 1984).

The Measure of Elementary Communication Apprehension or MECA overcomes this difficulty (Garrison \& Garrison, 1979a). This third tool is a 20-item, five-choice measure which offers a row of faces and written descriptions on each page to which the child responds by circling the choice that most closely reflects the feeling experienced in the stated situation (see Appendix A). The instrument employs a Likert scale which measures five positions of agreement or disagreement with the stated item and a neutral opinion given for the third position (Crano \& Brewer, 1973). The faces and descriptions of the measure express a progression of happiness and liking the situation to unhappiness and disliking the situation, and are presented in reverse order for half of the questions to avoid response 
bias (Garrison \& Garrison, 1979a). The questionnaire is in the form of a small flip-chart which displays only one question and one row of five faces with accompanying written descriptors at a time. The questions and written descriptions are to be read silently by the children while the administrator reads them aloud.

The MECA is scored by adding points assigned to each expression of feeling selected on the questionnaire--from one point for "really good" to five points for "afraid." Means are calculated based on total class MECA scores for each administration of the questionnaire. Then, students who score one standard deviation above their class mean are designated as high in communication apprehension, while those who score one standard deviation below their class mean are considered to be low in CA (McCroskey, 1970).

Garrison and Garrison (1979a) developed the instrument to measure communication apprehension in 595 fourth, fifth, and sixth grade boys and girls attending the Lincoln, Nebraska public schools. Hoffman (1990) administered a modified form of the MECA to 60 third and fourth grade boys and girls at a private elementary school in a large city in the Northwest. Class means for the third grade class in her study were: MECA Time $1 \underline{M}=48$, MECA Time $2 \underline{M}=44$. For purposes of her study, Hoffman designated as high CA only those who scored one standard deviation above the mean in 
both Time 1 and Time 2. The less extensive design of the present study allowed students who met the criteria in either or both of the MECA administrations to be designated as high CA.

The modification of the MECA was in response to a suggestion for further refinement by Garrison and Garrison (1979a). Hoffman (1990) developed a form of the MECA that includes facial indicators and descriptive phrases which more directly measure anxiety or fear rather than like or dislike as in the earlier version of the instrument. The new facial indicators show a range of expression from feeling good to feeling fearful, and written descriptions of these feelings accompany the indicators. This is the instrument used in the current study (see Figure 2). The wording of three of the original questions was also changed by Hoffman (1990). Talking to teachers and talking to the principal were combined in question number one in the original instrument (Garrison \& Garrison, 1979a). Hoffman's adaptation allows children to respond to each circumstance. The situation described in the original question number six involved riding a bus. Since not all students ride the bus to school, but may be transported in cars or vans, Hoffman substituted the playground situation in which most children regularly participate. An additional 

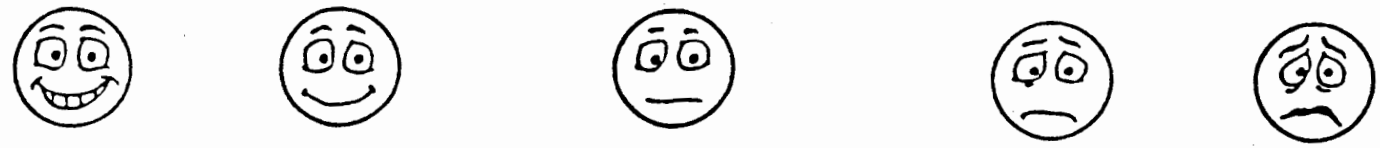

Really Good Good Doesn't Bother Me Nervous Afraid

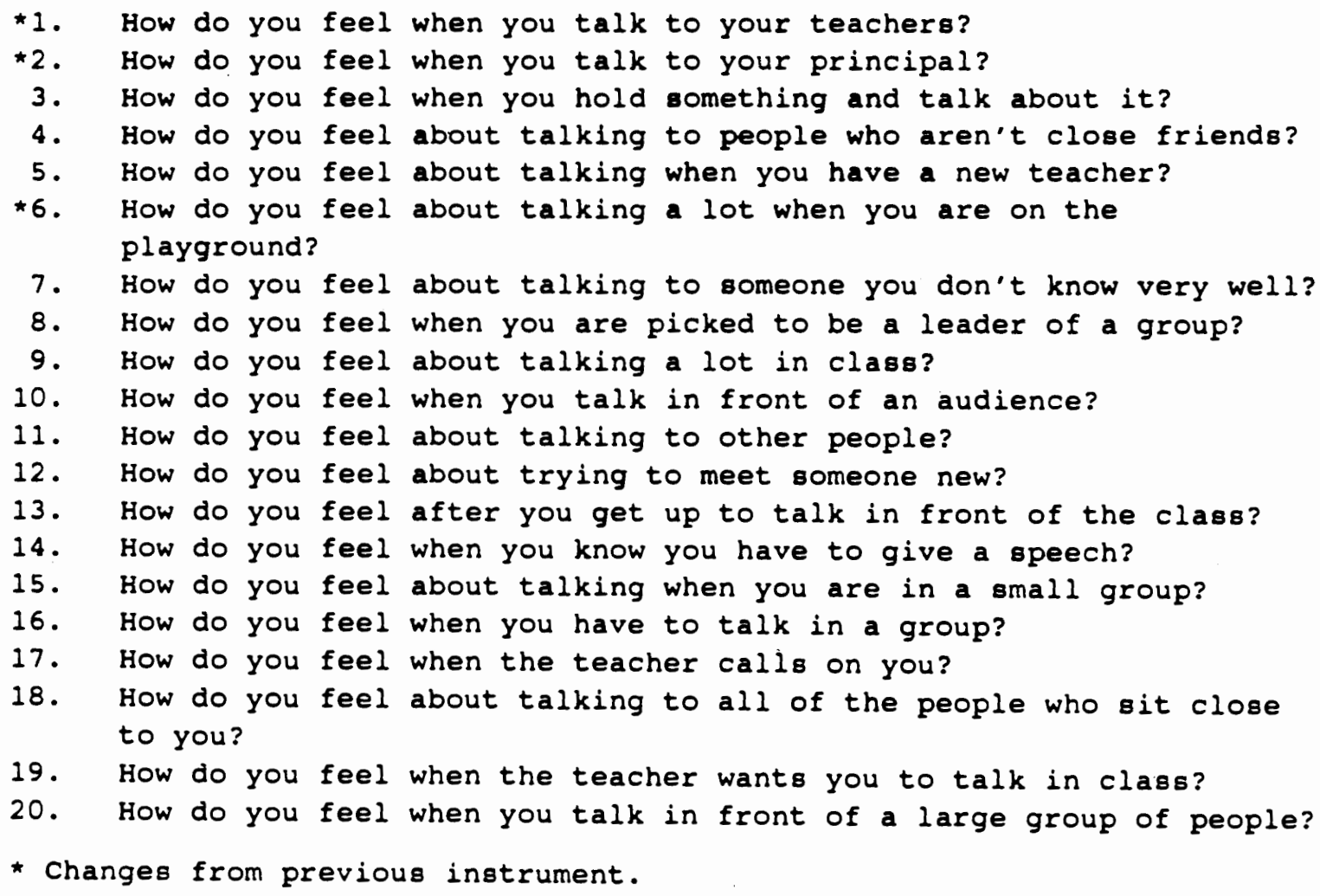

Figure 2. Modified MECA Instrument (Hoffman, 1990).

question on the original instrument (question number 14) was eliminated because the circumstance in which a child would give a speech on television was considered inappropriate for the everyday experience of a young child. Reliability estimates were provided by Hoffman using Cronbach's Alpha, and ranged from .79 to .88 in comparison with a range of .76 to .80 for reliability estimates provided by Garrison and Garrison. In Hoffman's study, Time 1 and Time 2 
administrations of the measure were 15 weeks apart, whereas the two administrations of the MECA were two weeks apart in the Garrison and Garrison study, and one week apart in the current study.

\section{Upper Body Self-Adaptor scoring Form (UBSSF). This}

study tests the hypothesis that a positive correlation exists between levels of communication apprehension and counts of displayed self-adaptor behaviors. In a study of self-adaptors and $C A$ in college students, Comadena and Andersen (1978) state:

since individuals with high CA experience increased anxiety when confronted with a communication encounter, the research presented suggests that individuals with high $C A$ as compared to individuals with low $C A$, will exhibit an increase in self-adaptor activity as an indicant of the anxiety experienced. (p. 4)

In this study, since children were sometimes seated at their desks which blocked a full-body view, only upper body self-adaptors were coded. Self-adaptors or touches which might be considered intimate such as touches to genital areas were therefore excluded. The following self-adaptors were included in the pilot study scoring Form: "self-touch, - . scratching, biting, cradling some part of the body" (Harrison, 1974, p. 137), "licking the lips, rubbing hands" (Harper, Wiens, \& Matarazzo, 1978, p. 138), "holding, . . pinching" (Knapp, 1980, p. 8), "plays with something" (Clevenger, 1961, p. 298), touching clothes or jewelry or other objects without using them as a tool for speech 
(Freedman et al., 1972), "tugging at clothing . . ." (Leathers, 1986, pp. 62-63). These categories of self-adaptors were included in the pilot study scoring Form because they were the behaviors I have seen most often in the classroom setting. Four self-adaptors discussed in Chapter II were not included in the pilot study as I considered them too general to be identified easily on the videotape: "soothing" (Harrison, 1974, p. 137), "moving into a more comfortable position" (Mehrabian, 1972, p. 3), "squeezing" (Knapp, 1980, p. 8), and "sways, swings arms" (Clevenger, 1961, p. 298).

Although the forgoing researchers and others have studied self-adaptors and/or developed scoring systems for their frequency, none addressed $\mathrm{CA}$ and self-adaptors in young school children (Baesler \& Burgoon, 1987; Comadena \& Andersen, 1978). However, a study which utilized an interview format combined with a focus on attentional processes during task performance to examine self-adaptors in children proved useful for the current study (Barraso, Freedman, \& Grand, 1980). The form for the type of data recording it employed appeared appropriate and practical for this study to identify self-adaptors in CA students working in small groups in the classroom setting. Self-adaptors were measured according to the following descriptions and procedures:

The scoring of body-focused movements involves timing with a stop-watch the duration of the 
movements of the hands on the body... or onto each other. . The hand activity can appear as rubbing, - . scratching, or light motions of the hands on . . . the body or its clothing or of the hands onto each other. By definition, movements are considered continuous if they last longer than three seconds. (Barraso, Freedman, \& Grand, 1980, p. 1,085 )

In the Barraso et al. study, two observers watched the tapes repeatedly to record the number of movements, their description and duration. Though a third observer was asked to resolve differences in observations, the authors noted that the differences were very few.

Drawing on the previously cited authors regarding self-adaptors and additional relevant information on the topic (Baesler \& Burgoon, 1987), I developed an instrument specific for the present study (see Appendix B). Changes were made in the instrument as a result of the pilot study, and the modified form was used in the main study.

The place for the student name at the top of the form was removed, and a location for a student number was provided so that greater anonymity could be established. Space was also indicated for the date of the videotape and a student group number since the children were filmed in their work groups. The second category "playing with something" was eliminated as too general, and the third category, "rubbing self or object" became the second self-adaptor on the form. Touching of the hair was included under the fourth category of grooming to differentiate from a touch to the skin of the head. Demographic information requested at 
the bottom of the form was replaced by initial directions for coding self-adaptors. The back of the form was later used for the third sequential tally when many self-adaptors were observed. This was also a convenient location for any additional observations or dilemmas noted during the video segment (see Figure 3).

*Student Number *Group Number *Date of Videotape Identifying description of student in the group:

Nonverbal Self-Adaptor Categories

Touching separate parts of head, upper body, clothes, jewelry (adornments).

*Rubbing self or object

Holding self, cradling or supporting upper body part

Grooming--e.g. flipping, ${ }^{*}$ touching or brushing hair with hand(s)

Biting self or object

Scratching self

Squeezing self or object

Tugging at clothing or upper body part

Pinching self

Licking lips

Calculate frequency for each child three times. Use left and right margins to mark categories, and the lower margin for a final sequenced frequency count with notations as to type of nonverbal behavior. Place total count of all discrete (short) and continuous (longer than three seconds) self-adaptors at the top of the page as follows: 8

This example shows a total of eight self-adaptors including three continuous ones.

${ }^{*}$ Changes from the pilot instrument.

Figure 3. Modified Upper Body Self-Adaptor Scoring Form (UBSSF). 
More extensive directions for coding self-adaptor behaviors were developed during three meetings with the research assistant (see Appendix C). I reviewed videotapes with the assistant to resolve our differences in frequency counts and check her coding ability (see pilot study in this chapter for detailed discussion).

\section{Qualitative Methods}

Four qualitative methods were used in the study: taped observations, film elicitation, interviews with teachers and $C A$ students and field notes.

Taped Observations. Videotaping was used to record details of the classroom observations as well as frequencies of self-adaptors. During the conduct of the main study, I observed four 20-minute learning segments in each classroom at intervals of one to three days, and an assistant I recruited, videotaped the sessions. This provided a total of 160 minutes of taped observations of naturally occurring classroom activity.

The students were observed as they worked in small cooperative learning groups within the traditional self-contained classroom. The first two observations provided baseline nonverbal data prior to administration of the MECA Time 1. The last two observations were made to gather additional nonverbal data prior to administration of the MECA Time 2. 
Videotaping of children in the classroom has often been a useful tool for research and instruction. For example, Cahir and Kovac (1981) videotaped kindergarten through third grade students to explore how children and teachers use language to accomplish classroom tasks. Sevigny (1981) suggested videotaping in his discussion of qualitative research, and corsaro (1981) filmed children in their classroom twice a week for most of a school year to analyze process outcomes in light of social rules that are established.

Prior to the conduct of the present study, teaching specialists were asked to excuse their third grade students for the data-gathering sessions. Non-participating students were not allowed to return to the classroom during videotaping in order to prevent accidental filming of them without permission.

Film Elicitation. The film elicitation technique was used to obtain the CA participant's perspective of classroom events as he or she reviewed tapes with me during individual interviews. As suggested by Lustig and Grove (1975), videotaping can "freeze characteristic communicative behaviors . . " (p. 163). Anderson (1987) states that, "Our responsibility is to produce a view of the content from the perspective of the actor" (p. 334), and this is facilitated by the film elicitation technique (Denzin, 1989; Terasaki, Morgan, \& Elias, 1984). In this study, interviews 
of $C A$ students assisted the attempt to ascertain their perceptions of specific sections of videotape content and their feelings at the time of the original taping of their classroom group. This is an example of the phenomenological approach which seeks to interpret reality from the perspective of the individual whose unique nature and experience influence how life is viewed (Schutz, 1967). It is another form of self-report and an example of the multi-method triangulation approach which serves as a cross-validation for the MECA (Albrecht \& Ropp, 1982). Interviews of Teachers and CA students. During the conduct of the main study, taped interviews were conducted with two classroom teachers and seven CA students. An interview is a type of encounter characterized by a central characteristic (Lofland \& Lofland, 1984). While the teacher interviews focused on perception and description of $\mathrm{CA}$ students, the main feature of the children's interviews was the attempt to elicit speech in the form of conversation from children, who by self-report are apprehensive about talking. Only then could the goals of the interview be addressed. According to Mccracken (1988),

The purpose of the qualitative interview . . . is to gain access to the cultural categories and assumptions according to which one culture construes the world . . . it is the categories and assumptions, not those who hold them that matter. (p. 17)

Patton (1980) indicates ". . that perspective is meaningful, knowable, and able to be made explicit" (p. 
196). The interviews were recorded and later transcribed. Texts were then reviewed in a manner similar to Lu (1992) to first identify and then analyze emerging themes (see chapter $\mathrm{V}$ for discussion).

Open-ended interview questions similar to those used in this study avoid the pitfalis of a dichotomous (yes/no) response (Patton, 1980). Patton describes the format for such questions:

The standardized open-ended interview consists of a set of questions carefully worded and arranged with the intention of taking each respondent through the same sequence and asking each respondent the same questions with essentially the same words. (p. 198)

However, Lofland and Lofland (1984) suggest some flexibility in using the interview guide in that interviewees should feel they can also talk about other issues than those included in the guide. Jorgensen (1989) indicates that more descriptive information will be received if the "why" question is avoided. Two moderately structured interview guides were constructed, and teachers were asked:

1. Are there any children in your classroom who seem a little uneasy about talking?

2. How do you notice them?

3. How would you rate the quality of their work?

4. How well do they get along with you and the children in the class?

CA children were asked the following questions: 
1. Tell me a little bit about what is going on [on the screen] and what you are doing (see discussion of film elicitation technique in Chapters IV and V).

2. How did you feel when this was happening?

3. If you could arrange the desks in the classroom, would you like everyone to sit in rows with the teacher in the front, or have everybody sit in work groups with the teacher helping the students?

For the $C A$ children, the first question involves a technique employed by Kawamitsu (1992) in which a general question opens the interview, and more specific information is later requested. However, in the current study this was also done to put the student at ease by focusing attention on the VCR instead of the $C A$ student. The open-ended questions for $C A$ students are related to the viewing of the videotapes in that together the questions and the film elicitation evoke the perspective of the apprehensive child, thereby supporting other qualitative methods as well as the quantitative methods in the study.

Field Notes. Field notes were taken by the researcher during each 20-minute classroom observation and throughout the study. This was done to capture data not recorded by the video camera, and to provide relevant context utilizing additional data. According to Lofland and Lofland (1984), field notes include short mental and written notes as well as complete notes that refer to long periods of time such as 
an entire morning. Field notes, which were also used in the main study, included:

1. Time of day of classroom observations, general classroom environment including noise level, and behaviors of the teacher and children.

2. Teaching style preferences both observed and expressed by the teacher, approximate length of the teacher interview, and suitability of the interview questions.

3. Conversational topics and student behaviors while moving to and from the interview room, unusual speech mannerisms (including volume), and student behaviors (including self-adaptors) during interviews.

4. Difficulties and successes experienced and personal reflections on how effective each procedure appeared to be as the pilot study progressed, and recommendations for changes, additions or deletions in measurement tools, procedures, forms, and letters.

5. Demographic information regarding ethnic background, birth date, and date of entry to the school.

6. Information from specialists on $C A$ students designated as talented and gifted, handicapped, needing instruction in academics, speech, or assistance in dealing with emotional problems. 
Validity and Reliability of

the study

According to Kirk and Miller (1986), an important goal of researchers in the natural and social sciences is objectivity which leads to scientific credibility. In the current study, objectivity was pursued through the establishment of internal and external validity and reliability.

Lecompte and Goetz (1982) state that method triangulation or a multi-method approach facilitates this purpose ". . augmenting reliability or validity of an experimental design" (p. 35). Beyond augmentation, method triangulation provides a basic framework from which cross-validation is achieved (Albrecht \& Ropp, 1982; Sevigny, 1981).

Validity. Validity is "the degree to which researchers measure what they claim to measure" (Williams, 1986, p. 21). This study attempts to address predictive, construct, content, and ecological validity (Babbie, 1992; Frey et al., 1991). The MECA possesses predictive validity in that correlation exists between Time 1 and 2 administrations of the measure. The same kind of validity was not established for observations of self-adaptor behaviors.

Although a logical relationship (construct validity) was predicted between highly apprehensive students and large numbers of displayed self-adaptors or nervous behaviors, the 
study test results did not establish a significant connection between the two variables. Content validity was addressed in the Upper Body Self-Adaptor Scoring Form in that the form reflected the described self-adaptors as completely as possible (Babbie, 1992).

While Babbie (1992) addresses the need for validity in quantitative research, the "accuracy of scientific findings" to which Lecompte and Goetz (1982, p. 32) refer depends more on the conduct of qualitative research. Accuracy of judgment is important as indicated by Kirk and Miller (1986), ". . - we are under considerable constraint to keep our thinking clear by calling things by their right name" (p. 24). In the current study, I searched the literature for examples of self-adaptor behaviors, recalled former students who displayed self-adaptors, and talked to other teachers about these behaviors in students. Taking all of this into account, I compiled a list of self-adaptors to be observed. However, training the research assistant to recognize these behaviors was of the utmost importance for agreement between us on exactly what constituted a self-adaptor.

To establish internal validity, a researcher must demonstrate that what is said to be observed is reflected in the reality of human life. According to Frey et al. (1991), such ecological validity "reflects, or does justice to, real-life circumstances" (p. 135). The classroom setting in 
which the observations and videotaping were carried out appears to closely approximate the natural classroom environment. Also, the presence of the researcher for seven years as a teacher in the school provided an informed view of that environment and the events that occurred within it, thus contributing to the internal validity of the study. Also, identified CA students did not dispute the findings of the self-report measure during interviews with the researcher though it was felt that they might have readily disagreed with the label of "nervousness" if it was perceived as a negative condition. However, they appeared to acknowledge the reality of communication apprehension in their lives and this strengthened internal validity for the MECA tool (Sevigny, 1981).

Issues of maturation or changes within individuals were taken into consideration, at least in one respect (Babbie, 1992). New students (those who arrived less than one month before the study began) were excluded from the study since their anxiety may have been based in their recent-arrival status. This possibility was confirmed by one child in the pilot study interview. When asked why he might be nervous about talking with others, he replied rather loudly, "I'm new!"

Though I was able to take advantage of my former position as a teacher in the school to re-establish relationships with students, as in Kawamitsu's 1992 study, 
my experience in the field was also a disadvantage in that it removed the "critical distance" that is needed to insure validity (McCracken, 1988, p. 22). However, McCracken states that the sense of surprise can sometimes supply the needed distance and may occur on informal occasions. I experienced this when I realized that the communication apprehensive children not only appeared willing to be interviewed but spoke at some length about subjects of interest and concern. Obtaining considerable speech from children who were afraid to talk provided the "violated expectation which points to the presence of otherwise hidden cultural categories and assumptions" (p. 23). Most important, I had to re-examine the Iiterature's portrayal and my initial understanding of these children as consistently avoiding speech.

Finally, I attempted to minimize the possible threat to validity which the Hawthorne effect presents--the result of the researcher's presence on participants' behavior (Roethlisberger \& Dickson, 1939). I did this by trying to present a friendly, open, low key and sympathetic attitude toward the CA students. Hopefully, the participants could then respond as truthfully and accurately as possible without undue influence during the interviews.

Reliability. Reliability, the ability to replicate the findings of research, is addressed in specific ways in this study. Quantitatively, reliability is defined as "the 
external and internal consistency of measurement" (Williams, 1986, p. 21). Babbie (1992) indicates that the test/retest method, such as the MECA Time 1 and 2 , constitutes a means to provide reliability, and that using established measures is appropriate where their reliability has been proven. Reliability estimates were obtained for the original MECA instrument (Garrison \& Garrison, 1979a) and for Hoffman's (1990) modification.

Internal reliability considers whether more than one observer would agree with a researcher's basic understandings so that the same conclusions would result in one study or many following studies. Inter-rater reliability was achieved during the development and use of the measurement tool for self-adaptor behaviors in two ways: development of clear categories of behaviors and independent counts and statistical correlation of behavior frequencies (Davis, 1981)

While the results of a qualitative study may not be generalized to another student population, Lecompte and Goetz (1982) indicate that they could be compared to other groups if the general characteristics of the sample population, the concepts, categories and methods in the study are discovered, developed and rigorously applied. Also, use of the same underlying assumptions, constructs and 
definitions is necessary to avoid basic defects in a similar study.

However, external reliability in qualitative research (such as ethnography) is achieved if independent researchers come to the same conclusions as the study researcher, or develop the same concepts in a similar environment (Goetz \& Lecompte, 1982). Though the events and behaviors recorded during this study could not be duplicated, the varied methods and tools used in the research design may enhance the possibility of external reliability or the re-creation of the original data by other researchers. This also facilitated data gathering and analysis of numerous direct quotes from the participants involved (Lecompte \& Goetz, $1982)$

\section{PROCEDURE}

Approximately six months before the researcher entered the field, numerous steps were taken in anticipation of the study. Planned procedures were then carried out in conducting the data gathering stage of the work.

\section{Initial Processes}

The researcher felt that access to the field of study would be given if the general purpose of the research and the means to undertake the work were communicated clearly in an organized way to the school "gatekeepers" (Corsaro, 1981) 
such as the principal, secretary, and teachers of the third grade students. Since the school district's department of testing and evaluation and the university's human subjects committee had to approve the study proposal (approvals granted April 30 and May 14, 1992), the principal gave tentative permission to conduct the study. However, cooperation, flexibility, and trust by all "gatekeepers" were needed throughout the course of the study in order to carry out the project.

According to sevigny (1981), in qualitative research there are four positions the researcher may take: "the complete participant, the participant-as-observer, the observer-as-participant, and the complete observer" (p. 69). Generally, my position during this study was as an observer, but to gain entry to the field I needed to participate to a certain extent in some of the activities of the school (attending recess) and with some of the students in their classrooms (reading them a story). Therefore, my position was also observer-as-participant.

The study was conducted with the cooperation of the principal and three third grade teachers at the elementary school in which I had taught for the previous seven years. I met individually with the teachers on three occasions prior to conducting the study in their classrooms. They were given a general summary of the proposed work and asked about group-oriented learning activities that might 
facilitate communication among the students and be suitable for videotaping. The pilot study teacher suggested learning centers in which students work on individual projects while the other two suggested that one activity be used with their classroom groups, and that cooperative learning strategies which encourage individual responsibility for learning within a group structure be employed. I felt that both structures would result in the desired communicative environment needed for this study.

Inquiries were also made regarding students who might be excluded from the study by parent request, and alternative activities were suggested for them. Verbal permission was obtained from the teachers to observe and interview them and videotape them with their students. The teachers were asked to be aware of any negative effects of the research procedures on the students.

I also met three times with the principal to provide a general summary of the work and review the cover letters and consent form that would be sent to parents of the students (see Appendices $D, E$, and F). The secretary agreed to help from time to time when access to files was needed.

A room was requested for interviews, and they were scheduled to be held in an available computer room. The president of the parent/teacher organization, a parent of the researcher's former students, was informed of the study and asked to videotape the sessions. She was also 
asked to assist in development of the self-adaptor measurement tool by independently reviewing the pilot study classroom observation tapes according to criteria provided by the researcher to establish inter-rater reliability. The choice of president of the parent/teacher organization as research assistant reflected the observations of Richardson, Dohrenwend, and Klein (1965) as to the importance of a good relationship with the "gatekeepers" in the school and their suggestion to involve the parent/teacher organization when research is conducted in the school setting.

\section{The Pilot Study}

Sixteen third grade students from one class (seven boys and nine girls) took part in a pilot study in order to provide checks for clarity and feasibility of all study procedures and instrument reliability. Consent letters and forms, videotaping and tape recording techniques, teacher and student interview questions, film elicitation, the MECA questionnaire and Self-Adaptor Scoring Form, and appropriate scheduling could only be evaluated through enactment of procedures. 1

Observations and Videotaping. In May, 1992, on two separate days, two 15-minute learning segments were videotaped in the classroom. Total class size was 22 students. Twenty-one students were present for the first observation, and 20 for the second. 
At the beginning of the first observation, the teacher assigned students to five learning activity centers. A high level of interaction and involvement was observed in most students. The teacher softly reprimanded two groups, and mentioned to the researcher that she was not happy with the behaviors of the class.

The second 15-minute videotaping took place the next day. The groups worked quietly during the observation, and the teacher moved rather constantly among the groups. After the second session, the teacher said she had told her class she expected better behavior during the second observation. She expressed satisfaction that her warning had apparently been heeded by the children.

As a result of the teacher's response to the videotaping of her students, I decided to informally advise the teachers in the main study to view the natural (though sometimes loud and disobedient) behaviors of the children as completely acceptable for purposes of the study.

\section{Administration of the Measure of Elementary}

Communication Apprehension (MECA). Time 1 and Time 2 administrations of the modified self-report measure (Hoffman, 1990) MECA, followed the first and second classroom observations. ${ }^{2}$

When all completed MECAs had been collected, the students were asked to comment on the questionnaire. One student said she circled two faces on the same page of the 
questionnaire because she sometimes felt one way about the situation and at other times she felt differently about the same event. Two other students pointed out that the question about talking in front of an audience seemed the same as the one about talking in front of a large group since a large group could be an audience. Another student observed that one question simply asked about talking in a group, and asked the size of the group.

The researcher was surprised at the students' observations as they appeared insightful for children who were 9 or 10 years old. She complimented the students on their good questions, but did not attempt to answer the questions directly other than to indicate to the first student that the way she felt most of the time (about the communication situation) would be the best answer. The students were told that their comments would be shared with other researchers who have used the questionnaire, and that some children would be asked to look at parts of the videotapes and talk with the researcher.

No attempt was made to alter Hoffman's (1990) modified form of the MECA for the study sample, as this was only the second test of the modified form. Also, the researcher felt that she lacked the time or expertise to restructure the questionnaire prior to the conduct of the main study.

Interview of Pilot study Teacher. After both administrations of the MECA and the classroom observations 
were completed, the researcher interviewed the pilot study teacher. The interview lasted approximately 20 minutes, and took place in the teacher's classroom at the end of the school day.

The purpose of interviewing the teacher (and CA students) during the pilot study was to ascertain whether the interview questions and setting, scheduling and length of the interview was appropriate, and to determine reliability and feasibility for the interview process. Analysis of the interview was instrumental in confirming the chosen interview content and format for the main study. The teacher discussed at length her perceptions of the anxious children in her class, relating a number of remedies she had tried and her frustrations in dealing with the academic and social problems of these students. She identified two of the five communication apprehensive students in the pilot study, but only at the end of an extended interview session and as a result of questions by the researcher that functioned as prompts.

The researcher anticipated no changes in the interview schedule, but decided to hold to the 10 to 12 minute time frame as the extended time would not be practical in the main study interviews. Also, the long pilot study interview resulted in a rather fragmented format in which questions had to be repeated. A more structured format and expedient manner that ignored side issues and comments was expected to 
produce the same information without the distraction of prolonged commentary.

Selection and Interviews of pilot study sample. Four students scored more than one standard deviation above the mean and were interviewed. Later, the researcher learned that two of the four students were new to the school. One student had arrived one week before the observations and had attended four schools during the year. The other had been in attendance for only three weeks prior to the observations. When the researcher mentioned the nervousness the newest student had reported in the MECA questionnaire and asked him why he thought he was anxious, he quickly and loudly replied, "I'm new!"

since the MECA is derived from a previous instrument that attempts to measure a relatively constant condition of communication apprehension (Biggers \& Masterson, 1984; Richmond \& Mccroskey, 1985), the researcher decided to exclude participants from the main study who had been in attendance for less than one month prior to participation. This was done to avoid the temporary anxiety of new student status which also obscures the scores of other CA students. After the scores for the new students were set aside, the standard deviation was re-calculated. Three additional high CA students were identified, bringing the total to five CA students who were subsequently interviewed. ${ }^{3}$ 
Interviews were scheduled to last 10-12 minutes although each varied somewhat in length. The average length of interview was approximately eight minutes. During the interviews, the students individually viewed portions of videotapes of them in their classroom work groups.

All students except the first one interviewed appeared quite talkative and watched the videotape of their work groups closely, sometimes pointing toward the screen or laughing at something happening there. On two occasions, I attempted to "lead" the CA student by suggesting a response. such suggestions might influence the child's answer. Also, I sometimes asked multiple questions, and Patton (1980) indicates that the interviewer should ask only one question per speaking turn to avoid participant's tension and confusion. On one occasion I did not seem to leave enough response time for the student.

The word "quiz" was used with one of the students in the pilot to describe the MECA instrument, and she began to look confused. I decided that use of this word would be avoided during the main study interviews, since the term is similar to "test" which was more intimidating than the less threatening word "questionnaire" which was used instead. During the student interviews, I tried to include more than one video segment, but I could not quickly locate additional segments. I then chose the segment closest to the one viewed by the preceding interviewee. The re-winding 
noise of the videotape interfered with the voices recorded on the tape recorder during the pilot interviews so I positioned the tape recorder a few feet away from the VCR. However, it was anticipated that the CA child may speak softly, and thus the tape recorder should be close to the child.

Results. All statistical tests were run on pilot data to determine appropriateness of methods for the main study. Data were analyzed using the MINITAB statistical package. Alpha level for all tests was set at .05 . Using the MECA Time 1 and 2 scores, the researcher obtained a correlation of .875 which agreed with Spearman's Rho of .875 to establish reliability for the measure. Five students who scored one standard deviation above the class mean on the MECA Time 1 and Time 2 were designated as high in communication apprehension (Garrison \& Garrison, 1979a). T tests produced no evidence for changes in MECA scores over time or between boys and girls. The statistical package was retained for use in the main study.

The Scoring Form for nonverbal self-adaptor behaviors (UBSSF) provided a tally of such behaviors displayed by the students. Both researcher and assistant separately viewed the two 15-minute films of the classroom observations and using the scoring Form, coded self-adaptor behaviors for each child. Sixteen children were observed twice with a 
total count of 150 self-adaptors (by the researcher) and 161 (by the assistant).

Initial correlations were obtained of .489 (boys) and .936 (girls) for the first observation, and .984 (boys) and .665 (girls) for the second observation. The largest number and range of discrepancies occurred in five boys' scores for the first observation with a discrepancy for only one girl in the second observation. Regression of these scores provided low inter-rater reliability $(\underline{r-s q} .=.239$ for boys' first observation), $(\underline{r-s q .}=.442$ for girls' second observation). That is, only a minimal amount of error (variance) was accounted for by the regression procedure. Discrepancies between researcher and assistant occurred due to the inexperience of the coders, vague descriptions of some categories, and the difficulty of the task. Accurate timing to determine discrete from continuous self-adaptors appeared possible only when behaviors were anticipated through repeated viewings. Because scoring calls for an intense focus of attention without interruption, the work becomes tedious and cannot be maintained steadily for more than 15-20 minutes at a time.

Movements were also overlooked, obstructed, or hard to discern because of students' positions, especially when lying on the floor. One category included in the pilot study scoring Form--playing with something--was too vague to 
evaluate because the concept of "play" was hard to interpret.

After review of the tapes and discussion of the foregoing problems, reconciliation of the six unusual cases resulted in a total self-adaptor count of 157 for the researcher and 160 for the assistant. Recalculation of boys' scores for the first observation resulted in improved inter-rater reliability $(\underline{r}=.951)$. The same was true of the girls' scores for the second observation $(\underline{r}=.856)$. A detailed discussion regarding resolving the intercoder differences is available upon request.

\section{RESOLUTION OF PROCEDURAL PROBLEMS AND RECOMMENDATIONS FOR THE} MAIN STUDY

As a result of the pilot study, a number of changes were made in research procedures and interview criteria. The following are in addition to those changes already mentioned in the previous section.

During the videotaping, the assistant often stopped the camera to obtain a better view of a child, resulting in timing inaccuracies. Since the videotaping ran over the scheduled 15 minutes on both days because of interruptions, I advised the assistant to record continuously and to adjust her position to achieve a better view. Also, the zoom lens allowed the assistant to approach the group more effectively without disturbing the students' work. 
student work at different "learning stations" resulted in varying levels of physical involvement which might be interpreted as self-adaptive. In the main study, all students would be working on the same task in their groups.

Regarding teacher interviews, I attempted to determine how to prevent comments by teachers about children who were excluded from the study. Rather than reminding the teachers before the interview, I resolved to dismiss such an issue more quickly if it was raised again in the main study interviews.

Data would not be excluded from the main study due to student absence from one administration of the MECA or a class observation. Average scores for the MECA and self-adaptors were obtained and assigned to the missing data, as Babbie (1992) indicates that an assigned mean prevents valuable data from being discarded. This is especially important in small study samples similar to those in the present research.

\section{PREPARATION AND CONDUCT OF THE \\ MAIN STUDY}

The main study proceeded as the pilot study had, incorporating the preceding additions and deletions.

General visitations to the classroom included reading a story to each class to help the researcher establish rapport and facilitate my re-acquaintance with some students. 
Questions from students as to the researcher's presence in the school during the pilot study were answered briefly. I understood that since inquiries were made of her, other pilot study students were also being questioned, and the main study students would already have some idea of the study and opinions about participating.

one goal in explaining the study to all student participants was their understanding of the voluntary nature of participation. However in class A, a student stated openly that he did not want to be part of the study and was quickly followed by another student who voiced the same opinion. Consent forms and explanation letters were not sent home with these children (see Appendices E and F). All students in Class B wished to participate and were given consent forms except for a newly arrived student from Russia who could not speak English.

Both main study classes were much slower in returning the forms than the pilot study class, and the researcher had to make a number of phone calls and visitations to homes without phones to explain the forms and obtain the signatures from the students and parents. However, all 42 expected consent forms were returned in about two weeks, and ice cream parties were held in the cafeteria (Perlman, 1970). No parent inquiries were received by the principal, the thesis director, or the researcher. ${ }^{4}$ 
The assistant and the researcher inspected the classroom for the most appropriate placement of the video camera. It was decided to videotape from the front of the classroom in class $A$, as students would be at their desks in groups, and to begin videotaping class B at the back of the room and work toward the front area since children would be scattered throughout the room in their groups.

It was anticipated that end-of-the year activities would disrupt the daily schedule somewhat, and observations and interviews might be interrupted or rescheduled. In fact, one interview was shortened, and another one had to be rescheduled because the child was attending an assembly.

In late May, 1992, two 20-minute observations and videotapings were conducted in both Class $A$ and $B$ to gather baseline data before the MECA Time 1 was administered (three days after the second baseline observation in the main study). During the third observation, some taping problems occurred, but these problems were solved and did not ultimately interfere with data gathering or analysis. Three days after the last observation, the MECA Time 2 was given to the classes.

Quantitative and qualitative analysis of the study data was conducted. Communication apprehensive students were identified through the MECA instrument, and frequency of self-adaptors was recorded on the Upper Body Self-Adaptor Scoring Form. MECA Time 1 and 2 scores were compared to the 
frequency counts of self-adaptor behaviors to obtain a possible correlation between MECA scores and use of self-adaptors. ANOVA procedures showed effects between and among males and females, both classes, and MECA Time 1 and 2. I tests then examined the specific nature of significant effects discovered in the ANOVA procedures.

Consultations were held with the teachers during and after the study to determine whether the students had suffered any negative effects from the research procedures, and safeguards were put in place for the protection of the student participants. To ensure participant anonymity, code numbers and letters were used in place of names, and findings were reported out as group data. Research results can then be kept on file without violation of confidentiality.

Identified $C A$ children were interviewed, and the researcher viewed videotapes of all students. Teachers were interviewed regarding identification and social and academic perceptions of communication apprehensive students.

To identify emergent themes and reconstruct the participants' perspectives, I listened to the teacher and student interviews a number of times, and read and re-read the interview transcripts. Frequency counts were made of certain words, phrases or topics, and items reflecting common themes were arranged according to themes. Interview transcripts were read both vertically and horizontally (Lu, 
1992). I then began to construct participants' views about communication apprehension based on emerging and common themes found in the interview responses. Chapter IV presents the analysis of the quantitative and qualitative data collected during the study. 
ENDNOTES

1 Prior to conducting the pilot study, the researcher visited the classroom approximately four times to become acquainted and reacquainted with students. Before videotaping, the researcher explained to the class that the research was an important project regarding how children feel about talking with each other and others. Participants were assured that they were free to withdraw from the research at any time without jeopardizing the relationship with the researcher or their teachers.

A cover letter explaining the pilot study to parents and a consent form were then sent home for student and parent approval and signatures (see Appendices $D$ and $E$ ). In order to insure timely return of the consent forms, the researcher told the class that all students would have ice cream bars when the forms were returned whether or not the parents and students consented to participation in the study. According to Perlman (1970) such inducements may be employed to hasten participant response since "Like most relationships, the researcher/informant relationship is often based ultimately on some kind of exchange.. ." (p. 305). With this in mind, when the study was concluded I also gave each third grade teacher an hour away from the classroom while I presented a science and art lesson on the corals of Fiji to their students in thanks to teachers and students for their cooperation.

Two parent phone inquiries were received regarding the following phrase located at the bottom of the informed consent form: "If you experience problems as a result of your child's participation in this study, please contact -. ." One of the parents mentioned that the term, "human subjects" was unsettling. The study was explained to both parents, and further questions were solicited by the researcher. The parents had no further questions, consented to participation in the pilot study, and returned the signed forms to the school.

The researcher contacted the parents of one student who did not return his consent form and received verbal consent. When all other forms were returned, the class had their ice cream party. The missing form was replaced and signed and returned to the school within a few days.

Concern for the students' task of learning was held as the highest priority, and procedures for the research were carried out with this in mind. Use of the students' time was kept to an absolute minimum, and the short periods of 
observation and videotaping were conducted in the least obtrusive manner possible.

Since the researcher had taught in the school, her presence and the presence of her assistant (the PTA president), was not a novel occurrence. Many of the students had been videotaped in school and at home, and the videotaping equipment did not seem to be any kind of major distraction in the small group cooperative learning environment of this third grade classroom.

2 The researcher introduced the questionnaire to the class, explained the format, gave the directions and read each item slowly so that all students could make their choices before moving on to the next page and item. However, some of the students began to move ahead of the class. After three or four items were covered, the researcher asked the children to put one finger on the number of each item to make sure the children were all on the same page. After this, the students all appeared to proceed at the same pace with the researcher. The same procedure was followed for the second administration of the MECA.

3 The interview process encompassed time spent with the students before and after as well as during the actual interviews. The researcher had decided that unless she was questioned directly by a student, she would not address the criteria for interview selection since an explanation immediately prior to the interview might elevate communication anxiety and affect interview responses. only one child asked the reason for the interview, and the researcher told her she wanted to know more about why the subject sometimes felt nervous about talking.

Prior to beginning the student interviews, the researcher enlisted the student's help in operating the VCR and adjusting the lighting in the room to draw the initial focus away from the student and allow the child some control over the interview proceedings. Through this accommodation and an initial question about what was happening on the screen, less sensitive material was dealt with first, and trust and rapport could be more easily established (Lofland \& Lofland, 1984). Combined with conversation in the hallway while on the way to the interview room, and further conversation of a general nature just prior to the first interview question, such attempts on the part of the researcher seemed to put the students somewhat more at ease.

4 On one occasion, the form was left on the parents' doorstep. A language problem occurred in another case as 
the parents spoke only Spanish, and the student was not home to interpret when the researcher arrived. The researcher's command of Spanish was too limited for her to attempt an explanation of the study. 
CHAPTER IV

RESULTS

This chapter presents the research findings. Included are results of the tests of the hypothesis, responses to the first research question, and initial data derived from classroom observations and interviews with communication apprehensive children and their teachers.

\section{TEST OF THE HYPOTHESIS}

An exploratory data analysis determined the parametric or classical form of statistical procedures to be used in addressing the study hypothesis which predicted a positive relationship between levels of $C A$ and displayed nonverbal self-adaptors. Significance level (the probability of Type I error) was set at .05 for all tests. Young and Veldman (1965) indicate that this level balances the possibility of Type I and Type II (beta) error. Though power (related to Type II error) was not calculated for tests in the study, it was increased through use of the .05 significance level and efforts to insure reliability and validity of measurement as discussed in Chapter III (Kohout, 1984). As in the pilot study, an estimate of reliability was determined through a correlation between MECA Time 1 and 2 scores $(\underline{x}=0.756$ ) (A 
similar correlation was used by Davis [1981] to establish reliability for a measurement of children's prosocial behaviors of helping, teaching, sharing, and comforting). MECA Time 1 and Time 2 scores and frequency scores for nonverbal self-adaptors were submitted to a Pearson's product-moment correlation to determine a positive relationship between MECA scores and self-adaptors. Twoand three-way analyses of variance procedures (ANOVA) were also used to test the hypothesis and identify possible significant main effects and interaction effects among the measures of $\mathrm{CA}$ (Times 1 and 2), the frequencies of self-adaptor behaviors (Times 1, 2, 3 and 4), class, and sex. I tests then provided comparisons of any two means of groups identified as significant in the ANOVA procedures. The hypothesis tested was not supported in this study. However, comparisons of MECA, self-adaptors, class, and sex resulted in the identification of class as a significant factor. The following sections discuss the statistical measures used to test the hypothesis, determine any relationship among MECA scores, self-adaptors, class, and sex, and note significant changes in group means.

\section{MECA AND SELF-ADAPTOR SCORING} AND ANALYSIS

Out of 21 Class A students who completed the Time 1 MECA questionnaire, 20 scores were obtained for use in the study, including a class mean assigned to one absent 
student's score. All data for one student (including her MECA 1 score) were excluded from the study due to her absence from the second administration of the MECA and two of the four observations of self-adaptors. Twenty-two Time 1 scores were obtained from all participating students in Class $B$.

of the 21 students in class A, 20 MECA Time 2 scores were obtained as the student who was later excluded was absent. Twenty-three MECA Time 2 scores were obtained from Class $B$ including a class mean assigned to one absent student's score. Information for one participant was then excluded from the study as she was a recent arrival from Russia and could not speak or understand English, though she tried to complete the second MECA questionnaire. For class $B$, the total MECA scores less the excluded student's score resulted in 22 scores available for calculation of the class mean (see Table II).

In the present study, those designated as communication apprehensive from Class A included Male students A7 (MECA 2 score--68), A10 (MECA 1 score--67), A12 (MECA 2 score--68), and Female student A19 (MECA 1 and 2 scores- $-68,72$ ). From Class B, Male students B4 (MECA 2 score--93), and B6 (MECA 1 and 2 scores--72, 75), and Female student B19 (MECA 1 score--72) were designated as high CA (see Table III for all MECA scores of high CA students). According to class means, CA appears higher for the MECA 
Time 2 in both class $A$ and B. By contrast, third grade students in Hoffman's 1990 study showed a decrease in CA from Time 1 to Time 2 (from $\underline{M}=47.5 ; \underline{n}=30$ to $\underline{M}=44 ;$ $\underline{n}=30)$. Possible reasons for higher $C A$ scores in Classes $A$ and $B$ and an increase in $C A$ scores are addressed in Chapter V. Five students in Class $A$ and three students in Class $B$ obtained low CA scores (one standard deviation below the class mean).

TABLE II

TIME 1 AND TIME 2 MECA SCORES BY CLASS

Sample

size
Class $M$ 20

20

MECA 2

CLASS B

MECA 1

MECA 2
22

22
49.26

51.8

56.86

57.38

\section{CLASS A}

Standard

Deviation
Range

$\begin{array}{lllll}\text { MECA } 1 & 20 & 49.26 & 11.87 & 23-68 \\ \text { MECA } 2 & 20 & 51.8 & 12.98 & 22-72\end{array}$


TABLE III

MECA SCORES OF HIGH CA STUDENTS

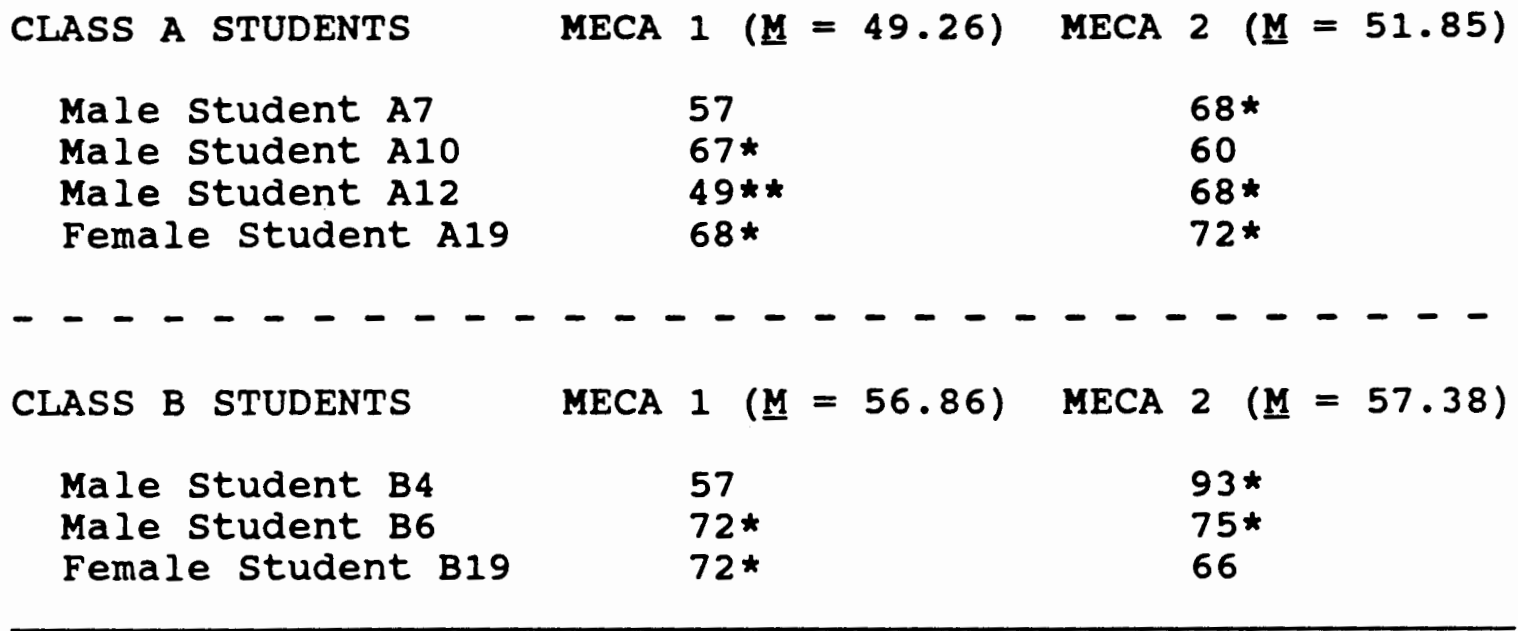

* Scores identifying students as high in communication apprehension.

$\star \star$ Assigned class mean rounded to whole number.

Recording of Self-Adaptor

Scores Through Use of the

Upper Body Self-Adaptor

scoring Form

Individual self-adaptor frequencies were obtained (see Appendix G for study participants' self-adaptor frequency scores). Total frequencies for Class $A$ males and females were calculated across four taped observations of self-adaptors; 861 and 478 respectively. Totals were also calculated for Class B males and females; 491 and 399 respectively.

Initial Data Analysis and

Assignment of Cell Means

The exploratory data analysis included use of dot plots, normal probability plots, and box plots to determine 
the distribution of MECA scores and self-adaptor scores according to class and sex. Distributions were approximately normal in all cases, and therefore parametric statistical tests were determined to be the appropriate procedures for data analysis. Gender group cell means were assigned for the 12 students who missed either an administration of the MECA or any of the four observations of self-adaptors. That is, in each class for boys and girls, the cells identified were the MECA 1 scores, the MECA 2 scores and the self-adaptor scores for the first, second, third and fourth observations, resulting in a total of 24 cells. If a student's score was missing in any of these cells, the mean of the cell was calculated. This appeared to be the most specific and appropriate application of an assigned mean for purposes of the study.

\section{Within-class same-sex}

Comparisons of MECA Scores and Self-Adaptors

The next step in the statistical analysis was the conduct of initial correlations to determine whether an increase in MECA scores would be accompanied by an increase in self-adaptors. Between class comparisons were made of all boys' MECA scores and self-adaptors and all girls' MECA scores and self-adaptors. Correlations were then performed using boys' and girls' scores in each class for within class calculations. These same-sex correlations were performed with the correlation requirement of equal length of entries 
in mind, and moderate correlations of 0.6 and above were noted.

Moderate correlations between MECA Time 1 and 2 were found for males in class $A(x=0.670)$ and males in Class $B$ $(\underline{x}=.628)$. Higher correlations between Time 1 and 2 were established for females in class $A(x=0.928)$ and class $B$ $(0.891)$. However, the only positive correlation supporting the hypothesis which predicted a positive relationship between MECA scores and self-adaptors was found between Class B males' MECA 2 scores and the fourth observation of their self-adaptors $(\underline{r}=0.638)$. This does not constitute enough evidence to support the study hypothesis, and in fact, high to moderate negative correlations were found for females in Class $B$ between the Time 2 MECA and the first observation of self-adaptors $(x=-0.725)$ and Time 2 and the second observation $(\underline{r}=-0.649)$.

\section{Analysis of Variance Tests} (ANOVA)

ANOVA tests to examine differences among the means of two or more groups were then conducted with MECA and self-adaptor scores, class, and sex. A similar test of college students by Comadena and Andersen (1978) included self-adaptors as determined by the authors and scores from a single administration of McCroskey's (1970) Personal Report of Communication Apprehension (PRCA) from which Garrison and Garrison (1979a) derived the MECA instrument. ANOVA 
procedures determined that males consistently displayed more self-adaptor behaviors than females in the comadena and Andersen study. Where significant differences were noted through this study's ANOVA procedures, more specific $t$ tests were then performed.

First, a three-way ANOVA was conducted comparing class and sex with either one of the two MECA scores. Class constituted the only significant main effect $(p=0.026)$ when mean scores $(\underline{M})$ were compared. That is, when gender, and MECA 1 and 2 scores were held constant, the main effect of class was noted, indicating that the only significant difference in the student groups was according to the class the students attended. No interaction effect was noted showing relationships within the groups. See Table IV for results.

Six outlying MECA scores were noted: in Class $A$, Female student A18 (MECA 1 and 2 scores--23, 22) and in Class B, Male student B3 (MECA 1 and 2 scores--27, 28), high CA Male Student B4 (MECA 2 score--93), and Female student B20 (MECA 2 score--29). 
TABLE IV

THREE-WAY ANALYSIS OF VARIANCE

FOR ALL MECA SCORES

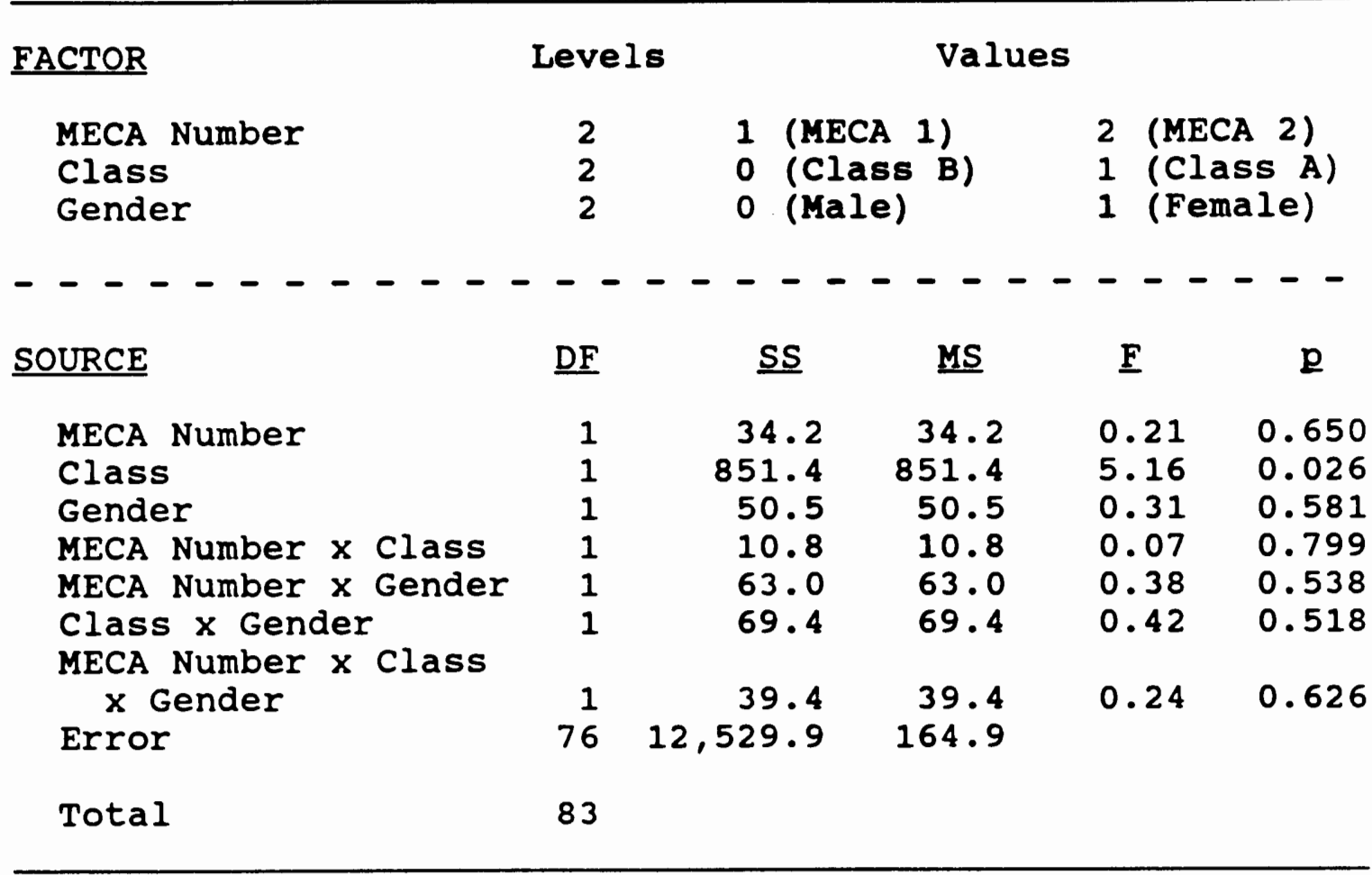

The second three-way ANOVA test compared class and sex with any one of the four observations of self-adaptors. Again, class constituted the only significant main effect $(\underline{p}=0.000)$ when mean scores were compared. However, an interaction effect was also noted between one of the four observations of self-adaptors and one of the two classes $(p=0.044)$. The interaction effect is variation that is not caused by any main effect or error, but rather due to a combination of other sources (see Table V). 
TABLE V

THREE-WAY ANALYSIS OF VARIANCE FOR

ALL SELF-ADAPTOR SCORES

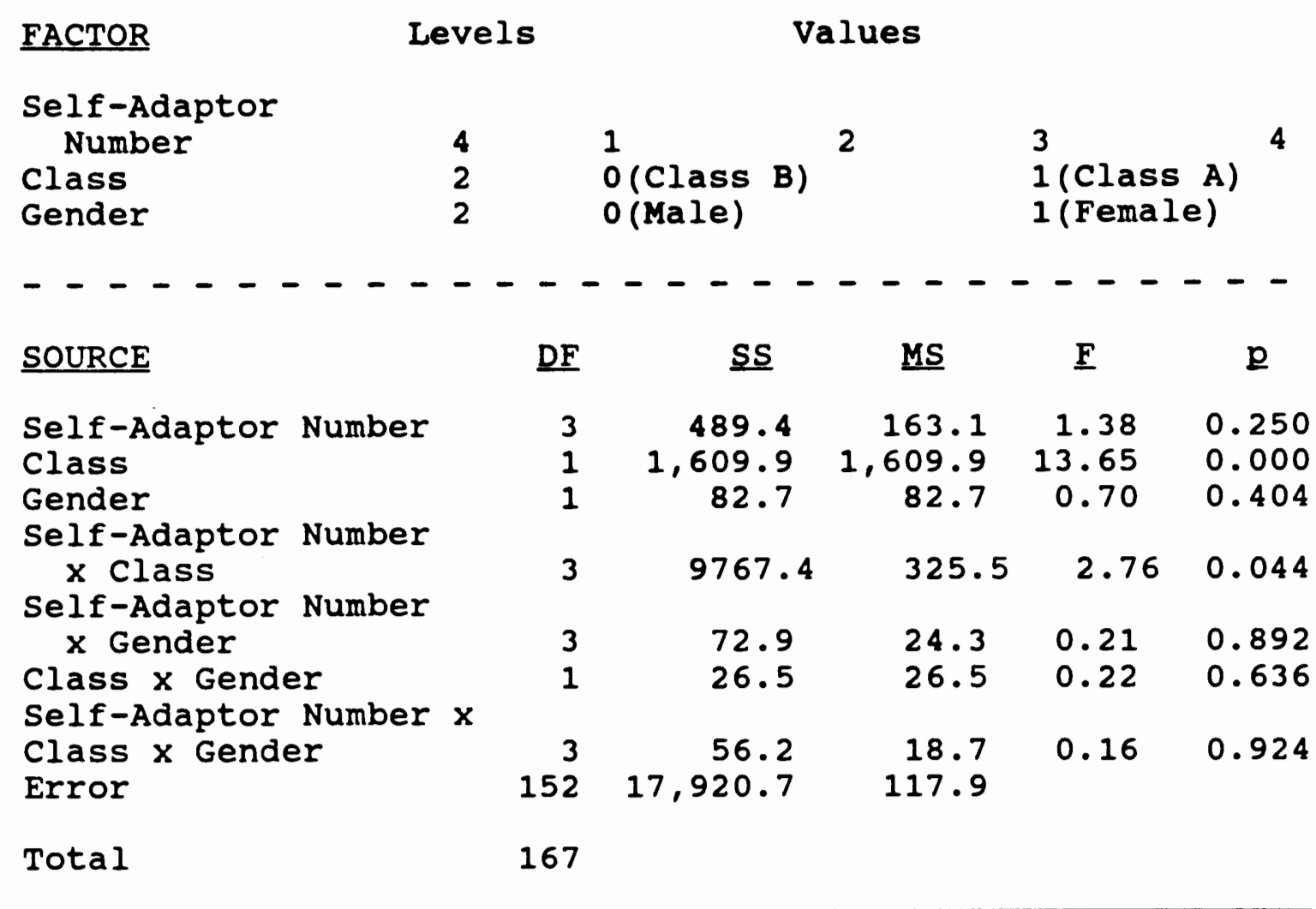

Eight outlying self-adaptor scores were noted: in Class A, Male Students A1 (Time 1 score--2), A3 (Time 4 score--50), A5 (Time 2 score--35, Time 3 score--93), A8 (Time 4 score--38), A11 (Time 1 score--50), and Female student A13 (Time 1 score--42). In class B, Male student B5 (Time 2 score--33) was also designated.

Since the gender source produced no main effect or interaction effect in either of the three-way ANOVA tests, it was set aside in a two-way ANOVA comparing any one of the 
four observations of self-adaptors and either of the two classes with all self-adaptor scores. Results were the same as above in that a significant main effect for class was noted when mean scores were compared $(\underline{\underline{p}}=0.000)$, and an interaction effect existed between one of the four observations of self-adaptors and one of the two classes $(p=0.027)$. That is, the classes appeared to differ significantly as seen by the main effect, and a relationship between a certain observation of self-adaptors and one of the two classes exists as seen by the interaction effect (see Table VI).

\section{TABLE VI}

TWO-WAY ANALYSIS OF VARIANCE FOR

ALL SELF-ADAPTOR SCORES

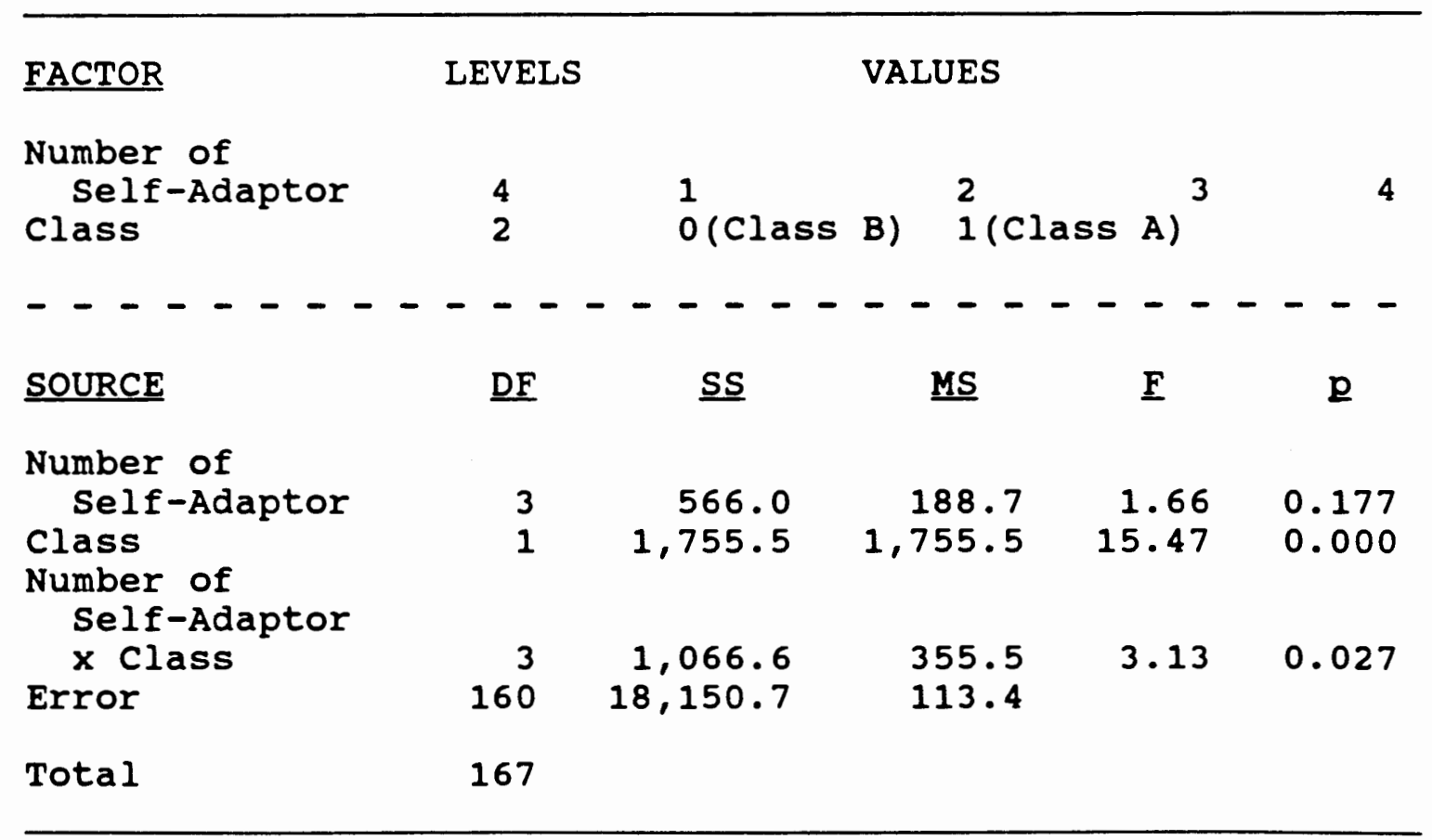


The same outlying self-adaptor scores were again noted for five of the eight previously listed students: in class $A$, Male students A3, A5 (two scores), A8, and A11, and in Class B, Male student B5.

Five more specific $\underline{t}$ tests were then conducted to determine the nature of the significant differences in compared group means. First, all MECA Time 1 and 2 scores were compared regardless of class (no significant difference, $\underline{\underline{p}}=0.580)$. Since class differences appeared to exist regarding $M E C A$ and self-adaptor scores, four more $t$ tests for the following were conducted for both classes: total MECA scores, MECA 1 scores, MECA 2 scores, and total self-adaptor scores. Significant class differences were determined for total (overall) MECA and self-adaptor scores, and MECA Time 1 scores (see Table VII).

TABLE VII

T TESTS COMPARING CLASS A AND B MECA

AND SELF-ADAPTOR MEAN SCORES

MEANS COMPARED

Total (Overall) MECA

Scores

MECA Time 1 scores

MECA Time 2 scores

Total (Overall)

Self-Adaptor Scores
RESULTS

$\underline{\mathbf{P}}$

$\begin{array}{ll}\text { Class B-higher scores } & 0.017 \\ \text { Class B-higher scores } & 0.042 \\ \text { No significant difference } & 0.180 \\ \text { Class A-higher scores } & 0.0003\end{array}$


class differences by gender were explored further in 16 additional t tests. Significant differences in MECA scores were noted for Class $B$ males and in self-adaptor scores for class A males and females (see Table VIII).

\section{TABLE VIII}

I TESTS COMPARING CLASS A AND B MECA AND SELF-ADAPTOR SCORES BY GENDER

\section{MEANS COMPARED}

RESULTS OF

HIGHER SCORES $\quad$

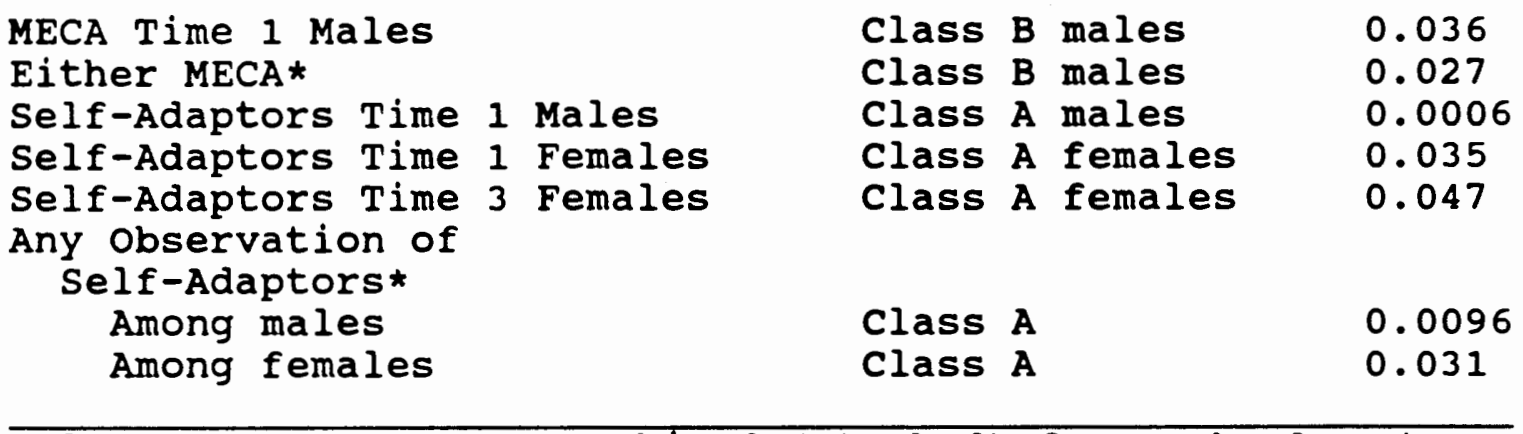

*A11 MECA Scores were combined (stacked) for each class/ gender combination. All Self-Adaptor Scores were also combined in this way.

\section{Final Procedures}

A multiple linear regression was calculated to determine whether a mean self-adaptor score could be predicted from either MECA 1 or MECA 2, class, or sex. Though the factor of class could predict self-adaptors $(\underline{p}=0.005)$, only 23.78 of the error was eliminated by the regression procedure. That is, though class appeared to be the only significant predictor of self-adaptors, the regression model was a poor one. 
Finally, correlations were calculated for all students among (combined/stacked) mean scores for self-adaptors, MECA 1, MECA 2, class, and sex. The only significant positive correlation obtained was between MECA 1 and 2 scores $(\underline{r}=.756)$.

To summarize, initial correlations were found between MECA 1 and 2 scores for both males and females in classes A and $B$. However, the only correlation supporting the hypothesis of a positive relationship between MECA scores and self-adaptor scores was between Class B males' MECA 2 scores and the fourth observation of self-adaptors. Two correlations indicated a negative relationship between MECA scores and self-adaptors.

When comparing class and sex with MECA 1 and 2 scores, the only significant difference noted was that of class. When class and sex were compared with all four observations of self-adaptors, the results were the same except an interaction was noted between one of the four observations of self-adaptors and one of the two classes. This interaction was explored in a comparison of one of the four observations of self-adaptors and one of the two classes with self-adaptors. This removed the gender consideration, and once again, class exhibited significant difference with an interaction effect noted again between one of the four observations of self-adaptors and one of the two classes. This finding offers support for the initial correlation 
showing a relationship between Class B males' MECA 2 scores and the fourth observation of self-adaptors.

Results of five $t$ tests indicated that overall MECA scores were higher in Class B while overall self-adaptor scores were higher in Class $A$, again denying support for the hypothesis. Further $t$ tests determined significant differences in that class B MECA scores for males were higher than others, and Class A self-adaptor scores for males and females were also higher than others. I tests conducted by Hoffman (1990), found no gender differences among third grade students tested separately or when scores were combined with those of the fourth grade students in her study. In a final correlation of all factors (MECA scores, self-adaptor scores, class, and sex) the only positive relationship that was determined was between the two administrations of the MECA. The study hypothesis as well as the quantitative aspect of the first research question were not supported. In addition, Class A and Class B appeared to reflect different populations. That is, the students from both classes appear to have different properties or characteristics. Discussion of these possible differences and the positive relationship between the two administrations of the MECA is addressed in chapter $V$. 


\section{VIDEOTAPED CLASSROOM OBSERVATIONS}

Qualitative data were collected during two pre-MECA administration baseline observations with two more observations taking place before administration of MECA Time 2 to determine whether changes had occurred over time. The data were helpful in addressing the research questions of the study through comparisons with MECA results to provide cross-validation for the instrument and support for the cross-situational and enduring quality of CA (Mccroskey \& Richmond, 1987). It also provided videotaped material on which $C A$ students commented, allowing the later reconstruction of their perspectives of their own communication apprehension.

\section{Four Classroom Observations}

Five-minute taped observations of each small work group were conducted for a total taping time of approximately 20 minutes in each classroom for each observation period (total observation time of approximately two hours and 40 minutes). Class B was taped first for the first three observations, and Class A was taped first for the last observation due to a scheduling conflict. All observations took place during the mid-morning. Students worked in groups of three to five students each, depending on number of absent students. First, tapes were reviewed to calculate individual frequencies of nonverbal self-adaptors 
displayed by all students in both classes for the four observation periods (see Appendix G for individual self-adaptor totals). Then tapes were reviewed for teaching styles, group structures, types of group activities, and participation by communication apprehensive students.

Class A. In Class A, 18 students were present on the first day of videotaped observations, with two male students absent. The cooperative learning activity was called "talking chips," a lesson in which each child used a marker to claim time for opinions on different topics. After each question was asked, the volume level raised and then lowered as the teacher called on student "reporters" from each group. All groups participated, though one girl in a group with three boys spoke very little. Students in that group did not take the indicated speaking turns, and one student threw a pencil which was his marker. Toward the end of the session, the teacher reminded the students in this group to be quiet and reprimanded one other group for swearing.

The second Class A observation took place two days after the first one, and 19 students were present with one male student absent. The students were involved in a geography activity called "numbered heads together," in which numbered students took turns writing the group's response to a question from the teacher on a slate. The name of the cooperative learning strategy used here describes the numbered students working closely together at 
the same table or with their desks pulled together. Almost everyone in the class was involved in the activity during the entire time of the observation. The room was quieter than during the first observation, but when one student (high $C A$ Male student $A-10$ ) was asked by the assistant to move out of the view of another group, he continually leaned into view, sticking out his tongue a number of times.

The following day, the third set of observations took place, after the administration of the MECA Time 1, and 19 students were present with one female student absent. The groups in Class A played a math game which involved guessing a math procedure to apply to sets of numbers on the chalk board. Students then gave other number combinations that reflected the same math rule and were awarded team points for correct responses. The "numbered heads together" structure was used, but though it appeared that all were participating, some students may have not been conferring with others. All were reminded to do so by the teacher who personally directed one student to sit closer to his group.

Two days later, the fourth and final taped observation was conducted in class $A$, with all 20 students present. The students were again using "numbered heads together" for a geography lesson regarding responses to twelve questions from the teacher in the front of the room. All group members were involved in the activity, and no students were observed making faces or leaning into the camera view. 
class B. In Class B, 21 students were present on the first day of videotaped observations, with one male student absent. The students worked in their groups on a math project involving multiplication and division. The teacher and her aide gave assistance to groups as they moved among the students to clarify the directions for the lesson, and all groups participated.

Twenty-one students were present again with one male student absent on the second day of Class B observations. The lesson observed was a combination art and math activity that involved the construction of paper ice cream cones using combinations of flavors. The aide was correcting papers at a desk and did not work with the children.

Though most children were busy with materials, some conflicts occurred among students as they began working. One boy threw paper at the girls in his group. The teacher moved among three groups during the observation, always returning to one group where children were disagreeing. One student in that group was asked to remove himself for a time out.

One day later, the third observation took place, after the administration of the MECA Time 1, and 19 students were present with one male student and two female students absent. The students were shading in progressive multiples to 100 on a chart to observe the emerging patterns of numbers. The classroom was quite warm, and the children 
seemed a bit listless as they slowly began to work with little talking among themselves. The teacher had mistakenly put them in groups of two which would have more than doubled the time of the observation. However, after the researcher requested groups of four or five, the teacher quickly restructured the class and the observation continued. one boy, (not previously mentioned) made remarks to the assistant, and later was quietly addressed by the assistant when he tried to lean into the view of another group. The conversation volume in the room remained low throughout the session, however, all group members appeared to be participating.

Two days after the third observation, the final observation was conducted in Class B, and 21 students were present with one male student absent. The class groups were involved in a math counter activity in which chips were to be divided equally into different numbers of cups. The aide worked in the back of the room, and all groups worked quietly, though one student was overheard suggesting that he was simply trying to help organize the activity in his group and no one was "cooperating" with him.

\section{INTERVIEWS}

The last section of this chapter provides a general description of student interviews and teacher profiles and 
interviews. Also, initial emergent themes are noted with detailed analysis found in chapter $v$.

\section{student Interviews}

overview. Interviews were conducted with four of the $C A$ students from Class $A(\underline{N}=20)$ and three $C A$ students from Class $B(\underline{N}=22)$ who scored one standard deviation above the class mean for either MECA Time 1 or 2 (McCroskey, 1970). Each interview took approximately 10 minutes. Two days after the Time 2 MECA was administered, two CA students from Class $A$ were interviewed, and the following morning one student each from Class $A$ and $B$ was interviewed. The next day, one student from Class $A$ and the final two students from class B were interviewed.

The researcher approached the $C A$ students individually in their classrooms, and asked them if they would like to come to the computer room to watch the videotapes of the classroom sessions and talk about them. While walking to the computer room, the researcher initiated some "small talk" with the students in an attempt to establish rapport prior to the interview. This consisted of acknowledgements about knowing each other or encouraging student opinions of the school and how it was the same or different than former schools attended. only one student (Male student A10) did not participate in this kind of conversation, though he responded to all but one question during the interview. 
Attempts to put the $C A$ students at ease as much as possible may have helped them be comfortable enough to participate in the interviews. All students seemed ready to leave the classroom and take part in the interviews when approached by the researcher, and none of them asked to return to the classroom during the interview or appeared to be so nervous as to indicate that the interview should be terminated. However, most of the CA students displayed some general self-adaptor behaviors during the interviews, though frequency counts of specific adaptors were not tallied during the interview process.

Since the interviews were conducted soon after the MECA questionnaires were administered, all students recalled the MECA. However, though the word "quiz" was not used during the interviews, as occurred once in the pilot study, the term "questionnaire" caused some of the students to look confused. When this happened, I paraphrased or reworded the interview question. This departure from the actual wording of the question is appropriate when using a flexible approach to the interview schedule to insure as much comprehension as possible (Lofland \& Lofland, 1984). Paraphrasing becomes somewhat common practice by teachers who have taught for a number of years at the elementary level. It is practiced continually as a way of adjusting the content of the lesson for the varying abilities of the students. 
Use of the film elicitation technique assisted me in obtaining the students' views of classroom events and accompanying feelings (Anderson, 1987; Denzin, 1989; Terasaki et al., 1984). While viewing the videotape, all students spoke of their anxieties about talking as well as other concerns.

student Interview Descriptions. The following section of the chapter contains the first of two levels of interview analyses. It consists of description of the CA students' and interviewer's communication behaviors in the interview context, comparison with student behaviors observed in the classroom, and responses to film elicitation and other questions as well as observational data including counts of self-adaptors and dominant type of self-adaptor displayed during classroom observations.

Each description opens with CA scores, self-adaptor frequencies and totals, and dominant type of self-adaptor used by the $C A$ student. The second level of analysis which discusses interpretation of meaning of student behaviors, relationships of students and teachers, teaching-learning environment, and patterns of similarity and dissimilarity among the identified CA's in this study is presented in Chapter V. Four categories of fear, preferred seating arrangements in the classroom, and ways of coping during the interviews are included in themes of student responses which are also discussed in the following chapter. 
Male student A7 (MECA 2 Score--68; Baseline

Self-Adaptor Data: Observation One--32 self-adaptors including 10 that were continuous, Observation Two--assigned mean of 11 self-adaptors due to student absence; Total Self-Adaptors--55, including 12 that were continuous; Dominant Type of Self-Adaptor--hand contact with areas of the head and upper body).

student A7 appeared to be quite thin, and because of this, he seemed taller than his peers. However, he actually was similar in height to most other students in his classroom work group. He initially seemed eager to accompany me to the interview room, but became rather quiet in the hallway. This may have been due to my comment that I knew him and his reply that he did not know me. When I persisted in attempting to make this connection through another remark, he looked at me and said nothing more. He assisted me with the VCR and the tape recorder after I asked if he would help, and he viewed the videotape of his classroom work group as he sat next to me.

I thought he would look at the videotape as I asked the interview questions, but during each response he turned and looked directly at me as if he was watching my face. This behaviors was somewhat unsettling for me. His answers were brief, and he seemed somewhat confused by the term "questionnaire" until I reminded him that it had 20 questions and that he had marked "nervous" a number of 
times. He sat still, and did not exhibit any of the dominant self-adaptor touches to the head and upper body that were recorded during the classroom observations. His manner was serious, unlike his behavior during the first observation when he moved quite a bit while smiling, participating with his group, and exhibiting what appeared to be almost uncontrollable laughter on two occasions. Student A7 seemed more involved in the learning task during the third observation, and raised his hand to volunteer information to the class. He appeared calm throughout the observation, displaying only three self-adaptors, as opposed to his self-adaptor behaviors during the first observation in which 32 self-adaptors were counted which included 10 that were continuous. During the last observation, he was laughing and talking with $C A$ student $A 12$, and using the chalk and slate when his turn came to record group responses to the teacher's question. Again, perhaps because he appeared more involved with his recording responsibility, only nine discernable self-adaptors were observed by this researcher.

When asked to relate what was happening on the videotape, he responded that he was thinking about a possible response to a question on the board, and said that he felt good when the activity was going on in his group. When asked about his nervousness in talking with others, he said, "I don't, um, like talking in front of big groups of 
people. . Talking to people I don't know." When asked about his preferred arrangement for classroom seating, he said, "Rows. . . I'd put . . every other row I'd put, um, two boys on the outside and one girl in the middle. And the rows in between that, I'd put a boy in the middle and two girls on the outside. . . So the kids don't talk as much."

Male Student A10 (MECA 1 Score--67; Baseline Self-Adaptor Data: Observation One--32 self-adaptors including 8 continuous ones, Observation Two--3 discrete self-adaptors; Total Self-Adaptors--70, including 25 that were continuous; Dominant Type of Self-Adaptor--hand-on-hand contact).

Though I greeted student A1O in the classroom by name and he responded immediately by getting up out of his chair, he did not speak with me on the way to the interview. I felt that he simply did not want to speak and was concerned that he would not do so during the interview. I did not attempt to engage him further in conversation prior to the interview.

He sat next to me as did the other $C A$ students while we watched the VCR. I believed this seating arrangement would be non-threatening, but both the student and I had to turn our heads slightly to face each other directly. student AlO kept his gaze averted and his arms folded through most of the interview. The folded arms were also 
evident during the first part of the second classroom observation and the third classroom observation of his group. In the framework of an interview with a CA child, the resulting appearance looked guarded, but it had more of a "strong man" look in the videotape of the classroom observation, possibly because he wore a black tank top and had the stocky build of an older child though five other students in his class are older than student AlO.

He sat quietly during the interview, and did not exhibit the dominant self-adaptor of hand-on-hand contact that was noted during classroom observations. His behavior was different during the last part of the third observation. When the assistant asked him to move out of the view of another group, he repeatedly leaned into the view of the camera, stuck out his tongue a number of times and then smiled.

A possible manifestation of fear or anxiety was seen in the third class observation. ${ }^{1}$ Student Alo began chewing his fingers as his teacher approached to firmly reprimand a student seated in front of him (Male student A2). As the teacher continued to discipline the student, student Alo kept one arm folded across his chest as he chewed the nails on the same hand, and his knees are seen moving rhythmically. The latter movement of the knees was not counted in the self-adaptor category because it was a movement below the waist, but it appeared to function on 
this occasion as one of a cluster of nonverbal self-adaptors. His preferred way of talking with other group members during this observation was to whisper behind his hand.

In addition to the high baseline count (first observation) of 36 self-adaptors with 8 that were continuous, observational data for this third class session included the highest number of displayed self-adaptors for this student--26 self-adaptors, with 15 that were continuous--indicating a more serious condition of the nervous behavior according to Barraso, Freedman, and Grand $(1980)$. His lowest count was recorded during the second observation during which only three self-adaptors were displayed.

He initially asked about the VCR, and I said he could operate it. Though he did not respond to my invitation, he watched the videotape on the screen. His brief responses to the questions were delivered in a monotone voice. He frequently cleared his throat, and the one time he laughed, the sound was brief and appeared forced. In spite of this, when I asked him to tell me what was occurring on the screen, he was able to relate specifically what was happening. When asked how he felt during the classroom observation, he responded that he felt fine. In response to the question about nervousness, he said, "Well, (clears throat) with most kids I get nervous and stuff. And most 
teachers." When asked how he would construct a classroom seating arrangement, he replied, "Put 'em in groups. . . Because kids seem to get along better when they're put in groups."

Three times during the interview he became silent, once in the middle of a sentence and twice in response to a direct question after making a slight sound ("Hmm. Mmm."). I was surprised that he did not respond to all the questions, thereby breaking the interchange pairs of conversation (Littlejohn, 1989). This behavior appeared consistent with the presence of $C A$ and the attendant reluctance to speak with others. Other $C A$ students in the pilot study also responded at times with silence.

This student appeared to be apprehensive about communication and might possibly have been anxious about other issues as well. His noncommittal choices on the second MECA, his folded arms and minimal verbal response may have served as a source of protection for him. He did not speak on the way back to the classroom, and I chose to respect his silence.

As stated by Sattler (1988), rapport results from mutual acceptance. However, with $A-10, I$ do not believe rapport between interviewer and interviewee was really achieved, though $I$ attempted to maintain a natural relaxed manner, spoke slowly in a calm way, and felt that I showed a friendly and accepting attitude. Perhaps in this case, 
rapport was not an appropriate goal for the interview with student $A 10$, and in fact, his seeming reluctance to respond may be what Rich (1968) terms a "perfectly friendly silence" (p. 72)

\section{Male student A12 (MECA 2 Score--68; Baseline}

Self-Adaptor Data: Observation One--because of absence, assigned mean of 24 self-adaptors given which reflected the high score of Male student $A 11$ [50] who scored as Iow $C A$ on the MECA Time 1, Observation Two--14 self-adaptors including eight continuous ones; Total self-Adaptors--59, including 19 which were continuous; Dominant Types of Self-Adaptor-touches to the mouth and biting of the thumb, finger, and lip)

Student A12 was quite small in stature, thin, and rather frail in appearance. I was hesitant in my manner with him as we walked to the interview room, since I knew he was from the special education program, asking only one question to which he replied in a rather soft voice. I chose not to continue talking with him.

I forgot to ask him if he wanted to operate the VCR or the tape recorder, and he did not mention the equipment though I showed him how it worked as we began. Because he was from the special education program, I felt a bit apprehensive at the beginning of the interview as he quietly viewed the videotape of his classroom group. He did not respond to my initial questions, though he seemed to be 
comfortable in the interview setting in that he did not display any easily noticeable self-adaptors or any of the biting or mouth touches that were predominant during the classroom observations. During the second classroom observation, he participated in using the slate and chalk when it was his turn to be the group recorder, but during the third observation, he appeared distracted from the group activity and was lying across a desk with his fingers in his mouth. During the last observation, in which he displayed 11 self-adaptors including 5 that were continuous, he also smiled, threw a piece of chalk and hid his face behind the slate. I could not determine the reason for such changes in appearance and behavior, and did not address this issue with him as he viewed only the third classroom observation, in which he displayed the least number of self-adaptors--10 with 6 that were continuous.

When Student A12 was asked what was happening on the screen, he replied that the class was guessing a number and a math operation. When asked if he liked the activity, he replied that he did, and that he "sort of" liked being in his group. Though he could not seem to recall the MECA, after I mentioned that he had marked "nervous" on the questionnaire, he responded, "I'm nervous when I talk in front of people.. . that I don't know." He did not seem to understand the question about choice of classroom seating. In fact, he did not appear to understand what I 
meant by "rows" or "groups," and responded "I don't know." When he finally chose the row configuration (with my urging), it seemed that he made his choice so that I would move on to something else. He then said he did not know why he favored that arrangement. I did not realize during the interview that he whispered all responses to the interview questions, and that I then began to whisper also. We did not speak to each other while walking back to the classroom.

I felt that I did not re-phrase the interview questions in an appropriate way for student A12, although he gave one clear response regarding his anxiety about talking with others. I was concerned that my lack of understanding about his disability and resulting apprehension about this may have interfered with the interview. Student A12 was the only student in the entire study who was identified as communication apprehensive by the classroom teacher. He was identified at the end of the teacher interview, and his teacher noted that student A12 was in his classroom for only about an hour to an hour and a half each day. since this might not have been enough time for the student to feel comfortable in his classroom work group, his comment about talking in front of people he did not know would be understandable. Although it was not clear if he had actually spoken "in front of" the class, the form of cooperative learning observed in class A sometimes required 
class attention for a student's response, and this might also explain student A12's observation.

Female student A19 (MECA 1 and 2 Scores--68, 72 ;

Baseline Self-Adaptor Data: Observation One--22

self-adaptors including 8 continuous ones, Observation Two--23 self-adaptors including 12 continuous ones; Total Self-Adaptors--65, including 29 that were continuous; Dominant Type of Self-Adaptor--lip biting). During initial conversation on the way to the interview room, student A19's manner seemed comfortable and friendly. However, none of her responses to my "small talk" indicated that she knew me. She had a stocky build, and appeared to "bounce" a little when she walked, and entered the interview room quickly. I started the interview without enlisting her help with the VCR and/or the tape recorder as she seemed ready to begin.

Since she did not appear to know me from previous contacts at the school, I might have enlisted her help with the VCR or the tape recorder to "break the ice" as I did with two of the other CA students. Instead, I interpreted her initially outgoing appearance as a sign that she was relaxed and ready to proceed. Her speech began to speed up as the interview started, and her words ran together with repetitions and the use of connectors like "you know," "like," and "um," with 48 of these connectors identified in 
the transcripts. This could have helped her get through the talking episode without stopping.

Her speech continued to speed up as the interview proceeded, and she indicated in one of her responses that feeling excited was fun for her, and she felt this way during the guessing game activity she identified in the videotape. She also said that during the activity she was concerned that she might make a mistake. Sometime during the interview she stood up and began to move back and forth, but she sat down quickly when asked by the researcher.

Although student $A 19$ remained seated with her hands down for most of the interview, during the second classroom observation, she moved her hair repetitiously to her mouth and may have been biting her hair, and during the fourth observation, in which she displayed the least number of self-adaptors--nine including one that was continuous, she also stood up and kicked in a bucking motion. These behaviors occurred while she appeared to be paying attention to the teacher and interacting with other group members, but they were not in evidence during the third observation, or during the first observation in which she displayed the highest number of self-adaptors--22 including 8 that were continuous.

on one occasion late in the interview, she spoke for about 20 to 30 seconds without stopping, and began rubbing her hands together. Her voice sounded breathless, and in 
fact it seemed that she did not take a breath during this long stretch of speech in response to the question about the causes of her nervousness. Though the dominant self-adaptor behavior observed during classroom observations was lip-biting, (occurring in all four observations for a total of 12 times, 7 of them lasting more than three seconds), this behavior did not occur during the interview.

Feelings about about being nervous and being with unknown teachers were reflected in her response to the nervousness question:

on, on you know sometimes it makes me nervous like, like you know, I'm talking to a teacher I, like, like (uninteligible word or phrase), and sometimes it makes me nervous 'cause you know I might, might say no (unintelligible) extra credit, and you know I, I, I get nervous you know, when um, you know, in separate groups, not separate groups, but you know, one-person group, and you know, I get very nervous because I'm not used . . Well, um, well sometimes I feel, um, like afraid (U). You know, some teachers I don't really know and (U) you know, sort of nervous around them, and then when I get up, when I get up, you know (unintelligible) or something, I get realiy nervous.

Given student A19's behaviors in the classroom and during the interview, it was difficult for me to understand how her teacher could not recall her as a nervous child.

When student A19 was asked her choice of classroom seating arrangement, she replied:

I think they'd probably be in groups. . . Well because, un you know people work out better in groups you know, so people like, mostly some people can't um, you know, lean back in their chairs, you know, that much if they're in groups, and when you're in groups, um, you know like, like if you're (unintelligible word or phrase) a separate group. 
Like if you're in rows then, um, people would, then people would probably be fighting and leaning back in their chairs and, and um so, that's why. . . . I like small groups because, um, it's a lot easier to cooperate, and you don't have to shout out everything so you're not, you're not very far away.

Male student B4 (MECA 2 Score--93; Baseline

Self-Adaptor Data: Observation One--0 self-adaptors, Observation Two--10 self-adaptors including 1 that was continuous; Total Self-Adaptors--52, including 13 that were continuous; Dominant Type of Self-Adaptor--touches to the head) .

Only five other students scored lower than student B4 on the first MECA, but his second MECA score was higher than any other student's first or second score in the main study classes or the pilot study class- -93 points out of a possible score of 100 . He displayed no self-adaptors during the first observation, but when two students made motions to cut at the hair of another student who had a short "buzz" cut, he made motions to cut his own hair and then made a face at the camera after another student had done so. His highest number of self-adaptors occurred during the fourth classroom observation when 29 self-adaptors were displayed, including 12 that were continuous. At the end of that observation, he also stuck out his tongue very quickly four times while making faces at the camera, then stared at other students in the group, rubbed his eyes and held his head as if tired. 
Before the interview, he quickly initiated conversation with me in the hall. His heavy build and tall stature made him appear older than some of his peers. Since the computer room was in use, the interview was held next door in a corner of the library. The setting was satisfactory except for the crying of a child who was with his/her parents in the library. I did not enlist student B4's help with the VCR or the tape recorder since he appeared to be eager to converse with me.

When asked what was happening on the videotape, Student $B 4$ related that the students were working on a math counting activity. He said that he was feeling "sort of down" during that time because some students were calling him names. When I asked him to tell me about marking the nervous category on the questionnaire, he replied, "Well, I am pretty afraid and nervous, every, everything I do." when asked to clarify his remark, he continued:

Well, I don't know. I'm in a bigger city, and in Montana there weren't any problems. Now I've been looking on the news, and there's been problems--gangs, coming down to schools. I've been afraid of all that.

In response to a question about anything else that made him nervous about talking with others, he said, "Well, kids make me, uh, call me names like, 'You talk funny,' and all that." After the first four minutes of the interview had passed, another student arrived to tell student B4 to return to the classroom to receive instructions for the field day 
activities. Before he left, I asked him to quickly tell me his preference for a classroom seating arrangement, and he said, "Uh, rows," but did not have a reason for his answer other than he liked it that way. Then he left the library rather quickly. It was unfortunate that the interview was interrupted, and he spent the rest of the day outside with his class so I could not conclude the interview.

From one perspective, student B4's interview responses indicated that he was anxious about talking with others as indicated by his MECA Time 2 score. Additionally, he may have used certain behaviors (making faces at the camera while sticking out his tongue, pretending to cut his hair, appearing tired or disengaged from the group activity) to "cover" this anxiety. The dominant type of self-adaptor observed during the classroom observations, touches to the head, was not noted during the brief interview.

Note: Prior to the interview, I asked his teacher if something had occurred that would have made him so anxious as to mark the MECA in the way that he did. She related that by student B4's talkative nature, his willingness to present his baby sister for "show-and-tell" and his performance in the talent show, she would not have thought he was apprehensive. In fact, she disputed 19 of the student's 20 responses on the questionnaire. She talked about his difficulties in socializing with others, and suggested that his responses were actually examples of 
oppositional behavior and did not reflect how he really felt. She indicated that he would be receiving special services soon. The effect of this contact with student B4's teacher is addressed in the thesis limitations section of Chapter V.

Male student B6 (MECA 1 and 2 Scores--72, 75; Baseline Self-Adaptor Data: Observation One--10 self-adaptors including 1 that was continuous, Observation Two--5 self-adaptors including 1 that was continuous; Total Self-Adaptors--52, including 17 that were continuous; Dominant Type of self-Adaptor-hand-on-hand contact) .

The subject appeared to enjoy visiting with me on the way to the interview in that he readily entered into a casual conversation, so I did not enlist his help with the VCR or the tape recorder. I thought that perhaps he had known me from previous years at the school. However, during the interview, student $B 6$ said that he was nervous (as he had indicated on the MECA) because he was a new student, although he had arrived in the fall of the school year.

He was slightly built and rather pale, and he spoke quickly and somewhat loudly. He also tried to introduce an unrelated topic of conversation about the warts on his fingers, and responded in somewhat contradictory ways to the questions presented. When asked to comment on how he was feeling during the math activity he identified on the 
videotape he responded, "Mm good" only to follow immediately with "I don't really like math, uh uh."

I said ". . You marked 'nervous' a bunch of times," tried to amend the use of the idiom "bunch," and in my own anxiety I used a double question which may have been confusing to him. He agreed with my statement about how he had marked the questionnaire and added, "Cause this is my first year here." When I asked him if he could tell me more, he said, "Well up on stage I'm afraid to talk in the microphone 'cause I, I'll be afraid I'll messed up, I'Il mess up on something." When asked about other times he was nervous about talking, he responded:

on roller coaster rides. That's why I always talk to my friend on roller coaster rides. (Unintelligible) anybody else. (laughs) We went on this one.. . it was just, just a small roller coaster ride. . . just went in circles, and I almost threw up on that. . . My, my brother would take me on real, on a big roller coaster ride, and he would have me sit in the back, and I would throw up.

The subject's remarks, were all delivered in a confident tone with constant eye contact with me as if watching for a reaction.

However, when I asked for a fourth instance of being nervous about talking, he mentioned in a tentative way that this happens when he feels bad. When I repeated his response as a question, he dropped his eyes and his shoulders, looked down at the floor and nodded in agreement. I quickly went on to the question about arranging the desks 
in the classroom. He responded that he preferred a group arrangement "Because it's more better. Because the groups would help each other." He was less talkative at the end of the interview and spoke very little on the way back to the classroom.

Though he only displayed five self-adaptors during the second observation including one that was continuous, 19 were recorded during the third observation including nine that were continuous. His dominant type of self-adaptor, hand-on-hand contact, was not noted during the interview, though his general demeanor and possible avoidance of my question about nervousness appeared congruent with the high number of self-adaptors displayed during the second observation. Videotapes of classroom behavior showed him interacting with group members and participating in the activities.

Female student B19 (MECA Score 1--72; Baseline Self-Adaptor Data: Observation One--15 self-adaptors including 2 that were continuous, Observation Two--2 discrete self-adaptors; Total Self-Adaptors--36, including 4 that were continuous; Dominant Type of Self-Adaptor-grooming).

The student was quiet on the way to the interview room, and I forgot to ask her help in operating the VCR and tape recorder, although I explained how it worked. She responded readily to most of the interview questions, but 
when she hesitated on the first one that had to do with interpreting what was occurring on the screen, I attempted to put her at ease by noting that it could be hard to remember what was happening in the videotape since it was filmed a few days before the interview. She agreed that it had been a few days, and then recalled the classroom math activity with the help of a prompt from me. When asked how she was feeling at the time of the videotaping, she replied that she did not know.

Each of the four frequency counts of the student's self-adaptors included occasions of grooming, which is a more obvious self-adaptor than hand contact or other vague self-adaptor occurrences. However, none of this activity occurred during the interview.

When she was asked about being nervous she replied, "In being in a large group, yeah, 'cause it's (unintelligible) I get a wrong answer." When asked how that felt she said, "Very nervous." I then asked her about other times that might make her feel nervous about talking, and she said, "In the whole class." When I asked for clarification, her response was, "Um. Talking in front of the class, I think." This was an example of her consistent agreement with what I said and possible attempts to guess what I wanted her to say. This compliant attitude could also be viewed as somewhat submissive behavior in light of the fourth observation which shows minimal interaction with 
the three boys in her group, and lack of a self-protective response to Female student $\mathrm{B} 21$ who repeatedly hit her on the head with a pencil during the videotaping during the second observation. Other girls in the group received the same treatment, and all events occurred in view of the camera. However, student B19 only showed what seemed to be an embarrassed smile as a response to this rather aggressive act, even though she appears to be saying "Ow!" Though 15 self-adaptors were recorded during the first observation including two that were continuous, she displayed only two self-adaptors during the second observation. Her slight build, lack of interaction with group members, and hair which hung into her face seemed to constitute a rather untidy and vulnerable appearance.

When asked about her classroom seating preference she replied:

I'd put 'em in groups. . . That would be better for people to work together. . . So they could, uh, when they grow up, they're not afraid to talk with the person they work with or the boss or something.

Though her responses were clear and helpful, I felt like I did not gain additional insight as to her communication apprehension as a result of the interview. She appeared to be a rather quiet but friendly and pleasant girl who was not overly afraid to converse with me. Some patterns of student interview behavior were noted. These behaviors were similar in that all the 
students appeared somewhat nervous during the interview process, and while all discussed situations that made them anxious, none of them displayed the self-adaptor that was most dominant during the classroom observations. Other behavior patterns were less universal. All students responded to each question except Male student $A 10$, and with the exception of Male Student $A-7$ all used a clear, strong voice. All CA students except Female student A19 sat during the interview, and only two students did not engage in conversation with me on the way to and/or from the interview room.

Teacher Profiles and

Interviews

on the afternoon in which all student interviews were completed, the teacher interviews were conducted after all third grade students had left the building. The interviews were held in the teachers' classrooms. The teachers indicated which of their students they thought might be anxious about talking with others and how they perceived this apprehension. They also discussed the academic and social skills of these students.

The teacher of class A has taught fifth grade for many years and third grade for the past three years. He has taken classes in cooperative learning techniques, and his observed teaching style was mainly the lecture/question type, though he uses cooperative learning activities and 
indicated that he enjoys them. He uses a strong voice in the classroom, and during most of the observations, he remained in front of the room near the chalk board. His directions to the students and the vocabulary he used with them seemed to reflect his experience at the fifth grade level, as he spoke to the students in what teachers would call "adult language." Over a number of years, he has stated to the researcher that he prefers to set firm discipline guidelines, indicating that such a learning environment is best for all the students and that they do well with such structure. He was able to identify one CA student from his classroom.

The teacher of Class B was teaching third grade for the first time at the school, and has taught first grade for ten years. She has not received special training in cooperative learning methods but used similar techniques suggested in the math text for the lesson observations.

Her teaching style appeared more casual and personal than that of Teacher $A$, and her voice was lower in volume. During the observations she moved from group to group in the way that the pilot study teacher had done. Once she stopped to get down on the carpet with a student. She sang directions to the class on one occasion, and later asked them to use their "one-inch" voices while working in their groups. She related to me that she had always used this kind of language with her younger students. 
Teacher B allowed group talk for almost all of the session. By contrast, on each day of observation in class A, much of the time was spent in listening to individual responses to the questions directed to the class. This allowed less time for group conversation.

Teacher interview text revealed four emergent themes which constituted a category of perception and description of CA children. Detailed interpretation of these themes and teacher discussion of the causes of $C A$, and its consequences for learning and socialization are addressed in the following chapter.

\section{SUMMARY}

Comparisons of MECA scores and nonverbal self-adaptor data did not support the hypothesis which predicted a positive correlation between MECA scores and self-adaptor behaviors. Rather, in two cases, a negative correlation was found for MECA scores and self-adaptors. MECA Time 1 and 2 were positively correlated, and overall MECA scores were found to be higher in Class B, while overall self-adaptor scores were higher in class A, and higher for all males and all females in the study. No gender effect was found, though five CA students were boys and only two were girls. It was determined that significant differences may exist between Class $A$ and $B$. Possible reasons for class 
differences as well as other statistical findings are addressed in Chapter $\mathrm{V}$.

General descriptions of classroom setting and patterns of interview process with CA students were discussed in this chapter, and emergent themes of perception of CA by both students and teachers were noted. Teacher profiles including teaching style differences were discussed. Detailed analysis and discussion of emergent themes found in interview texts, the relationship between the qualitative and quantitative study data, and implications for evaluation and instruction of $C A$ students follow in Chapter $V$. 


\section{ENDNOTE}

1 Although the terms "fear" and "anxiety" are used interchangeably in the speech communication literature to refer to communication apprehension, it is understood that these words are not used in the same way within other fields such as the field of psychology. 


\section{CHAPTER V}

\section{DISCUSSION AND CONCLUSIONS}

This chapter discusses the findings of the data analyses including responses to the four research questions, study limitations and strengths, and recommendations for future research. The purpose of this exploratory study was to identify primary school children who tested as communication apprehensive and determine a possible relationship between communication apprehension (CA) and a set of nonverbal kinesic behaviors known as self-adaptors. Based on the literature concerning $C A$ in children and nonverbal indicators of anxiety, a hypothesis was constructed predicting a positive correlation of scores on the Measure of Elementary Communication Apprehension or MECA (Garrison \& Garrison, 1979a) among a sample of 42 third grade children from a Northwest suburban school with the frequency of displayed self-adaptor behaviors as recorded on the Upper Body Self-Adaptor Scoring Form (UBSSF).

The hypothesis stated that a positive relationship exists between levels of communication apprehension and frequency of displayed self-adaptor behaviors. However, the hypothesis was not supported. The following section discusses possible reasons for nonsupport of the hypothesis, 
as well as analysis of qualitative data to obtain participants' perspectives and understandings, and test for cross-situational consistency for $C A$ and self-adaptors. Also included is the analysis of student and teacher interview data which provides responses to the research questions through direct answers to interview questions as well as emergent themes and categories of meaning developed through the interpretation of interview texts.

\section{DISCUSSION}

This study employed the use of quantitative measures (the MECA and UBSSF instruments) to determine the possible correlation between MECA scores and self-adaptors in addressing the study hypothesis. In addition, observations, field notes, and interviews, added to the information gathered concerning the communication apprehensive students. Teaching specialists who worked in the building helped me make research decisions and interpret academic and demographic data more fully. These sources, additional considerations of statistical data, and extant literature in the field of education provided information to suggest rival interpretations and explanations for CA students' behaviors which have been discussed in chapter IV. The use of both quantitative and qualitative methods aided in the identification of $C A$ and certain nonverbal behaviors thought to be associated with the anxiety, and provided multiple 
perspectives that informed emergent themes from participants' (teachers and CA students) data.

\section{Quantitative Data}

The study hypothesis predicting a positive correlation of MECA scores with self-adaptor behaviors was not established in initial within class same-sex comparisons of MECA scores and self-adaptors (significance set at .05). It was theorized that since self-adaptors may indicate the presence of anxiety, and communication apprehension is thought to be an internal cognitive anxiety about talking with others, self-adaptors could signal the presence of CA in young students. However, out of 32 initial correlations, 19 that were less than $(\underline{r}=0.6)$ were negative. Only one moderate correlation was positive (between the males' MECA Time 2 scores and the Time 4 observation of self-adaptors), and, in fact, high and moderate negative correlations were found for females in Class B between the Time $2 \mathrm{MECA}$ and the Time 1 and Time 2 observations of self-adaptors. These results indicate that, at the level of statistical significance, internally experienced anxiety as revealed in the self-report measure of CA (MECA) was not related to displayed self-adaptor behaviors (recorded on the UBSSF) among young children in this study. Although self-adaptors may give clues to an individual's feelings (Harrison, 1974), and $C A$ interview data do suggest a relationship between communication apprehension and self-adaptors, from the 
quantitative perspective, the behaviors cannot be said to be indicative of the presence of CA (McCroskey, 1976).

Several alternative explanations exist for these findings. First, the Upper Body Self-Adaptor Scoring Form (UBSSF) which was used to record self-adaptors may be limited in several ways. Outlying data could not be discarded due to the small study sample of 42 available students; only upper body self-adaptors were recorded, limiting frequency counts; and only 10 self-adaptor categories were included on the scoring Form. In addition, the inexperience of the researcher and lack of refinement in the Directions for Use of the UBSSF (see Appendix C) may have allowed some self-adaptors to go unnoticed while others were counted more than once as the same self-adaptor moved in and out of camera view.

second, "all" students in both classes exhibited self-adaptor behaviors. Communication apprehensive students' self-adaptor totals ranged from 36 (Female student B19) to 70 (Male student A10). By contrast, a low CA student (scoring one standard deviation below the class mean on the MECA 2) displayed the highest total of 200 self-adaptors (Male student A5). It may be that nervous or self-adaptor behaviors occur for other reasons. Possible reasons for occurrence of self-adaptors are discussed in the chapter section addressing other possible influences upon MECA and self-adaptor scores. 
Third, the presence of the researcher and the assistant may have limited the display of nonverbal behaviors due to students' self-conscious feelings or their desire to "play to the camera" as Male students A10 and B4 seemed to do (see chapter IV). However, as discussed, low $\mathrm{CA}^{\prime}$ 's did not appear to be limited in their display of self-adaptor behaviors.

Finally, although the presence of $C A$ had been previously and reliably established through use of the MECA, changes in the instrument based on pilot study student questions and observations were not made before the conduct of the main study. Therefore, confusion over wording of MECA items noted by the pilot study students may have also been present during later administrations of the MECA. Also, for the 10 identified non-Caucasian students (see Appendix $\mathrm{H}$ ), the language of the MECA questionnaire as well as the communication situations it suggests may not be appropriate. This is further addressed in the limitations section of this chapter. These factors may have affected self-adaptor counts and MECA scores, and therefore the results of the initial statistical tests. Other issues related to development and use of measurement instruments may have influenced test results. Further treatment of these issues are discussed in the study limitations and suggestions for future research in this chapter. 
Two- and three-way ANOVA procedures failed to produce any significant main effect except for that of class, but interaction effects existed for one observation of self-adaptors with one of the two classes. Cross-sex comparisons through $\underline{t}$ tests indicated overall MECA scores were higher in Class $B$ while overall displays of self-adaptors were higher in Class $A$. Further $t$ tests showed higher MECA scores for males in Class B, a difference not noted in Hoffman's 1990 study which indicated no gender difference in MECA scores. Also, higher frequency of self-adaptor behaviors occurred among both males and females in Class $A$.

The positive correlation between the two sets of MECA scores was expected since the MECA instrument has been established as reliable and only seven days separated the two administrations. Minimal differences also occurred among results of displayed self-adaptors. The only significant factor which may be related to lack of support for the hypothesis appeared to be the class in which students were placed. Since Class A and B may reflect different populations, random distribution of communication apprehension and self-adaptor behaviors may not have occurred.

Therefore, for purposes of discussion of study results, the unit of analysis must shift from consideration of the seven CA students from both classes to those from 
Class $A$ and those from Class $B$. The following section includes a discussion of differences in the classes which may have influenced test results.

\section{Qualitative Data}

Using method triangulation (Albrecht \& Ropp, 1982; Denzin, 1989; Sevigny, 1981), qualitative as well as quantitative data were gathered and analyzed for evidence of cross-situational consistency of $\mathrm{CA}$. Responses to the research questions are found within the qualitative data analysis.

\section{CA student Interviews}

The use of personal data acquired during the interview process provided responses to the first, second, and fourth research questions regarding display of self-adaptors, confirmation of MECA results, and self-awareness of apprehension and participation in small group structures. This data also allowed a more holistic view of the CA child. student interviews functioned as a vehicle in attempting to ascertain CA students' perceptions of specific segments of videotaped content and their feelings at the time of the original taping through use of the film elicitation technique (Denzin, 1989; Terasaki et al., 1984). By viewing the cooperative learning groups at work, they could also reflect on their feelings about such a learning structure. 
The interviews also served research ends in another way. As the $C A$ student described the videotape and addressed feelings about communication situations and other issues, I was able to observe and record general verbal and nonverbal behaviors employed by the student. This provided additional behavioral data during the actual interview itself on use of possible self-adaptors and other verbal and nonverbal behaviors which may be associated with $C A$, helped to address the issue of cross-situational consistency of $\mathrm{CA}$, as well as suggesting other interpretations for children's behavior. This data was then compared with other self-report data (MECA scores) and observational data gathered by the researcher.

\section{Thematic Interpretation of $C A$ student Interview} Behaviors and Text Data. In the following section three major themes address research questions 1,2 , and 4 . The first theme to emerge from analysis of interview field notes identifies those behaviors of identified $C A$ students that may be considered coping mechanisms or ways of adjusting and adapting to the interview process. Ekman and Friesen (1969) and Leathers (1978) discuss the use of self-adaptor behaviors as a way the individual manages emotions and adapts to certain conditions or environments. Though the behaviors noted were not the specific self-adaptors counted on the Upper Body Scoring Form, those which occurred during the student interviews that may be interpreted as possibly 
being adaptive include: silence, laughter, clearing of the throat, rapid speech, constant eye contact, introduction of unusual topics, and claims of ignorance to divert attention. I interpreted student A7's high MECA score as descriptive of an anxious student who might use nervous "chatter" and giggling as a means of hiding his anxiety (Mccroskey, 1984). By speaking very little with me but appearing to interact freely with his peers during the observations, student A7 may have demonstrated his stated fear about talking with those he does not know well. M-A10 used what appeared to be forced laughter on one occasion, then grew silent in response to three questions. He also cleared his throat eight times while being interviewed, but not before or after the interview. While his folded arms posture also occurred during two of the classroom observations, he did not bite his nails during the interview as observed during the third observation.

Additional interview behaviors that were noted refer to general impressions of the students' demeanor and comprise the "latent content" or overall view of the students' behaviors (Babbie, 1992). F-Al9 is a child whose manner and speech exemplified this kind of general impression. As noted in chapter IV, she used rapid speech, unusual speech patterns, and hardly paused for a breath. This seemed to serve as an adaptive response to help her get through or "last" through the interview. An alternate 
explanation may be that her way of speaking may be an affectation used by some teenagers called "valley girl talk" (Crawford, Lane, \& Coolidge, 1982). A third possibility was that her manner of speaking could have been a symptom of nervousness.

Sattler's (1988) verbal indices of anxiety in children include sentence corrections, repetitions, stuttering and frequent use of "ah," and are regarded as interfering with rapport. Although he suggests that the interviewer invite the interviewee to discuss such nervous speech, I did not want student Alg to focus on her speech, as I thought she might not be able to concentrate on responding to the content of the interview questions.

Though all CA students mentioned fear of making a mistake in front of others, no other child appeared to demonstrate this fear more intensely throughout the interview. She certainly seemed, as she said about her group efforts, to be "trying" very hard, and her appearance, speech, and behaviors both filmed and observed during the interview seemed to support her identification as an apprehensive child.

M-B4 kept constant eye contact with the researcher to the point of staring, and seemed to be watching for a reaction to his responses. Similarly, staring or glaring behavior, was also seen during the last observation. This lends support to the findings of Andersen and coussoule 
(1980) which indicate that high CA's do not prefer averted gaze over continuous gaze.

M-B6 referred to unusual topics like curing warts and throwing up in a roller coaster and also watched the researcher rather intently. Richmond and Mccroskey (1985) point out that high CA's may speak with less relevance to the topic in order to minimize attention to themselves. However, indirect, incomplete and unrelated remarks such as B6's comments about warts and throwing up could also be seen as purposeful adaptive, coping behavior in an attempt to lead the researcher away from the question about his anxiety.

The second theme, fear, is noted in the interview responses. When questioned about their anxiety by referring to the way they marked the MECA items, most of the students responded in a clear, understandable way. In my teaching experience at many grade levels, I have discussed negative information about students with them only to be contradicted immediately. It appeared that the interview students were at least as much "at risk" and perhaps even more so than other students I have known, and yet none of them denied the existence of their fears.

A typology of fears or anxieties consisting of four category types was developed through analysis of the student interview responses (see Table IX). 
TABLE IX

TYPOLOGY OF FEARS

Types of Fears

I. Change of environment

II. Fear relative to others: peers/teachers/other people 1. When talking to teachers

2. When talking to or in front of others

3. Being in large groups

4. When insulted by others

5. Fear experienced under unusual circumstances

III. Fear of error

IV. Unspecified fear

In this section, references will identify students by abbreviations for male (M) or female (F), followed by identifying class letter designation and student number.

The first major category of fear was that of environment change: "Well, I am pretty afraid and nervous, . . I'm in a bigger city . . ." (M-B4); "Uh huh . . . cause this is my first year here" (M-B6). The second major type was in relating to children, teachers and other people: ". . with most kids I get nervous and stuff. And most teachers" (M-A10). There were five sub-types of this fear:

1. The first sub-type was a fear that occurred when talking to teachers or being in the presence of a teacher unknown to the student: ". . sometimes it makes me nervous like. . I'm talking to a teacher" (F-A19),".. sometimes I feel, um, like afraid. . some teachers I don't really know and (U) you know, sort of nervous around them . ." (M-A12), and "Well, um, well sometimes I feel, 
um, like afraid (unintelligible). You know some teachers I don't really know and (unintelligible) you know, sort of nervous around them . . ." (F-A19).

2. A second sub-type of fear was felt when talking to or in front of others, including those unknown to the CA child: "Talking to people I don't know" (M-A7), and "I'm nervous when I talk in front of people--that I don't know" (M-A12); and/or talking in front of an audience which may be a class or a large group: ". . up on stage I'm afraid to talk in the microphone" (M-B6), "Talking in front of the class. . ." (F-B19), and "I don't, um, like talking in front of big groups of people (M-A7).

3. The third sub-type of fear was experienced in the presence of large groups: "Yeah . . In being in a large group" (F-B19).

4. The fourth sub-type was that mentioned in response to a question about nervousness in other situations and constituted a fear when insulted by others: "Well, kids make me, uh, call me names like, 'you talk funny', and all that" (M-B4).

5. The fifth and final sub-type referred to unusual situations that cause fear: "On roller coaster rides. That's why I always talk to my friend..." (M-B6), and "Now I've been looking on the news, and there's been problems--gangs, coming down to schools. I've been afraid of all that" $(M-B 4)$. 
The third major kind of fear was that of making a mistake: "'cause I, I'll be afraid... I'll mess up on somethin. ." (M-B6); and ". . Yeah, 'cause it's if - . I get a wrong answer . . . Very nervous . . " (F-B19). The fourth and final major kind of fear was that which was unspecified, and was indicated in response to a question about what made a student nervous: "When I feel bad" $(\mathrm{M}-\mathrm{B} 6)$

This typology organized categories of meaning expressed by the $C A$ students and reconstructed through text analyses. Most expressed fears clustered around communication with others or being in the presence of others which is congruent with discussions of communication apprehension in this study.

By being able to acknowledge and discuss their anxieties, most of the $C A$ students appeared to typify Lofland and Lofland's (1984) activist image of individuals "who are coping, dealing, designating, dodging, maneuvering - . struggling, and so forth--that is, who are actively influencing their social settings" (pp. 114-115). Far from being passive and helpless, most of them named their fears in specific ways and appeared to be confronting their concerns.

A third theme emerged from the interview responses about classroom seating arrangements. Four of the seven communication apprehensive students stated a preference for 
a group seating arrangement in the classroom, though all CA students were observed participating within the small group learning structure (M-A10, M-B6, F-A19 and F-B19). Two communication apprehensive students who preferred a row arrangement (M-A12 and M-B4) responded, "I don't know" when asked about their choice. M-A12 seemed confused about the seating choices, and M-B4's interview was concluded so abruptly at this point that it was hard to know what more he might have said on the subject. Male student A7's description of a three-person row with boys and girls separated was confusing to me as it is not the usual way rows are constructed in the classroom. However, the students who expressed a preference for seating in groups appeared to have a clear understanding of the group configuration and definite reasons for favoring this arrangement.

These 9 and 10 year olds offered six reasons for small group seating: three positive aspects of such a seating arrangement, and three negative situations that might be avoided by small group seating. The first positive aspect concerned socialization: "Because kids seem to get along better when they're put in groups" (M-A10), and "Because the groups would help each other" (M-B6). The second referred to working more effectively in groups: ". . people work out better in groups. . it's a lot easier to cooperate [in small groups]" (F-A19). The third value of a small 
group seating arrangement related to a future advantage to be gained: "So.. - when they grow up, they're not afraid to talk with the person they work with or the boss..." $(F-B 19)$.

In contrast, the first negative situation that could be avoided through small group seating referred to fighting: "Like if you're in rows then, . . people would probably be fighting. . " (F-A19). A second referred to seating: "people can't. . lean back in their chairs. . that much if they're in groups . . ." (F-A19). The third and last negative situation to be avoided by small group seating referred to volume of noise in the classroom: ". . and you don't have to shout out everything so you're not... very far away" (F-A19).

The trend for a seating preference in small groups contradicts the findings of Mccroskey (1984) that CA's prefer to work alone, Richmond and Mccroskey (1985) who found that $C A$ 's will locate seating at the sides and the back of a classroom to avoid high interaction areas, and Hurt and Preiss (1978) who found that CA's will withdraw from contact with others in the classroom. Students' stated preferences for small groups agree with the views of Kagan (1990) who indicated that cooperative learning activities in small groups provide support for anxious students, reduction of competition, and promotion of socialization (Kagan, $1990)$. 


\section{Teacher Interviews}

Teachers of $C A$ students were interviewed when the student interviews had been completed. Except for Teacher B (Male student B4), prior to the interview they had not been told which of their students were communication apprehensive.

Research question 3 addressed the ability of classroom teachers to identify and describe their communication apprehensive students. Though the teachers' descriptions of $C A$ students centered around the themes discussed, and agreed, for the most part, with descriptions from extant literature, only one CA child, Male Student A12, was identified by his teacher.

with the same interview time frame (approximately 10 minutes) the pilot study teacher could not identify any of the $C A$ students in her class, and only did so when the interview was extended to about 20 minutes. Perhaps given as much time as the pilot study teacher, the main study teachers could have also identified more of the $\mathrm{CA}$ students. However, it was clear that for the most part, all teachers could not identify the $C A$ students or could only identify them after an extended period of time.

This seems to agree with Mccroskey's (1980) opinion that teachers do not know how many $C A$ children are in their classrooms. Though unsuccessful in identifying the CA students in this study, the teachers did believe they had 
apprehensive children in their classes, and went on to discuss characteristics of the communication apprehensive child.

\section{Thematic Interpretation of Teacher Interview}

Data/Description of CA students. Analysis of the teacher interview transcripts highlight predominant themes that began to emerge when teachers were asked to identify and describe $C A$ students and discuss their academic and social abilities. Several distinct definitions were offered by the classroom teachers in this study. One of the features of communication apprehension is that those who are apprehensive are quiet (McCroskey, 1980; Mccroskey \& Richmond, 1980). Teacher A repeatedly characterized some of his students as "quieter than others," "quiet," "a quiet child," "quiet voice," and "very quiet." He also described these children as "introverted," "loner," having "a nervousness about them."

He addressed a related kind of unwillingness to speak in describing $C A$ student reluctance:

They're somewhat [more] reluctant . . . A bit reluctant to speak out. At first especially I had to draw answers out of them . . . he's very reluctant to speak out. . . . she feels a little bit reluctant in the classroom setting in her new school. . And those are the ones I would... characterize as being more reluctant to speak than others.

The Class B teacher defined the communication apprehensive child in two ways: as those who were shy-acting as influenced by culture--the Asian girls in her 
class, or those hesitant to approach her--some boys in her class. Her first use of the term pertained to children from a minority culture who use low volume when speaking, and she described then as "timid." However, she made it clear to the researcher that she valued these students highly for their positive attitudes, ability to complete their work and high level social skills, and even indicated that she felt sorry that they had to be in a class with so many boys who misbehaved. Though communication apprehensive individuals may speak softly (like Male student Al2), the description of these Asian girls most closely matches Zimbardo's (1977) characterization of shy individuals who may not experience anxiety about talking with others. While the "quiet" theme from Teacher A's comments was in agreement with the definition of CA used in this study, the representation given by Teacher $B$ in connection with high social and academic attributes was not congruent with the description of $C A$ as used in this study, since it did not appear to fit the definition of anxiety experienced about talking to others.

However, Teacher B also spoke of "hesitance" (as did Teacher $A$ ) in her second view of $C A$, and this unwillingness to interact is congruent with definitions of the avoidance behaviors of CA individuals found in extant literature. (Butler, 1986; McCroskey, 1977b; Richmond \& McCroskey, 
1985). She referred to a student who will "hesitate [about talking]," and be unwilling to approach her for help:

- . just now coming up and talking to me .. . I can really see that it's a strain for him to come up and talk to me, . . they rarely will come up on their own, so I have to kind of seek them out.

Therefore, the notion of hesitance constitutes the second theme of unwillingness to communicate found in the interview texts.

Academic Achievement. While not discussing specific academic scores, the teachers addressed the difficulties communication apprehensive children may have in learning at the time of the teacher interviews. Teacher A indicated that CA children ". . have problems in school academically." He described students he thought were communication apprehensive as:

- . usually the poor learners... the ones who have difficulty with . . . listening and . . . they're poor readers. They have problems in school academically. . . . he's a very, a very low achiever, and he's also LD [learning disabled]. Uh, very poor reader. . [another student]. He's LD, and does have trouble with academics.

Teacher $B$ related that some students who appeared to be nervous about talking with others had trouble formulating questions, and usually needed re-explanation of concepts. She described the latter group as "having difficulty":

I have. . [Male student B3] and [Male student B11] who are very apprehensive, and who are just now coming up and talking to me and asking me questions. [Student B11] has trouble formulating what he wants to ask me.. . . I would have to go to them to explain things to them after they've handed in 
something that's been done incorrectly. Then I need to go back and.. . give them directions again.

Most of the foregoing comments from Teacher $A$ and $B$ would seem to support the findings of Comadena and Prusank (1988), Mccroskey and Richmond (1987), and Prusank and Comadena (1987), who have pointed out that CA children do less well academically than children who are not apprehensive.

I could not ascertain whether communication anxiety in the one student identified by Teacher A (Male student A12) was perceived and then translated into lower academic expectations, as suggested by Rosenthal and Jacobson (1968), or whether such perception might have caused the teacher to call on the identified $C A$ child less often thus eliminating the reinforcement needed to learn (Richmond \& Mccroskey, 1985). This was difficult to interpret as the identified CA student was in the classroom only about an hour each day. My belief, based on my own teaching experience, that both teachers would be able to speak to the CA students' general academic abilities without reference to test scores or grades, was in error.

Socialization. Issues of socialization were also addressed by the teachers, though Teacher B's observations consisted of identification of social skills in her Asian female students who were not appropriately identified as CA. on the other hand, Teacher $A$ was able to identify one CA student, and commented on the negative effects of $C A$ on general aspects of socialization: ". . have fewer friends 
- . I think basically that they have a harder time making friends. They're accepted by the others, but they're... definitely followers . . ." Richmond, Beatty, and Dyba (1985) indicated that CA children might experience difficulties in initiating relationships. However, all CA students were observed interacting with peers, and Female Student A-19 referred to her group members as "my friends." Teacher $A^{\prime} s$ most positive comments regarding social behaviors were: "They're easy to get along with . . They are easy-to-get-along-with children," and "Usually are the ones that do not get in a lot of trouble behaviorally." His comments on socialization are in general agreement with the views of Richmond and McCroskey (1985), who state that quiet students are less likely to get into trouble with the teacher.

Many of these foregoing remarks regarding socialization are similar to those of the pilot study teacher who was able to identify two of her five $C A$ students, and provide a lengthy description of the $C A$ child--someone who "clams up," is "more timid," "pretty shy," "doesn't like talking about anything," "keeps to herself," has "low self esteem," has "no confidence," and is "really low in math." She also said that such a child "prefers to stick to herself," "doesn't make eye contact very well," "won't raise his hand to participate in anything. And you call on him and [he says], 'I don't get 
it. I don't understand." She described the CA child as someone who "sits in the back row," "has been very quiet," "doesn't want to do anything in front of the class,... does not want any attention brought upon her for anything," and "embarrassed." Though each teacher identified some of the negative ramifications of $C A$, the pilot study teacher's extensive commentary constituted the most complete behavioral description given by a teacher during the study. Her descriptions were most consistent with Butler (1986), McCroskey (1984), and Richmond and Mccroskey (1985). Teachers of Class $A$ and $B$ and fourth grade teachers of the CA students were contacted six months after the study was conducted for their general past and present impressions of the CA students as well as specific information about progress or difficulty in academics and socialization (see Appendix I) .

Etiology. Although they were not asked to comment upon possible causal factors, both Teachers A and B suggested reasons for communication apprehension. While Teacher A's only comment on this was a trait explanation in his use of the phrase, "introverted by nature, by personality," Teacher B gave many reasons why a student would be apprehensive:

- . some of it is fear of being wrong. Some of it is just a fear of talking in front of the classroom. - . So I don't know if it's part of the culture, or if it is just their way. I know Female student B17's mother [who is from Czechoslovakia] is very 
soft spoken, so it could be, you know, something to do with, . . her family too.

Teacher B identified some of the communication situations discussed by the CA students. Further, she suggested possible cultural and family pattern explanations. Neither the pilot study teacher nor Teachers A or B suggested any possible influence of the school setting.

Alternative Explanations for Class/School Differences and Lack of Teacher Perceived CA. Differences in student class populations may have resulted because of student placement by the principal in either Class A or B based on individual teacher's experience, style, classroom environment, and use of cooperative learning strategies.

Teacher $A$ has told me that, in the past, children who needed a structured learning situation and strong discipline expectations have been placed in his class, though he could not say that this was the case for his students who participated in the present study. Teacher A's experience at an upper grade level may have contributed to his use of more "adult language," as discussed earlier. This way of speaking in addition to the strong voice that he used, and his presence at the front of the classroom during most of the observations may have provided the structured classroom environment needed to accommodate the behaviors of certain students. However, such discipline expectations and structured classroom environment may have been perceived as a challenge to student $A 10$, resulting in an intercultural 
conflict in which the student felt he had to assert his own "maleness" (Condon, 1985). It still might be possible that the more physically active, "acting out" or kinesthetic children might have been placed in his classroom, causing the higher counts of self-adaptors to be recorded. However, this cannot be said with certainty due to lack of refinement in the UBSSF instrument which may have affected self-adaptor counts.

McCroskey et al. (1981) and steward (1968) have suggested that the school environment may be responsible for increased levels of communication anxiety through restricted conversation and seating assignments. The use of cooperative learning activities observed in the study school appeared to allow more interactive speech and flexibility of seating arrangement than in the traditional classroom that is structured in row configurations. Cooperative learning activities also may have provided for distribution of communication responsibility, and attention to task which is thought to lessen nervousness (Steward, 1968).

Though the pilot study teacher and Teachers A and B employed cooperative learning strategies and activities, the way they were used was indicative of individual teaching style (Kagan, 1990). Group conversation in class A was restricted somewhat during the cooperative learning activities due to requirements by the teacher for silence when group answers were presented to the entire class by 
individual students. This appeared to focus attention on a single student as in the traditional lecture/question form of instruction. On the other hand, while Teacher $A$ appeared to expect full participation (he strongly corrected a student for lack of involvement in the class activity), he also encouraged an alternative form of class participation, that of simply raising a slate with the written answer for acknowledgement by the teacher. Comadena and Prusank (1988) state that classroom management techniques that encourage $C A$ children to participate should be used, and others advise against any universal requirement for oral performance, while encouraging different forms and levels of participation to assist the CA child (Booth-Butterfield, 1986; Hittleman, 1988; Kagan, 1990; McCroskey, 1984; Watson, 1989). Nevertheless, the focus on teacher direction and minimal student movement found in Classroom $A$ may be a result of specific student placement as well as individual teaching style.

The opposite may have been true for Teacher $B$, who had taught at a lower grade level. She used a softer and lower voice and certain phrases (her request for students to use their "one-inch voices") that reflected her experience with younger children. Also, she moved around the classroom to listen to students, encourage participation, assist group discussions, and check group answers for almost the entire time of the classroom observations. She also allowed 
students to be more or less active in their participation (she did not reprimand students for non-participation) and let the students move about the room to ask her a question or leave to use the restroom. Though she indicated that the girls' behavior was better than that of the boys in her classroom, I did not observe this difference in behavior. Her teaching style and the resulting classroom environment appeared to result in more unrestricted communication as suggested by Mccroskey (1980): "Such a climate [communication permissive] is developed when a teacher reinforces students for communicating with others" (p. 243). When placement of students was considered by previous teachers and the principal, quiet or timid children may have been placed in Teacher B's classroom in which the teaching/learning environment appeared more informal. Overall MECA scores were higher in this classroom, though only three out of the seven $C A$ students came from Class $B$. In light of Mccroskey's support for a communicationpermissive classroom to assist the CA child (1980), placement of such a child in classroom B would have been appropriate, though it cannot be said that perception of $C A$ was a consideration for placement.

\section{other Possible Influences Upon MECA and Self-Adaptor}

Scores. Given the demographic background of the children in this school, it is understandable that some of the students might have chosen the highest level of anxiety response on 
particular MECA items, and therefore received scores that identified them as CA. Recent arrival at the school may have had a noticeable impact on a student's level of anxiety (see Appendix $\mathrm{H}$ for demographic information). Two students in the pilot study seemed particularly affected by personal problems and scattered attendance at many schools, and two CA students in the main study (Male students B4 and B6) mentioned relatively recent arrival as cause for their anxiety. Since I believed that "newcomer anxiety" might quickly give way once relationships were established, the arbitrary requirement for one month's presence at the school seemed to be realistic for participation in the study, and that given a little more time in the school, a new student might respond differently on the MECA. I base this opinion on my experience of observing my new students during a "settling in time" of about this length. However, I cannot explain why two students would still feel that they are new to the school after one year in attendance.

Contributors to anxiety might include living in a lower socio-economic area where children receive chapter one services for special reading assistance as in the study school (Chesebro et al., 1992). The authors also indicate that attending a school with a high transient population such as the study school could also contribute to children's anxieties. At the time of the study, the school in which the study took place had the highest student transient rate 
within the school district. To address the needs of transient students and other needs as well, in addition to the Chapter one specialist, the school district also employs a full-time counselor, speech therapist and learning disability teacher as well as other specialists on a partand full-time basis. While conducting the study, I realized anew how much these services are needed at the school since many of the CA students appeared to have other problems in addition to communication apprehension.

MECA scores may not always give an accurate assessment of CA levels, even though they were taken at face value in this study. An unusually high MECA 2 score (by Male student B4) was questioned by Teacher $B$ who examined the MECA and refuted almost all of the student's responses. From her point of view, the student had extended some oppositional behaviors (caused, in her opinion by his personal problems) to the marking of the MECA. I noted some of his unusual interview responses, but because his interview was cut short, I did not have the full interview time to observe the kind of behaviors referred to by his teacher.

Cultural influences and differences could also have contributed to the identification of two of the $C A$ students. Though no indications were given by a pilot study $C A$ student who is Filipino, Male student Alo may have reflected some aspects of his Hispanic background that may relate to CA. He was the only minority student of the seven CA children 
interviewed for the main study, and in a recent study (Chesebro et al., 1992), Hispanic junior high school students scored higher in CA than Caucasian students. Gender and ethnic differences between us may have influenced him to remain silent at times during the interview. He presented a bold appearance (folded arms and averted gaze) that may have been culturally correct, which was enhanced by his long hair style and strong physical presence. One possible interpretation of this might be an imitation of "macho" behavior he has observed in older Hispanic boys (Condon, 1985). However, taking the self-reported presence of $C A$ at face value and interpreting student Alo's general posture as cautious and guarded might be the most consistent way of viewing the subject. He chose the noncommittal middle option ("Doesn't bother me") for each item on the second MECA.

In addition to possible class differences, school population as well as study procedures may account for differing MECA scores. Hoffman's (1991, 1992) more extensive studies which also utilized quantitative and qualitative data were conducted in a private school setting, and examined teacher/CA student initiation of interaction. Levels of student CA decreased in Hoffman's study while they increased in the present study. However, Hoffman noted the homogeneous quality of the school population in the private school in which her study took place. By contrast, the 
public school in which the present study took place serves the general school population which includes children who may have special needs. Such students might report increased levels of communication anxiety as a function of the many challenges they face (Chesebro et al., 1992). Also, 15 weeks elapsed between administrations of the MECA in the Hoffman study which took place during the first term of the school year, as opposed to one week between Time 1 and 2 of the MECA in the present study which took place during the last weeks of the school year.

However, Hoffman's $(1991,1992)$ research is similar to the present study in four ways. First, descriptive narrative addressed certain observed and recorded behavior of young students [initiation of interaction] which was examined in light of levels of CA established by $\mathrm{Time} 1$ and 2 administrations of the MECA. Second, instructional styles which may have influenced study results were more lecture-question oriented at the fourth grade level (similar to the style of Teacher $A$ who has taught fifth grade for a number of years) than at the third grade level where students were allowed to interact more with each other (similar to the style of Teacher B who has taught first grade for many years). Third, high CA third grade students communicated with other students in a seating arrangement (horseshoe) that seemed to encourage interaction:

All four high $C A$ students [two each from the third and fourth grades] initiated a medium amount of 
interaction relative to the rest of the students in their class, and all four students were observed to initiate and contacted for off-task social talk with their classmates. (Hoffman, 1992, p. 154)

These findings, which are also similar to those found by this researcher, are in contrast with the views of Hurt and Preiss (1978), McCroskey (1977a, 1984), and Richmond and Mccroskey (1985), who indicate that communication apprehensive individuals will avoid interaction with others, prefer to sit alone and remain quiet.

Finally, academic achievement (as assessed through standardized test scores) and predictions for academic success (as shown on a teacher expectation rating instrument) were examined in Hoffman's (1992) study and to a lesser degree in the current study.

Rival explanations of the self-adaptor behaviors displayed during the study also need to be considered. Although the hypothesis was not supported, self-adaptors may have indicated inner anxiety experienced by the $C A$ students as suggested in Chapter III and as discussed in the extant Iiterature (Comadena \& Andersen, 1978; Ekman \& Friesen, 1969). Evidence of a global display of self-adaptors appeared to exist as previously discussed in this chapter. Another consideration might be that general behaviors of students are not typical during the last few weeks of school. Children find it hard to sit still for long periods of time as the end of the school year arrives with the 
resulting interruptions and disruption of the school schedule and anticipation of summer vacation.

Their "fidgeting" might be taken for self-adaptor behaviors according to this study's definitions and criteria, and might simply consist of typical "end-of-theyear" behaviors. Frequency counts of self-adaptors may have been unusually high for some students for this reason. As stated by olson (1930), physical activity in the form of recurring nervous behaviors may be common to all children that is, normal. In fact, all students in the study displayed a number of self-adaptors. Lastly, kinesthetic movement may be related to learning. Grinder (1989) suggests another possible rival explanation in that some students utilize a kinesthetic learning modality, processing information in a different way than an auditory or visual learner. Some of the behavioral indicators of the kinesthetic learner include, "touches people and stands close, . . moves a lot, larger physical reaction, . . gestures a lot, responds physically, . . voice louder" (p. 20). Since many of these movements were observed in the $C A$ students in the study, the possibility of a kinesthetic modality of learning cannot be ignored.

In discussing his theory of multiple intelligences, Gardner (1983) goes beyond simply recognizing kinesthetics as a way of learning. The author suggests that when developed, a bodily-kinesthetic intelligence in which 
individuals "develop keen mastery over the motions of their bodies. . are able to manipulate objects with finesse" (p. 207) is as important as any of the other ways of knowing.

Possible reasons for lack of teacher perception of CA may include use of unreliable indicators to determine the presence of $C A$, related communication problems that may have been mistaken for $C A$, and lack of a self-report from students. First, the lack of a predicted positive relationship between $C A$ and self-adaptor behaviors in this study is supported by Mccroskey's (1976) view that behavioral indicators alone cannot prove the existence of CA. Other authors provide only limited support for teacher perception of CA through observation of behaviors (Garrison \& Garrison, 1979b; Watson, 1989; Watson \& Monroe, 1990). Therefore, such behaviors may not serve as useful clues for teacher assessment of $C A$, though both teachers in the study attempted to predict its existence through behavioral indicators. Additionally, many of the indicators cited by the teachers in the study could be taken as descriptors of constructs similar to $C A$, such as reticence or shyness. Since self-report is the most accepted way of discovering the existence of this internal anxiety about talking with others, some form of self-report would be needed for a teacher to identify a $C A$ student. However, use of the MECA for every student is unrealistic, and time is 
not available to interview all students to ask them about their possible communication nervousness. Also, I believe that because teachers are used to being considered the "experts" in academics, they do not often ask children about their feelings. Therefore, needed information about the CA child is simply not available.

\section{SUMMARY OF FINDINGS}

The present study identified levels of $C A$ in primary school children, and noted the display of self-adaptor behaviors. However, little evidence was available to establish a positive correlation between MECA scores and frequency of self-adaptors. Rather, self-adaptors from all 10 categories were displayed to some extent by all children in the study, and some unusual data were recorded: the student with the highest CA score (Male student B4) displayed no self-adaptors during the first observation, and one of the nine low CA's (Male student A5) displayed 93 self-adaptors during the third classroom observation--the largest number of self-adaptors observed in the study. statistical results indicated differences in the two class populations.

It was not determined whether the physically unrestricted classroom environment of cooperative learning groups encouraged self-adaptor behaviors, but freedom to move in chairs, and sit at or on desks or tables or on the 
floor allowed the display of unrestrained self-adaptors to occur and be observed.

In light of their high CA scores, it was anticipated that apprehensive children might not actively participate in interviews and would choose to work alone in classroom tasks. However, most CA children in the study spoke freely of their anxieties, expressed preferences for small group seating arrangements, and were observed participating and speaking with others in small groups. Only one CA student was identified during teacher interviews (Male student A12), though both teachers believed $C A$ students were in their classrooms and described many of the personal, social, and academic characteristics of the CA child that are referred to in the current literature on communication apprehension. Teachers of the CA students used similar teaching activities during classroom observations but conducted the activities in ways that reflected their preferred teaching styles which may have contributed to the identification of two possibly distinct class populations.

Anxieties experienced by the students interviewed may not be limited to communication apprehension. They may exist because of other difficulties discovered through family and student histories available to the researcher and shared by the students themselves. Given their problematic lives, general anxiety would not be an unusual circumstance for any of the interviewed children. 


\section{LIMITATIONS OF THE STUDY}

First, theoretical overlapping of constructs in the extant literature has caused confusion regarding related communication problems. Because of this, the researcher does not assume that nonverbal self-adaptor behaviors actually reflect the $C A$ condition, as reticence as well as a number of other related constructs may constitute the existing communication difficulty, either alone or jointly with $C A$ and/or other related constructs.

External validity or the ability to generalize findings to a larger population is not possible in this study due to the small sample size and the limited access to available subjects. Instead, comparability of results as suggested by Lecompte and Goetz (1982) may suffice to establish external validity. A future researcher unknown to school staff and students might constitute a threat to this comparability, as well as unusual data from subject "outliers" which cannot be removed from small sample data. These issues should be addressed in any similar future study.

By contacting Teacher B about Male student B4's MECA scores I jeopardized study results by incurring bias against this CA student. I was then somewhat predisposed to be unbelieving toward this student because of the strong response from his teacher. Rich (1968) suggests, ". . the more we know about any child before an interview the more 
effective the interview is likely to be..." (p. 81). Unfortunately, the opposite may have been the case with this child, since I later conducted the interview in a rather biased fashion. The teacher may have also become biased by my contact with her, since her interview also occurred after my meeting with her.

During the interview with student B-4, I reworded an interview comment in a rather challenging way: "I noticed on your questionnaire you marked almost every single one 'nervous' or 'afraid." There is no way of knowing if this error of judgment influenced student B4's response. Sattler (1988) suggests that while emotions should not be suppressed, a direct show of emotion may stifle the interview somewhat.

confusion may have existed regarding certain items on the MECA instrument (see pilot study in Chapter III). Also, development and refinement of the self-adaptor measurement tool was lacking in this study. It should be revised to include self-adaptors which occur below the waist, as this would allow a greater range of self-adaptors to be recorded. Intimate behaviors were not observed during the study and therefore may not occur when a full body view is included for count of self-adaptors. The tool has not been refined to screen outlying data such as Male student A5's continual clapping which affected the statistical analysis. Also, the 
format of the Scoring Form needs further refinement to allow more room for tallying self-adaptors.

one subject was too far away from the camera to make judgments about all possible self-adaptors that were displayed, and in one instance the waistline on a girl's dress was difficult to define so self-adaptor counts above the waistline were rather arbitrary. Children left their work groups at times or turned away from the camera resulting in frequency counts that may not have been typical. Also, on some occasions, the students "played to the camera" (such as Male students A10 and B4) or may have been influenced by the presence of the camera.

The researcher experienced difficulty in categorizing grooming of hair, hand contact with small objects, and biting of the lip when a child's prominent front teeth were simply resting on the lip. On two occasions, when the camera was lowered or the subject moved back and forth, a self-adaptor dropped out of view and then reappeared a number of times, increasing the count of self-adaptors. This increased number accounted for 3 extra self-adaptors during one observation and 18 during another observation, when the assistant seemed to have an unsteady grip on the video camera. The same result occurred when a book was moved back and forth alternately blocking and revealing the self-adaptor, accounting for three additional self-adaptors. These extra counts resulted from the directions to consider 
each viewing of a self-adaptor separately (see Appendix C). Also, presence of the researcher and assistant may have limited the count of self-adaptors due to self consciousness of study participants.

The viewing of certain groups was difficult because of inadequate lighting as the teacher turned some of the lights off in the classroom (two times). On one occasion, the researcher accidentally readjusted the color indicator on the television in an effort to lighten the picture.

Description of clothing colors are not accurate for at least one group, but patterns in clothing and general descriptions which include position in the group (right, left, forward, behind), length/style of hair and style of clothing remain the same, and additional differences noted in the subject description section of the tally sheet should suffice to identify subjects in each group.

Problems of timing and scheduling occurred during the study. The pilot teacher interview was allowed to run almost 20 minutes resulting in last minute identification of two $C A$ students in her classroom. Though the students were identified, the interview seemed to proceed aimlessly with my repetition of some of the questions. I felt it would be more efficient to retain the shorter interview time and conduct the interview in a more expedient manner. However, though I decided not to lengthen the main study teacher interviews, the shorter interviews lacked depth and 
development of topics. Some students were mentioned without adequate discussion of qualities that might have made them appear apprehensive, and only one of the main study teachers was able to identify a CA student.

The study took place at the end of the school year, and this had a positive effect in that it eliminated the possibility of temporary "getting-acquainted anxiety" that many children might experience in the early months of school. However, disruption of the regular instructional schedule resulted in observations and interviews having to be rescheduled to accommodate an assembly, field day or other activity. According to Frey, Botan, Friedman, and Kreps (1991), the concept of history as environmental changes affecting behaviors can threaten internal validity. The present study admits to limitations in this area in that many changes in the daily schedule took place at the end of the school year.

Further training in interview techniques and strategies would have assisted in providing more helpful data through the interview process, both with teachers and $C A$ students. Questions to the $C A$ students were few and brief. Though pauses in speech during the interview were noted, they lasted only a few seconds. I felt that longer periods of silence might cause the student to become more anxious and reluctant to speak. However, though I did not allow much time for silence during the student interviews, 
as indicated by Crano and Brewer (1973), the use of silence can be a stimulus for speech and therefore might be an appropriate interview strategy to use with CA students. Standardized tests of academic achievement were not compared with CA scores in this study. Future studies may wish to include such tests as part of a total student academic assessment. On the other hand, though negative effects of CA on academic achievement of elementary school students have been found in two studies (Comadena \& Prusank, 1988; Prusank \& Comadena, 1987), two other studies have found no such effect (Hoffman, 1991, 1992; Watson \& Monroe, 1989). According to Watson and Monroe (1990), "... studies suggest both significant and nonsignificant relationships between $C A$ and academic achievement . . . " ( p. 29). When follow-up information was obtained six months after the conclusion of the study, references to academic achievement confirmed the difficulty certain $C A$ students were having at the time of the study and later.

Additional considerations weighed against the use of achievement scores. In his discussion of multiple intelligences, Gardner (1983) states that such multiple intelligences have important ramifications for most methods of assessment in use today:

In the conventional test, the child is confronted by an adult who fires at him a rapid series of questions. The child is expected to give a single answer (or, when somewhat older, to write down his answer or to select it from a set of choices). A premium is placed on linguistic facility, on certain 
logical-mathematical abilities, and on a kind of social skill at negotiating the situation with an elder in one's presence. (pp. 386-387)

Gardner (1983) strongly advocates alternatives to the present system of standardized achievement tests, and in the district in which the study took place, new forms of evaluation include student-led parent conferences which feature the presentation of a student portfolio of work in all areas. Since some forms of assessment of ability appear to be changing, alternate views of the term "academic achievement" need to be addressed.

\section{STRENGTHS OF THE STUDY}

The current study has contributed to a greater understanding of communication apprehension in three areas. It challenges currently held views, presents new methods for use in examining communication apprehension among children, and suggests new ways in which the issues of communication apprehension can be addressed through research and education.

First, this study has raised questions regarding some widely-held views in the extant literature on communication apprehension. Though this study sample was limited, my results indicate that $C A$ students did not display more constrained behaviors (Mccroskey, 1976) and were not more timid in their manner than their non-apprehensive peers (Butler, 1986; Mccroskey, 1976). They did not withdraw from 
others, sit apart, or not participate (Hurt \& Preiss, 1978; Mccroskey, 1984), and did not appear to lack control over their language through inappropriate usage when their ages were considered (Jordan \& Powers, 1978). In fact, the interviewed $C A$ students were quite articulate in describing their perceptions, fears and choices, and generally appeared willing to be interviewed. Suggestions that $C A$ children experience problems in socialization were not confirmed in interviews or classroom observations (Hurt \& Preiss, 1978; Richmond, Beatty, \& Dyba, 1985) .

Four out of seven CA students indicated a preference for small group seating, a classroom learning structure advocated by steward (1968), though Richmond and Mccroskey (1985) indicated that such seating may cause CA's to feel more pressure to communicate. Classroom observations revealed that $C A$ students interacted with group members and participated in learning activities through use of the semi public responses that may occur in such small groups when students turn to each other to share responses, as in Hoffman's (1991, 1992) studies. study participants spoke of their $C A$ and stated their preferences for small group learning structures.

Though some sources indicate that CA students may be identified by their teachers, only one communication apprehensive student out of seven was clearly identified by a teacher in this study (Garrison \& Garrison, 1979b; 
McCroskey \& Daly, 1976; Watson, 1989). McCroskey (1980) indicates that most teachers, in fact, do not perceive communication apprehension in their students, and I have discussed some possible reasons for such a lack of perception.

Second, through method triangulation, data from quantitative and qualitative forms of self-report provided some evidence for cross-situational consistency in support of the enduring nature of communication apprehension as tested by the MECA (Mccroskey, 1982). At the same time triangulation also offered evidence for rival explanations that needs to be seriously considered. Also, for the first time in studies on CA among young children, CA students were interviewed and found to be aware of their communication fears and able to articulate them in rather direct ways. This is in contrast with the current view of $C A$ individuals as quiet (McCroskey, 1980; McCroskey \& Richmond, 1980), withdrawn (Hurt \& Preiss, 1978; McCroskey, 1984), and unable to use appropriate language (Jordan \& Powers, 1978). In addition, recording of their interview responses and observations of behaviors exhibited during the interviews were facilitated through the student viewing of videotapes of themselves in small classroom work groups. For the first time in such studies, the phenomenological view was applied to emergent themes in teacher and student interview texts, thus re-creating participants' perspectives 
of $C A$ and other concerns. This study also offered significant alternative explanations for possible MECA and self-adaptor results

Lastly, there are important educational implications for the results of this study. Accommodation of CA children might well be achieved through the use of small group seating arrangements which allow varying levels and methods of participation. These accommodations do not attempt to "cure" the communication anxiety, but to facilitate the communication apprehensive child by providing the most appropriate learning environment. As seen in student interview responses, CA students themselves can identify many valid reasons for using the small group structure.

since $C A$ children are able to address their communication anxieties, a practical and proactive application of study results would be to facilitate informal, small group discussions on communication problems, perhaps using the "talking chips" structure observed in Class A. If notes from these sessions indicate possible communication anxiety for certain students, the school counselor may administer the MECA and assist the student.

I believe teacher training is needed to raise awareness of the existence of $\mathrm{CA}$ as an internally experienced anxiety that needs to be addressed, as well as the implications of communication apprehension for learning and socialization. Such training should also include 
suggested methods of addressing and accommodating the $C A$ child as an important educational consideration. Suggestions and cautions might include:

1. We cannot assume that students are or are not communication apprehensive. Use a general discussion about fears to elicit comments from students, as they may share such comments with you and/or other students in their work groups. In addition, an indirect question to the class about how to arrange the room may reveal student attitudes about communication and seating preferences as in this study.

2. Develop a facilitative attitude toward your quiet students. Establish a communication-friendly classroom environment in which all non-disruptive communication is rewarded and reinforced.

3. Arrange classroom seating to provide for work in small groups.

4. Allow seating choice by students within this classroom structure.

5. Allow for levels of participation through assignment of rotating group responsibilities for obtaining materials, reading for information, recording answers, and reporting group responses.

6. Do not require formal presentations or assign grades on oral participation. Instead, use alternate ways 
of checking for student learning in addition to the single oral response to the class:

a. assign rotating team reporters;

b. provide use of slates, signs, or signals to indicate individual or group responses;

c. allow semi-public responses as in telling an answer to a neighbor.

\section{RECOMMENDATIONS FOR FUTURE} RESEARCH

Because I consider the present research to be exploratory, the continuing development of study procedures is necessary. Considering the confusion surrounding the definitions of communication apprehension and its related constructs, it can only be stated that the concern of this study was young children who are at risk academically and socially because of their inner anxiety about talking with others (Burgoon, 1976; Burgoon \& Koper, 1984; Clevenger, 1984; Daly, 1978; Daly \& McCroskey, 1984; Daly \& Stafford, 1984 ; Kelly, 1982; Kelly \& Keaten, 1992; Mccroskey, 1977b, 1982, 1984; McCroskey et al., 1981; McCroskey \& Richmond, 1987; Mortensen, Arnston, \& Lustig, 1977; Richmond \& Roach, 1992; Steward, 1968).

Future research should extend as much effort addressing possible and practical assistance for communication apprehensive individuals as it has examining the complex foundations and inter-relationships of $C A$ with 
other related constructs. Additionally, currently held theoretical views that were challenged in this study should be addressed in the future to build cumulative evidence for alternative views.

Methodological recommendations include establishment of validity and reliability, field issues, tool development and refinement, and interview considerations. I believe the reliability of the study provides for application to other student populations. Re-creation of the study using the same tools and procedures would provide greater external validity for them. This literal replication suggested by Frey, Botan, Friedman, and Kreps (1991) enhances the overall validity of the study. However, two considerations regarding the MECA need to be addressed. First, recommendations from the pilot study students should be considered before the MECA is re-administered (see Chapter III). Second, cultural implications of the MECA questions should be considered. Hoffman's (1991) private school study sample was rather homogeneous while the present study took place in a public school environment which includes a larger number of students from different cultural backgrounds. In such an environment, the following MECA questions suggest communication situations which may not be appropriate for certain students:

Question 4--talking to (initiating conversation) "people who are not close friends." 


$$
\begin{aligned}
& \text { Questions } 6 \text { and 9--Talking "a lot." } \\
& \text { Question 7--Talking to someone you do not know very }
\end{aligned}
$$

well.

Lastly, the language of the questionnaire must also be re-examined in that each question asks how the student "feels" about the communication situation. This word may seem intrusive or misinterpreted by a student from another culture. Words that convey similar meaning should be considered.

Corsaro's (1981) suggestions on how to enter the field when studying the behaviors of children were followed with positive results and are highly recommended for future research in the school setting. Initial preparation involving the "gatekeepers" of the school helped facilitate the gathering of data, alerting all staff to the study, and entrance into the classroom world of the child long before the study began provided a natural, familiar, and comfortable setting for all participants.

Allowing sufficient time to conduct a study of this scope is recommended. Since preliminary procedures consume most of the time, human subjects clearance and proposal work should be completed in the previous year, and initial observations could start as soon as children had become somewhat acquainted and the instructional schedule had been set in the fall. Such a schedule would allow time for observations at more than one school or at least more than 
one grade level throughout the year. Also, field work should be concluded well before the end of the school year to prevent disruption of scheduled interviews and avoid "end-of-the-year" student behaviors.

More unobtrusive methods of filming might be used to prevent the students from "playing to the camera." For example, a one-way mirror could be placed behind a work table to which each group would rotate.

Further refinement of the self-adaptor tool is also in order. Clarification of self-adaptor categories and directions would prevent confusion about what is counted as a self-adaptor and inflated counts of the behaviors. opportunities for improvement have occurred as a result of the pilot study and the main study, and this example of exposure to improvement and change to which the research project was committed may lead to a more accurate accounting of self-adaptor behaviors in the future.

In differing degrees, cooperative learning strategies used by teachers in this study also helped facilitate communication in the study classrooms, and future researchers wishing to view $C A$ children in a communicative environment should consider these strategies. These activities appear to address the communication needs of the CA student by allowing small group work, alternative tasks and different levels of participation including participation through speech. Additionally, I would suggest 
that teachers be advised to allow as much group talk as possible.

Improvements in interviewing techniques might include Grove's (1991) suggestion to use the "lag time" while the student is speaking to absorb and process what is being said rather than to consider the next question, as I did at times. Interviews with $C A$ children must be longer and more extensive to more adequately capture the perspective of the $\mathrm{CA}$ child. Because each student acknowledged being "nervous," a follow-up question might be: "What makes you most nervous about talking with others?" Other questions might be: "What do you think would help make talking with others easier?" and "What do you think would not be helpful about sitting in groups?" In addition, MECA questions which evoked the "afraid" response on the MECA questionnaire might be used to obtain information about the kinds of anxiety-producing circumstances.

Interviews with teachers could be somewhat longer to allow the possibility of student CA identification. Also, additional questions might be added to the teacher interview schedule. One question: "What are some ways you encourage communication in your classroom?" might reveal more information about teaching style. Another question, taken from Hoffman's 1992 study: "How did you choose the original seating arrangement?" might indicate communication preferences of the teacher (see Appendix E). 
I would suggest that a future teacher/researcher not be teaching at the study school while conducting research there. By not being employed at the time, my field experience at the study school allowed me the opportunity to consider only the educational and emotional challenges faced by some of the students while remaining free of the responsibilities of preparation, instruction, and assessment.

Though it is beyond the scope of this study to attempt to discriminate between bodily movement associated with anxiety and movement as a learning modality or a type of giftedness, future research should note the existence of different reasons for physical movement and suggest that instead of assuming that self-adaptor behaviors indicate poor self-discipline or anxiety, teachers might attend to such kinesic movements as a normal occurrence among children, a learning modality to be used, a talent to be encouraged, and so forth.

While this study did not establish a relationship between communication apprehension and self-adaptor behaviors in young children, all data gathered and analyzed revealed much about the $C A$ students. Since class differences were noted in this study, a future ethnographic study might explore individual classes as "speech communities." such a study would determine more thoroughly the effect(s) that teaching styles and classroom 
environments may have on the young $C A$ student and whether $C A$ students are treated differently by their teachers, an issue addressed by Hoffman $(1991,1992)$ in her studies. While this study was a first endeavor in helping $C A$ children "come alive" by presenting their actual speech and their feelings about communication, more extensive naturalistic studies of the $C A$ child need to occur so that additional ways of assisting such children can be discovered. And as larger classes of students with an increasing range of educational and social abilities and disabilities enter the public schools, educational assistance must be provided to the CA child as it is provided to all others. The "quiet" ones need to be heard, not ignored. 


\section{REFERENCES}

Albrecht, T. L., \& Ropp, V. A. (1982). The study of network structures in organizations through the use of method triangulation. Western Journal of Speech Communication, 46(2), 162-178.

Allport, G. W. (1968). The person in psychology. Boston: Beacon Press.

Andersen, P. A., Andersen, J. F., \& Garrison, J. P. (1978, Summer). Singing apprehension and talking apprehension: The development of two constructs. sign Lanquage studies, 19, 155-186.

Andersen, P. A. \& Coussoule, A. R. (1980). The perceptual world of the communication apprehensive: The effect of communication apprehension and interpersonal gaze on interpersonal perception. Communication Quarterly, $\underline{28}(1), 44-54$.

Anderson, J. A. (1987). Communication research. New York: McGraw-Hill.

Ayres, J., \& Hopf, T. S. (1990). The long-term effect of visualization in the classroom: A brief research report. Communication Education, 39(1), 75-78.

Babbie, E. (1992). The practice of social research. Belmont, CA: Wadsworth.

Baesler, E. J., \& Burgoon, J. K. (1987). Measurement and reliability of nonverbal behavior. Journal of Nonverbal Behavior, 11(4), 205-233.

Barraso, F., Freedman, N., \& Grand, S. (1980). Self-touching, performance and attentional processes. Perceptual and Motor Skills, 50(3), 1,083-1,089.

Beatty, M. J., \& Behnke, R. R. (1980). An assimilation theory perspective of communication apprehension. Human Communication Research, $6(3), 319-325$.

Biggers, T., \& Masterson, J. T. (1984). Communication apprehension as a personality trait: An emotional defense of a concept. Communication Monographs, 51 (4), 381-390. 
Booth-Butterfield, M. (1986). Stifle or stimulate? The effects of communicative task structure on apprehensive and non-apprehensive students. Communication Education, 35(4), 337-348.

Booth-Butterfield, M. \& Cottone, R. R. (1991). Ethical issues in the treatment of communication apprehension and avoidance. Communication Education, $40(4)$, 172-179.

Bourhis, J., \& Allen, M. (1992). Meta-analysis of the relationship between communication apprehension and cognitive performance. Communication Education, $41(1), 68-75$.

Burgoon, J. K. (1976). The unwillingness-to-communicate scale: Development and validation. Communication Monographs, $43(1), 60-69$.

Burgoon, J. K. (1989). The nature of arousal and nonverbal indices. Human Communication Research, 16 (2), 217-255.

Burgoon, J. K., \& Hale, J. L. (1983). Dimensions of communication reticence and their impact on verbal encoding. Communication Quarterly, 31(4), 302-312.

Burgoon, J. K., \& Koper, R. J. (1984). Nonverbal and relational communication associated with reticence. Human Communication Research, 10(4), 601-626.

Burgoon, J. K., \& Saine, T. (1978). The unspoken dialogue. Boston, MA: Houghton Mifflin.

Butler, J.F. (1986). Personality characteristics of subjects high and low in apprehension about communication. Perceptual and Motor skills, 62 (3), 895-898.

Cahir, S., \& Kovac, c. (1981). It's your turn: Exploring functional language. Washington, DC: Center for Applied Linguistics.

Cardot, J. (1982, April). Communication apprehension and intercultural nonverbal coding. Paper prepared for SSCA meeting, Hot springs, AK.

Chesebro, J. W., McCroskey, J. C., Atwater, D. F., Bahrenfuss, R. M. , Cawelti, G. , Gaudino, J. L., \& Hodges, H. (1992). Communication apprehension and self-perceived communication competence of at-risk students. Communication Education, 41(4), 345-359. 
Clevenger, T. (1961). A factor analysis of the visible symptoms of stage fright. Speech Monographs, 28(4), 296-298.

Clevenger, T. (1984). An analysis of research on the social anxieties. In J. A. Daly \& J. C. McCroskey (Eds.), Avoiding communication: Shyness, reticence, and communication apprehension (pp. 219-236). Beverly Hills: Sage.

Comadena, M. E., \& Andersen, P. A. (1978, April). Kinesic correlates of communication apprehension: An analysis of hand movements. Paper presented to the Interpersonal Communication Division at the annual convention of the International communication Association, Chicago.

Comadena, M. E., \& Prusank, D. T. (1988). Communication apprehension and academic achievement among elementary and middle school students. Communication Education, $\underline{37}(4), 270-277$.

Comadena, M. E., \& Prusank, D. T. (1989). Communication apprehension in children. In J. F. Nussbaum (Ed.), Life span communications: Normative processes (pp. 79-91). Hillsdale, NJ: Lawrence Erlbaum Associates.

Condon, J. C. (1985). Good neighbors. Yarmouth, ME: Intercultural Press.

Corsaro, w. A. (1981). Entering the child's world: Research strategies for field entry and data collection in a preschool setting. In J. L. Green \& C. Wallat (Eds.), Ethnography and language in educational settings (pp. 117-146). Norwood, NJ : Ablex.

Crano, W. D., \& Brewer, M. B. (1973). Principles of research in social psychology. New York: McGraw Hill.

Crawford, W., (Producer), Lane, A. (Producer), \& Coolidge, M. (Director). (1982). Valley girl [Videotape]. Hollywood, CA: Valley productions.

Daly, J. A. (1978). The assessment of social-communicative anxiety via self-reports: A comparison of measures. Communication Monographs, 45(3), 204-218.

Daly, J. A., \& Friedrich, G. (1981). The development of communication apprehension: A retrospective analysis of contributory correlates. Communication Quarterly, $\underline{29}(4), 243-255$. 
Daly, J. A., \& Mccroskey, J. C. (Eds.), (1984) . Avoiding communication: Shyness, reticence, and communication apprehension. Beverly Hills, CA: Sage.

Daly, J. A., \& Miller, M. D. (1975). The empirical development of an instrument to measure writing apprehension. Research in the Teaching of English, $\underline{9}(3), 242-249$.

Daly, J.A., \& Stafford, L. (1984). Correlates and consequences of social-communicative anxiety. In $\mathrm{J}$. A. Daly \& J. C. McCroskey (Eds.), Avoiding communication: Shyness, reticence, and communication apprehension (pp. 125-144). Beverly Hills, CA: Sage.

Davis, G. F., \& Scott, M. D. (1978). Communication apprehension, intelligence and achievement among secondary students. In B. D. Ruben (Ed.), Communication yearbook 2 (pp. 457-472). New Brunswick, NJ: Transaction Books.

Davis, S. (1981). Reliability and validity of a scale to measure prosocial behavior in young children. Unpublished master's thesis, Portland State University, Portland, OR.

Denzin, N. K. (1989). The research act. Englewood cliffs, NJ: Prentice Hall.

Dewey, J. (1915) . The school and society. Chicago, IL: The University of Chicago Press.

Ekman, P., \& Friesen, W. (1969). The repertoire of nonverbal behavior: Categories, origins, usage, and coding. Semiotica, 1(1), 49-98.

Freedman, N. (1976). Hands, words, and mind: on the structuralization of body movements during discourse and the capacity for verbal representation. In $\mathbf{N}$. Freedman \& S. Grand (Eds.), Communicative structures and psychic structures (pp. 109-132). New York: Plenum Press.

Freedman, N., O'Hanlon, J., oltman, P., \& Witkin, H. A. (1972). The imprint of psychological differentiation on kinetic behavior in varying communication contexts. Journal of Abnormal and social Psychology, 79(3), 239-258. 
Fremouw, W. J. (1984). Cognitive-behavioral therapies for modification of communication apprehension. In $J$. A. Daly \& J. C. McCroskey (Eds.), Avoiding communication: Shyness, reticence and communication apprehension (pp. 209-215). Beverly Hills, CA: Sage.

Fremouw, W. J., \& Scott, M. D. (1979) . Cognitive restructuring: An alternative method for treatment of communication apprehension. Communication Education, $\underline{28}(2), 129-133$.

Fremouw, w. J., \& zitter, R. E. (1978). A comparison of skills training and cognitive restructuring-relaxation for the treatment of speech anxiety. Behavior Therapy, $9(2), 248-259$.

Frey, L. R., Botan. C. H., Friedman, P. G., \& Kreps, G. L. (1991). Investigating communication. Englewood cliffs, NJ: Prentice Hall.

Friedrich, G. \& Goss, B. (1984). Systematic desensitization. In J. A. Daly \& J. C. McCroskey (Eds.), Avoiding communication: Shyness, reticence and communication apprehension (pp. 173-187). Beverly Hills, CA: Sage.

Gardner, H. (1983). Frames of mind: The theory of multiple intelligences. New York: Basic Books.

Garrison, J. P., \& Garrison, K. R. (1979a). Measurement of oral communication apprehension among children: A factor in the development of basic speech skills. Communication Education, 28, 119-128.

Garrison, K. R. \& Garrison, J. P. (1979b, May).

Elementary teachers' perceptions of communication apprehension among their students: $A$ research note. Paper presented at the annual meeting of the International Communication Associates, Philadelphia.

Goetz, J. P., \& Lecompte, M. D. (1982). Ethnographic research and the problem of data reduction. Anthropology and Education Quarterly, 12(1), 51-65.

Greene, J. O., \& Sparks, G. G. (1983a). Explication and test of a cognitive model of communication apprehension: A new look at an old construct. Human Communication Research, 9 (3), 349-366. 
Greene, J. O., \& Sparks, G. G. (1983b). The role of outcome expectations in the experience of a state of communication apprehension. communication ouarterly, $\underline{31}(3), 212-219$.

Grinder, M. (1989). Righting the educational conveyor belt. Portland, OR: Metamorphous Press.

Grove, T. G. (1991). Dyadic interaction. Dubuque, IA: william C. Brown.

Harper, R. G., Wiens, A. N., \& Matarazzo, J. D. (1978). Nonverbal communication: The state of the art. New York: John Wiley \& Sons.

Harris, K. R. (1980). The sustained effects of cognitive modification and informed teachers on children's communication apprehension. Communication Quarterly, $\underline{28}(4), 47-55$.

Harrison, R. P. (1974) . Beyond words. Englewood Cliffs, NJ: Prentice-Hall.

Hittleman, D. R. (1988, May). Silent participants: Understanding students' nonoral responses. Paper presented at the International Reading Association convention, Toronto.

Hoffman, J. (1990, February). The role of teacher-student communication in the relationship between teacher expectations for students with communication apprehension and subsequent achievement: A preliminary correlational analysis. Paper presented at the WSCA convention, sacramento.

Hoffman, J. (1992). The role of teacher-student interaction in the relationship between teacher expectations for students with communication apprehension and subsequent achievement in two elementary school classrooms. Unpublished doctoral dissertation, University of Washington, seattle.

Hurt, H. T., \& Preiss, R. (1978). Silence isn't necessarily golden: Communication apprehension, desired social choice, and academic success among middle-school students. Human Communication Research, $\underline{4}(4), 315-328$.

Jick, T. (1979). Mixing qualitative and quantitative: Triangulation in action. Administrative science Quarterly, 24 (4), 602-611. 
Johnson, D. W., Johnson, R. T., \& Holubec, E. J. (1988). Cooperation in the classroom. Edina, MN: Interaction Book Company.

Jordan, W. J., \& Powers, W. G. (1978). Verbal behavior as a function of apprehension and social context. Human Communication Research, $4(4), 294-300$.

Jorgensen, D. L. (1989) . Participant observation. Newbury Park, CA: Sage.

Kagan, S. (1990) . Cooperative learning: Resources for teachers. San Juan Capistrano: University of California.

Kagan, J., \& Reznick, J. S. (1986). Shyness and temperament. In W. H. Jones, J. M. Cheek, \& S. R. Briggs (Eds.), Shyness: Perspectives on research and treatment (pp. 81-90). New York: Plenum Press.

Kawamitsu, I. (1992). Multiple code switching in an okinawan speech community: An ethnographic perspective. Unpublished master's thesis, Portland State University, Portland, OR.

Kelly, L. (1982). A rose by any other name is still a rose: A comparative analysis of reticence, communication apprehension, unwillingness to communicate, and shyness. Human communication Research, $\underline{8}(2), 99-113$.

Kelly, L. (1984). Social skills training as a mode of treatment for social communication problems. In J.A. Daly \& J. C. McCroskey (Eds.), Avoiding communication: Shyness, reticence, and communication apprehension (pp. 189-207). Beverly Hills, CA: Sage.

Kelly, L., \& Keaten, J. (1992). A test of the effectiveness of the reticence program at the Pennsylvania state University. Communication Education, 41(4), 361-372.

Kirk, J., \& Miller, M. L. (1986). Reliability and validity in qualitative research. Newbury Park, CA: Sage.

Knapp, M. L. (1980). Essentials of nonverbal communication. New York: Holt, Rinehart and Winston.

Kohout, F. J. (1984). statistics for social scientists. Malabar, FL: Robert E. Krieger Publishing Company 
Leary, M. R. (1983). The conceptual distinctions are important: Another look at communication apprehension and related constructs. Human Communication Research, $10(2), 305-312$.

Leathers, D. G. (1978). Nonverbal communication systems. Boston, MA: Allyn and Bacon.

Leathers, D. G. (1986). Successful nonverbal communication. New York: Macmillan.

Lecompte, M. D., \& Goetz, J. P. (1982). Problems of reliability and validity in ethnographic research. Review of Educational Research, $\underline{52}(1), 31-60$.

Levine, T. R., \& Mccroskey, J. C. (1990). Measuring trait communication apprehension: A test of rival measurement models of the PRCA-24. Communication Monographs, 57(1), 62-72.

Littlejohn, S. W. (1989). Theories of human communication. Belmont, CA: Wadsworth.

Lofland, J., \& Lofland, L. H. (1984). Analyzing social settings. Belmont, $C A$ : Wadsworth.

Lu, L. (1992). A qualitative case study of Chinese teaching assistants' communication in the U.S. university classroom. Unpublished master's thesis, Portland State University, Portland, OR.

Lustig, M. W., \& Grove, T. G. (1975). Interaction analysis of small problem-solving groups containing reticent and non-reticent members. Western speech Communication, $\underline{39}(3), 155-164$.

Mccracken, G. (1988) . The long interview. Newbury Park, $C A$ : Sage.

McCroskey, J. C. (1970). Measures of communication-bound anxiety. Speech Monographs, 37(4), 269-277.

Mccroskey, J. C. (1972). The implementation of a large scale program of systematic desensitization for communication apprehension. Speech Teacher, 21(4), 255-264.

McCroskey, J.C. (1976). The effects of communication apprehension on nonverbal behaviors. Communication Quarterly, 24(1), 39-44. 
Mccroskey, J.C. (1977a). Classroom consequences of communication apprehension. Communication Education, $\underline{26}(1), 27-33$.

McCroskey, J. C. (1977b). Oral communication apprehension: A summary of recent theory and research. Human Communication Research, $\underline{4}(1), 78-96$.

Mccroskey, J. C. (1980). Quiet children in the classroom: on helping not hurting. Communication Education, $\underline{29}(3), 239-244$.

Mccroskey, J. C. (1982). Oral communication apprehension: A reconceptualization. In $M$. Burgoon (Ed.), Communication yearbook 6 (pp. 136-170). Beverly Hills, CA: Sage.

McCroskey, J.C. (1984). The communication apprehension perspective. In J. A. Daly \& J. C. McCroskey (Eds.), Avoiding communication: Shyness, reticence, and communication apprehension (pp. 13-39). Beverly Hills, CA: Sage.

Mccroskey, J. C. , \& Andersen, J. F. (1976). The relationship between communication apprehension and academic achievement among college students. Human Communication Research, $\underline{3}(1), 73-81$.

McCroskey, J. C., Andersen, J. F., Richmond, V. P., \& Wheeless, L. R. (1981). Communication apprehension of elementary and secondary students and teachers. communication Education, 30(2), 122-132.

Mccroskey, J. C., Booth-Butterfield, S., \& Paynes, S. K. (1989). The impact of communication apprehension on college student retention and success. Communication Quarter 1y, 37(2), 100-107.

McCroskey, J. C., \& Daly, J. A. (1976). Teachers' expectations of the communication apprehensive child in the elementary school. Human communication Research, $\underline{3}(1), 67-72$.

Mccroskey, J. C., \& Richmond, V. P. (1980). The quiet ones: Shyness and communication apprehension. Dubuque, IA: Gorsuch Scarisbrick.

Mccroskey, J. C., \& Richmond, V. P. (1987). Willingness to communicate. In J. A. Daly \& J. C. McCroskey (Eds.), Personality and interpersonal communication (pp. 129-156). Newbury Park, CA: Sage. 
Mehrabian, A. (1968). An analysis of personality theories. Englewood Cliffs, NJ: Prentice-Hall.

Mehrabian, A. (1972) . Nonverbal communication. Chicago, IL: Aldine Publishing Co.

Mortensen, D. C., Arnston, P. H. \& Lustig, M. (1977). The measurement of verbal predispositions: scale development and application. Human Communication Research, $\underline{3}, 146-158$.

olson, w. C. (1930). The incidence of nervous habits in children. Journal of Abnormal Psychology, 25 (2), 72-92.

Patridge, I. E. (1883). Notes of talks on teaching given by Francis W. Parker. New York: E. L. Kellogg \& Company.

Patton, M. Q. (1980). Qualitative evaluation methods. Beverly Hills, CA: Sage.

Perlman, M. L. (1970). Intensive field work and scope samplings: methods for studying the same problem at different levels. In M. Freilich (Ed.), Marginal natives (pp. 293-338). New York: Harper \& Row.

Phillips, G. M. (1968). Reticence: Pathology of the normal speaker. Speech Monographs, 35(1), 39-49.

Phillips, G. M. (1984). Reticence: A perspective on social withdrawal. In J. A. Daly \& J. C. McCroskey (Eds.), Avoiding communication: Shyness, reticence, and communication apprehension (pp. 51-66). Beverly Hills, CA: Sage.

Phillips, G. M. (1986) . Rhetoritherapy: The principles of rhetoric in training shy people in speech effectiveness. In W. H. Jones, J. M. Cheek, \& S. R. Briggs (Eds.), Shyness: Perspectives on research and treatment (pp. 357-374). New York: Plenum Press.

Pilkonis, P. A. (1977). Shyness, public and private, and its relationship to other measures of social behavior. Journal of Personality, $\underline{45}(4), 585-595$.

Prusank, D. T., \& Comadena, M. E. (1987, May). Communication apprehension and academic achievement among elementary school students. Paper presented at the annual ICA convention, Montreal. 
Rich, J. (1968). Interviewing children and adolescents. New York: St. Martin's Press.

Richardson, S. A., Dohrenwend, B. S., \& Klein, D. (1965). Interviewing: Its forms and functions. London: Basic Books.

Richmond, V. P., Beatty, M. J., \& Dyba, P. (1985) . Shyness and popularity: Children's views. Western Journal of Speech Communication, 49(2), 116-125.

Richmond, V. P., \& McCroskey, J. C. (1985) . Communication: Apprehension, avoidance, and effectiveness.

scottsdale, AZ: Gorsuch Scarisbrick.

Richmond, V. P., \& Roach, K. D. (1992). Willingness to communicate and employee success in $U$. $S$.

organizations. Journal of Applied Communication

Research, 20 (1), 95-115.

Roethlisberger, F. J., \& Dickson, W. J. (1939). Management and the worker. Cambridge, MA: Harvard University Press.

Rosenthal, R., \& Jacobson, L. (1968). Pygmalion in the classroom: Teacher expectation and pupils'

intellectual development. New York: Holt, Rinehart and Winston.

Sattler, J. M. (1988). Assessment of children. San Diego: Jerome M. Sattler.

Schutz, A. (1967). The phenomenology of the social world. Evanston, Ill: Northwestern University Press.

Scott, M. D., \& Wheeless, L. R. (1977). The relationship of three types of communication apprehension to classroom achievement. The southern speech Communication Journal, $\underline{42(3), 246-255 .}$

Sevigny, M. J. (1981). Triangulated inquiry: A methodology for the analysis of classroom interaction. In $J$. L. Green \& C. Wallat (Eds.), Ethnography and language in educational settings (pp. 65-85). Norwood, NJ: Ablex.

Siegelman, C. K., Adams, R. M., Meeks, S. R., \& Purcell, M. A. $(1986)$. Children's nonverbal responses to a physicaly disabled person. Journal of Nonverbal Behavior, 10(3), 173-186.

Smith, K. U., \& Smith, W. M. (1958). The behavior of man. Madison, WI: Henry Holt and Company. 
Smythe, M. J., \& Powers, W. G. (1978). When Galatea is apprehensive: The effect of communication apprehension on teacher expectations. In B. D. Ruben (Ed.), Communication yearbook 2 (pp. 487-494). New Brunswick, NJ: Transactions Books.

Steward, I. A. (1968). Attitudes toward communication: The content analysis of interviews with eight reticent and eight non-reticent college students. Unpublished doctoral dissertation, Pennsylvania state University, University Park.

Terasaki, M., Morgan, C. O., \& Elias, L. (1984). Medical student interactions with cancer patients: Evaluation with videotaped interviews. Medical and Pediatric oncology, 12(1), 38-42.

Watson, A. K. (1989, May). Relationships among communication apprehension, reading achievement, teacher-perceived communication apprehension, and inteligigence. Paper presented at the annual ECA meeting, Ocean City, MD.

Watson, A. K., \& Monroe, E. F. (1990). Academic achievement: A study of relationships of $I Q$, communication apprehension, and teacher perception. Communication Reports, $3(1), 28-36$.

Wells, G. (1986). The meaning makers: Children learning language and using language to learn. Portsmouth, NH: Heinemann.

Wheeless, L. R. (1971). Communication apprehension in the elementary school. Speech Teacher, 20(4), 297-299.

Williams, F. (1986). Reasoning with statistics. New York: Holt, Rinehart and winston.

Young, R. K., \& Veldman, D. J. (1965). Introductory statistics for the behavioral sciences. New York: Holt, Rinehart and winston.

Zimbardo, P. G. (1977). Shyness: What it is, what to do about it. Reading, MA: Addison-Wesley.

Zimbardo, P. G., Pilkonis, P. A., \& Norwood, R. M. (1975). The social disease called shyness. Psychology Today, 8 $(12), 68-72$. 
APPENDIX A

MEASURE OF ELEMENTARY COMMUNICATION APPREHENSION--MECA 
Measure of Elementary Communication Apprehension--MECA

(Garrison \& Garrison, 1979a)

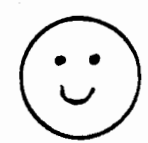

very happy

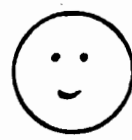

happy

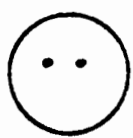

no feeling

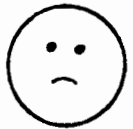

unhappy

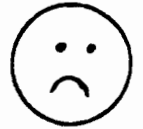

very unhoppy

I like it a lot I like it

1 don't care I don't like it I really don't like it

1. How do you feel when you talk to teachers or your principal?

2. How do you feel about talking to someone you don't know very well?

3. How do you feel when you hold something and talk about it?

4. How do you feel about talking to people who aren't close friends?

5. How do you feel about talking when you have a new teacher?

6. How do you feel about talking a lot when you are on a bus?

7. How do you feel when you are picked to be a leader of a group?

8. How do you feel about talking a lot in class?

9. How do you feel when you talk in front of an audience?

10. How do you feel about talking to other people?

11. How do you feel about trying to meet someone new?

12. How do you feel after you get up to talk in front of the class?

13. How do you feel when you know you have to give a speech?

14. How would you feel about giving a speech on television?

15. How do you feel about talking when you are in a small group?

16. How do you feel when you have to talk in a group?

17. How do you feel when the teacher calls on you?

18. How do you feel about talking to all of the people who sit close to you?

19. How do you feel when the teacher wants you to talk in class?

20. How do you feel when you talk in front of a large group of people?

Facial indicators requested by Garrison and Garrison (1979a) showing levels of fear instead of like and dislike were provided by Hoffman (1990) with accompanying written 
descriptions (see Figure 1 for Hoffman's modification). The first question above was divided into two questions to reflect the difference between talking to teachers or to a principal. Question six above was reworded as children may not always be transported by bus but generally use the playground daily. Question 14 above was eliminated as inappropriate for the everyday experience of a young child. 
APPENDIX B

UPPER BODY SELF-ADAPTOR SCORING FORM (UBSSF) 


\section{Upper Body Self-Adaptor Scoring Form (original instrument)}

Student:

name

identifying

Touching separate parts of head, self, clothes, jewelry (adornments)

Playing with something--e.g., a pencil or other object

Rubbing self or object

Holding self, cradling or supporting upper body part

Grooming--e.g., flipping or brushing hair with hand(s)

Biting self or object

Scratching self

Squeezing self or object

Tugging at clothing or upper body part

Pinching self

Licking lips

Has the student been at the school for the entire year? If not, how many weeks or months?

Ethnic background

Age 
APPENDIX $C$

DIRECTIONS FOR USE OF THE UPPER BODY SELF-ADAPTOR SCORING FORM (UBSSF) 
Directions for Use of the Upper Body Self-Adaptor scoring Form (UBSSF)

Original Directions Used in Pilot Study:

--observe each child and tally the behaviors displayed.

--Keep volume on VCR off when reviewing videotapes.

--Indicate continuous self-adaptors with (). They must be longer than three seconds.

--Do not count use of an object such as a pencil that seems to be in motion for the purpose of punctuating speech (an object adaptor).

Revised Directions Used With Study Sample:

*--Observe each child three times in a row, and tally and note the behaviors displayed. The first and second counts are category tallies. The third count is a written sequential account of the occurrence of the self-adaptors and is made at the bottom of the page.

*--Do not count behaviors unless the child can be identified and the movement clearly seen. (e.g., Do not count isolated hand movements when hand/arm is only part of the child that is visible and it is not possible to identify the subject.)

*--Use a voice-activated recorder for dictation of self-adaptors that occur so eye contact with the videotape can be maintained. Later, the tally of self-adaptors can be made by listening to the tape recorder without the distraction of viewing the tape and trying to look down at the tally sheet to locate the proper category of self-adaptors. Do not use an important word at the beginning of the statement as it may be lost as the recorder activates.

*--Keep the volume on the VCR off to concentrate on behaviors and to keep the recorder from being activated by the videotape.

*--Indicate continuous self-adaptors with (). They must be longer than three seconds. If the count differs for a child, use the final sequential tally.*

or glasses.

*--Do not count touching of headphones, dials, watches 
--Do not count use of an object such as a pencil that seems to be in motion for the purpose of punctuating speech (an object adaptor).

*--Exclude out-of-group behaviors due to difficulty in viewing (when camera is panning the room, or focusing on a group while including additional students).

*--When a new camera view is introduced or when a break occurs in filming the same view, count a viewed behavior as an additional one. For example, a behavior may appear to be continuing in the new view, but should be counted as a separate behavior since timing is a factor in judging continuous and discrete movements and can not be determined if there is an interruption.

*--When hand position changes, count as a separate movement. For example, a hand movement may "slide" from the forehead to under the chin, or from the front of the face to the side of the head. Count these as separate movements.

*--Differentiate between touching movements that are below the waist and not counted, such as touching a leg or foot, and those that seem to occur below the waistline but are actually performed in front of the body. The latter are counted.

*Changes made in Directions following the pilot study. 


\section{APPENDIX D}

LETTER OF EXPLANATION TO PARENTS--

PILOT STUDY 


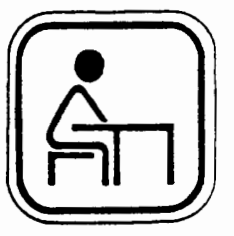

\section{Beaverton Schools \\ District 48}

P.O. Box 200 Beaverion, Oregon $97075-0200$

\section{Dear Parents,}

Linda Dunn has been a teacher at Aloha Park School for the past seven years, and is currently on a year's sabbatical leave. She has also helped develop speech curriculum for elementary students in the Beaverton School District. She is now completing her thesis work for a master's degree in speech Communication at Portland state University, and would like our assistance in that project.

Her research involves the study of children who are nervous about communicating with others. Linda hopes to gain information that will be of assistance to teachers of students who may become uneasy in a communication situation.

Linda will be conducting a preliminary study in your child's classroom. She will observe and videotape a brief segment of a class session and administer a short questionnaire on communication. She will then observe and videotape another brief session segment and administer the questionnaire a second time. Her final activity will be an interview with two or three selected students who will talk with her individually while viewing a section of the videotape. The total time needed will be approximately twelve minutes for each administration of the questionnaire, thirty minutes of observation in the classroom and ten to twelve minutes for an interview with a student.

The Beaverton School District Director of Research and Evaluation and the Portland State University Human Subjects Committee have approved Linda's proposal for this study. Your consent is part of that approval process as each child and parent must give permission before the child participates in the study.

Iinda has explained the pilot study to the children in the class, and your child has been asked to bring home the attached consent form for you to review with your child, sign and return to the classroom teacher.

The teachers who will be cooperating in this effort join me in encouraging your support of Linda Dunn's work. Please read the attached "Informed Consent" with your child, sign and return it as soon as possible to the school. If you have any questions, you may call me at 591-4502 or Linda Dunn at 646-4377. Thank you for your participation.

sincerely,

Principal

Aloha Park School 
APPENDIX E

INFORMED CONSENT 
I, hereby agree to allow my child, to participate in the research project called "Communication Apprehension and Associated Nonverbal Behaviors in the Primary School Child", conducted by Linda Dunn of the Beaverton School District under the direction of the Speech Communication Department of Portland State University.

I understand that the project will include use of a short questionnaire, brief, recorded observations and a possible interview with my child; and that collected data will be used to determine students' communication styles. I understand that there are no anticipated risks or inconveniences to my child, that no identifying information will be associated with my child's responses, and that my child's responses will be entirely confidential. My child will not receive direct benefit from participation in this study but his/her assistance in the experiment may help to increase knowledge in a way that may benefit others in the future.

I understand that my child is free to withdraw from participation in this study at any time without any penalty. I have read and understand this "Informed consent" document, and I agree that my child may participate.

Date

Signature of Parent/Guardian

Signature of Child

Note: If you experience problems that are the result of your child's participation in this study, please contact the Chair of the Human Subjects Research Committee, office of Grants and contracts, 345 cramer Hall, Portland state University, (503) 725-3417. If you have any questions about this study, please contact Linda Dunn at 646-4377 or Dr. Susan Poulsen at 725-3531. 


\section{APPENDIX F}

LETTER OF EXPLANATION TO PARENTS--

MAIN STUDY 


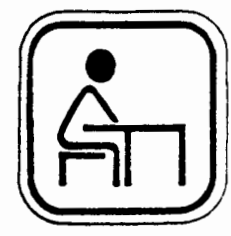

\section{Beaverton Schools \\ District 48}

P.O. Box 200 Beaverton, Oregon 97075.0200

Aloha Park Elementary School

\section{Dear Parents,}

Linda Dunn has been a teacher at Aloha Park School for the past seven years, and is currently on a year's sabbatical leave. She has also helped develop speech curriculum for elementary students in the Beaverton school District. She is now completing her thesis work for a master's degree in Speech Communication at Portland State University, and would like our assistance in that project.

Her research involves the study of children who are nervous about communicating with others. Linda hopes to gain information that will be of assistance to teachers of students who may become uneasy in a communication situation.

Iinda will observe and videotape two lessons in your child's third grade classroom and administer a short questionnaire on communication. She will then observe and videotape two additional lessons in the classroom and administer the questionnaire a second time. Her final activity will be an interview with selected students who will talked with her individually while viewing a section of the videotape. The total time needed will be approximately twelve minutes for each administration of the questionnaire, 1 hour and 20 minutes of observation in each classroom, and ten to twelve minutes for an interview with a student.

The Beaverton School District Director of Research and Evaluation and the Portland State University Human Subjects Committee have approved Linda's proposal for this study. Your consent is part of that approval process as each child and parent must give permission before the child participates in the study.

Linda has explained the study to the children in class, and your child has been asked to bring home the attached consent form for you to review with your child, sign and return to the classroom teacher.

The teachers who will be cooperating in this effort join me in encouraging your support of Linda Dunn's work. Please read the attached "Informed Consent" with your child, sign and return it as soon as possible to the school. If you have any questions, you may call me at 591-4502 or Linda Dunn at 646-4377. Thank you for your participation.

sincerely,

Principal

Aloha Park School 
APPENDIX G

MECA SCORES/FREQUENCY COUNTS OF SELF-ADAPTORS--STUDY SAMPLE 


\section{MECA Scores/Frequency Counts of Self-Adaptors-- Study Sample}

M1 and M2 are scores for MECA Time 1 and Time 2 scores. SAl through SA4 represent the frequency counts of discrete or brief self-adaptors and those which were continuous or lasting more than three seconds.

\begin{tabular}{lllllll} 
Class A & M1 & M2 & SA1 & SA2 & SA3 & SA4 \\
\cline { 2 - 3 } & 27 & 41 & $2-1$ & $4-2$ & $7-4$ & $9-5$ \\
A1 & 52 & 59 & $25-7$ & $21-10$ & $10-0$ & $3-0$ \\
A2 & 56 & 58 & $25-4$ & $13-5$ & $22-3$ & $50-19$ \\
A3 & 36 & 40 & $14-5$ & $6-2$ & $1-0$ & $2-0$ \\
A4 & 39 & 32 & $24 *$ & $35-21$ & $93-10$ & $22-6$ \\
A5 & 52 & 58 & $12-5$ & $7-2$ & $7-4$ & $1-0$ \\
A6 & 57 & 68 & $32-10$ & $11 *$ & $3-0$ & $9-2$ \\
A7 & 48 & 40 & $21-7$ & $6-2$ & $31-15$ & $38-11$ \\
A8 & 55 & 58 & $22-11$ & $11-4$ & $21-8$ & $12-5$ \\
A9 & 67 & $60 * \star$ & $32-8$ & $3-0$ & $26-15$ & $9-2$ \\
A10 & 37 & 54 & $50-14$ & $5-1$ & $11-5$ & $10-2$ \\
A11 & $49 *$ & 68 & $24 \star$ & $14-8$ & $10-6$ & $11-5$ \\
A12 & & & & & & \\
Fema1es & & & & & & \\
A13 & 51 & 47 & $42-10$ & $12-5$ & $12-3$ & $16-9$ \\
A14 & 55 & 48 & $15-9$ & $7-5$ & $16 *$ & $1-0$ \\
A15 & 57 & 47 & $15-7$ & $7-3$ & $16-7$ & $20-5$ \\
A16 & 57 & 64 & $20-10$ & $15-5$ & $17-5$ & $9-2$ \\
A17 & 56 & 59 & $27-8$ & $10-2$ & $33-10$ & $18-8$ \\
A18 & 23 & 22 & $5-3$ & $22-8$ & $15-4$ & $10-1$ \\
A19 & 68 & 72 & $22-8$ & $23-12$ & $11-8$ & $9-1$ \\
A20 & 43 & 42 & $11-4$ & $5-1$ & $10-4$ & $15-4$
\end{tabular}

* Student was absent, and an assigned class or cell mean was used which is shown here as a whole number. $* \star$ student chose middle option on MECA questionnaire ("Doesn't bother me") for each item. This option features the least expressive facial expression, and is the only choice which remains in the same position on the likert scale throughout the questionnaire. 


\begin{tabular}{lllllll} 
C1ass B & M1 & M2 & SA1 & SA2 & SA3 & SA4 \\
\hline Males & 63 & $59 *$ & $9-2$ & $3-0$ & $4-1$ & $28-11$ \\
B1 & 66 & 62 & $12-5$ & $2-0$ & $3-1$ & $4-3$ \\
B2 & 27 & 28 & $11-5$ & $11-6$ & $4-4$ & $6-4$ \\
B3 & 57 & 93 & $0-0$ & $10-1$ & $13 *$ & $29-12$ \\
B4 & 45 & 48 & $16-5$ & $33-8$ & $12-3$ & $3-0$ \\
B5 & 72 & 75 & $10-1$ & $5-1$ & $19-9$ & $18-6$ \\
B6 & 63 & 51 & $7-1$ & $18-7$ & $18-5$ & $2-1$ \\
B7 & $60 * \star$ & $60 * \star$ & $7 \star$ & $5-2$ & $8-5$ & $14-2$ \\
B8 & 61 & 64 & $8-3$ & $6-2$ & $5-0$ & $13 *$ \\
B9 & 61 & 64 & $2-1$ & $1-0$ & $25-12$ & $29-10$ \\
B10 & 62 & 56 & $4-2$ & $3-1$ & $21-4$ & $4-0$ \\
B11 & 62 & 50 & $1-0$ & $9 \star$ & $12-9$ & $10-5$ \\
B12 & & & & & & \\
Females & & & & & & \\
B13 & 47 & 59 & $9-5$ & $8-0$ & $17-10$ & $19-4$ \\
B14 & 62 & 64 & $0-0$ & $1-0$ & $1-0$ & $18-5$ \\
B15 & 67 & 61 & $4-1$ & $3-0$ & $7-2$ & $6-2$ \\
B16 & 58 & 60 & $1-1$ & $13-2$ & $15-3$ & $24-2$ \\
B17 & 58 & 62 & $8-6$ & $5-0$ & $3-0$ & $12-4$ \\
B18 & 41 & 42 & $16-7$ & $15-3$ & $13 *$ & $7-3$ \\
B19 & 72 & 66 & $15-2$ & $2-0$ & $15-0$ & $4-2$ \\
B20 & 31 & 29 & $22-4$ & $13-5$ & $16 *$ & $13-4$ \\
B21 & 59 & 53 & $8-0$ & $18-4$ & $6-3$ & $13-5$ \\
B22 & 57 & 58 & $3-0$ & $9-0$ & $12-6$ & $5-2$ \\
& & & & & &
\end{tabular}

* Student was absent, and an assigned class or cell mean was used which is shown here as a whole number. **student chose middle option on MECA questionnaire ("Doesn't bother me") for each item. This option features the least expressive facial expression, and is the only choice which remains in the same position on the likert scale throughout the questionnaire. 
APPENDIX H

DEMOGRAPHIC INFORMATION FOR STUDY SAMPLE 
Demographic Information for study sample

\begin{tabular}{llll} 
Class A & $\begin{array}{l}\text { Dchool } \\
\text { Program }\end{array}$ & $\begin{array}{l}\text { Date of Ethnic } \\
\text { Birth }\end{array}$ & $\begin{array}{l}\text { Date of } \\
\text { Backoround }\end{array}$ Entry \\
\hline
\end{tabular}

Males

A1

A2

A3

A4

A5

A6

A7

A8

A9

A10

A11

A12

4-04-83

9-29-83

8-24-82

Hispanic

9-05-89

$5-03-83$

Hispanic

9-06-90

LD*

$4-22-83$

LD *

$7-22-82$

1-06-83

9-13-82

$8-26-83$

CNSI*

$6-17-82$

$\begin{array}{ll}\text { CNSL* } & 1-02-83 \\ \text { SP.ED.* } & 5-27-83\end{array}$

9-03-91

8-30-88

9-05-89

9-08-87

9-06-88

1-14-91

4-11-90

Hispanic

9-04-90

11-18-91

9-04-90

Females

A13

LD *

1-29-83

$12-26-82$

$4-18-83$

6-06-83

2-06-83

$7-16-83$

6-22-83

7-27-83

$4-06-92$
$9-03-91$
$2-19-91$
$9-06-88$
$9-06-88$
$9-06-88$
$9-06-88$
$9-06-88$

A20

A15

A17

A 18 


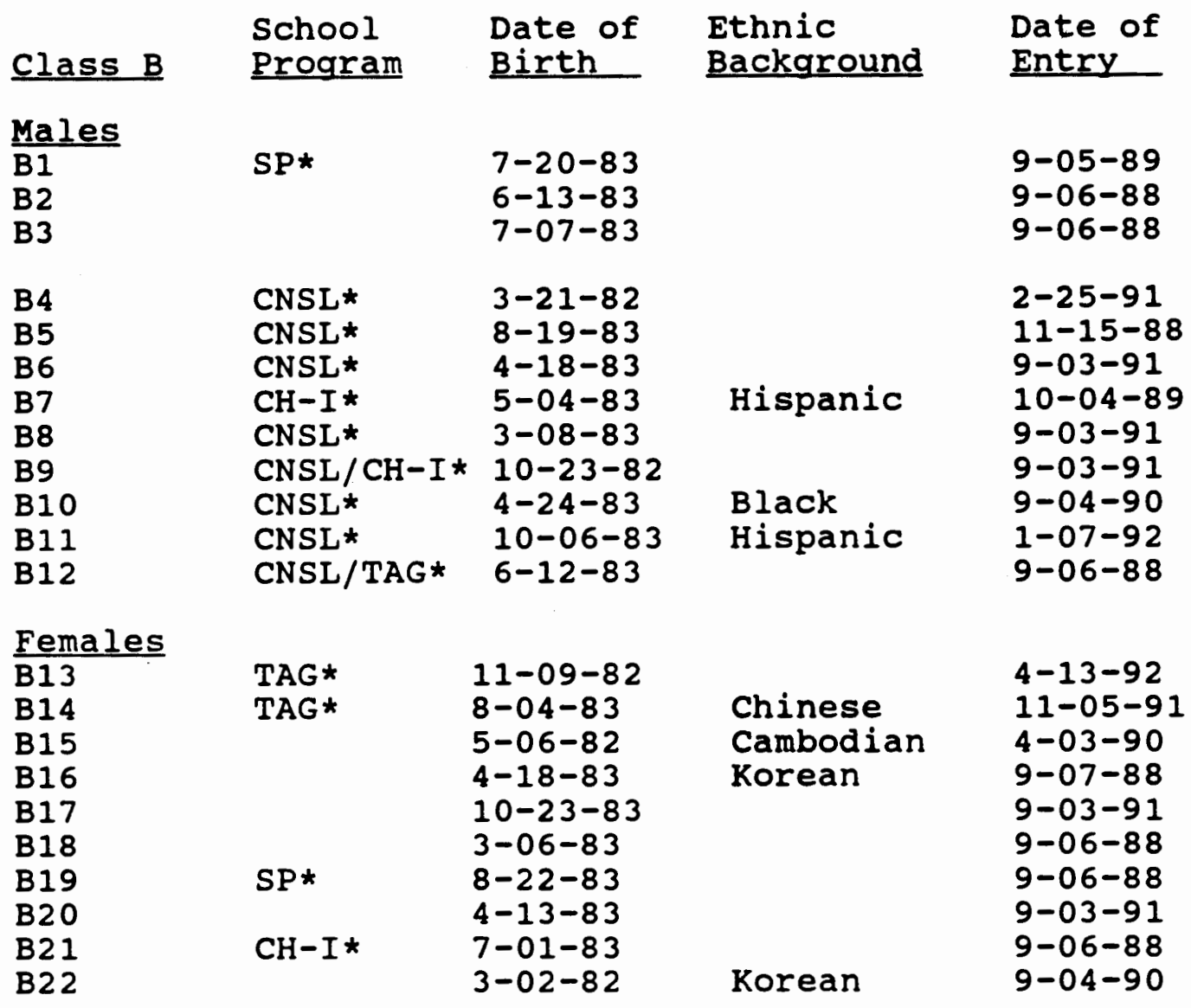

*Students participate in special program(s):

TAG (Talented and Gifted) The student attends separate classes conducted by the building TAG teacher.

CH-1 (Chapter One) The low income population of the school allows students with reading difficulties to receive extra help.

SP (Speech) The student receives help in speech or language from the speech therapist.

$\underline{L D}$ (Learning Disabled) The student performs below an expected level relative to ability and receives help in one or more subjects.

CNSL (Counseling) The student receives counseling services from the child developmental specialist in the building for problems which occur at home or at school.

SP.ED. (Special Education) The student attends classes in the special education department located in the building. Handicaps may include severely impaired language development, Downs Syndrome and other forms of retardation. Such students are mainstreamed into the grade level classrooms to the extent that they can benefit from such inclusion.

Note: Students are Caucasian unless otherwise noted. 
APPENDIX I

FOLLOW UP INFORMATION ON STUDY SAMPLE CA STUDENTS 
Teachers $A$ and $B$ had followed their CA students' activities as they moved on to new classrooms, and they shared information with the CA students' new teachers and related to me that they were interested in how their former students were getting along. They reflected on the personal nature of the problems their former students experienced, but compared them to other students with similar or more serious problems than those identified as being communicatively apprehensive. Other external information was also obtained at this time (see Appendix $\mathrm{H}$ ) to add to the qualitative data.

Though I was not able to reach Teacher $A$ for comments regarding student A7 six months after completion of the study, the fourth grade teacher described him as a "motor mouth," in the classroom, and did not perceive him as being even slightly anxious about talking with others or as having nervous speech patterns. Student A7 had attended the school since first grade, and had not received any special services from the school. He appeared to have no history of family, social, or behavioral problems.

Teacher $A$ again described Male student $A 10$ as a "loner," a descriptor he had used for the hypothetical CA student at the time of the teacher interviews. Based on classroom observations, this is not a descriptor I would have used for this student, since he interacted with group members and participated in the filmed classroom activities. Teacher $A$ indicated that student $A 10$ had exhibited what he would call "a strong sense of justice," but in a further reference he clarified the concept as "not letting up until he got revenge." This appeared to confirm Teacher A's perception of the boy's behavioral problems.

Student Alo's fourth grade teacher also stated that he had not done well so far in school. Threats of loss of privileges seemed to have no effect in urging him to do his work, his grades were quite low, and the teacher used the same word to describe him that Teacher $A$ had used--a "loner." He had not been identified to receive any special services other than counseling. Registration records indicated that he had only attended the school for one year, but the secretary told me that he had also attended at an earlier time until the family moved away for about a year.

School records indicate that $C A$ Male student $A 12$ had only been in attendance since the fall of the school year. There appeared to be no history of family, social, or behavioral problems for this student. I was aware that he was receiving services from the special education department located in the school, though I did not know the nature of his disability and none was apparent. 
In retrospect six months later, Teacher $A$ commented that student A12 had tried hard in class, but had to struggle a bit to keep up with the other students. His fourth grade teacher related that student A12's reading skills were average, and that he appeared to be working hard, and was doing fairly well in school considering his placement in special education.

Six months after completion of the study, Teacher A said that Female student A19 was still at the school and getting along fairly well, though she had to work hard to keep up with the other students. She had not received any special services at the school, and no history of family, social, or behavioral problems was known for this student. School records indicated that she had been in attendance at the school since the first grade.

Six months later, Teacher B reported that Male student B4 was still having peer difficulties, and had taken on a kind of "victim role" in the classroom in that he complained often about mistreatment from others. This kind of comment was noted by me during his interview. Though he did not receive formal services other than counseling, student B4 went to the special education center where his position as a "big brother" had increased his self esteem in his teacher's estimation.

References to his "troubled nature" by his teacher, and the possibility that he would soon be receiving services for his problems led me to suspect the presence of other issues which may have contributed to certain classroom behaviors and the marking of almost all the extreme responses in the second MECA (Time $2=93$ ) though he did not do this during Time 1 (score $=51$ ). Student B4 was a tall and somewhat overweight boy, and I had thought he was older than some of the other students. In fact, the demographic information obtained revealed that he was almost a year and a half older than the youngest $C A$ student interviewed.

I later learned from his teacher of Male student B6's personal circumstances which were extremely unfortunate, and suggested some other reasons for his behaviors and responses during the interview. Considering his background, he did share quite a bit of information about himself, although as noted in Chapter IV, he was somewhat elusive during the interview. He was receiving counseling services to help him with his problems, and at the time of the interview appeared to be able to continue his school life without serious interference from his other problems. Teacher B later related that Male student $B 6^{\prime} s$ placement the following year in a combination class of third and fourth graders had been helpful in allowing him to be in the "more grown up part of 
the class." However, shortly after he received a good self-discipline award, he was then placed in a counseling group when his behaviors later deteriorated.

Teacher B later reported that Female student B19 seemed more sure of herself possibly because she had grown much taller since the time of the study. Her fourth grade teacher agreed with Teacher $B$ that she was more confident in the following year, and that her speech problem had disappeared.

student B19 had received services from the speech therapist located at the school who related that her speech problem consisted of mispronunciations usually connected with what is termed "babytalk." Since this problem was diagnosed as a slight developmental delay, it was being monitored by the therapist with the expectation that the speech pattern would soon disappear. However, even minimal attention by the therapist which is usually initiated by a student leaving the room for help, and any notice of her unusual speech by her peers might have influenced student B19's responses on the MECA. By the end of the year when the main study took place, no obvious speech defect was detectable by the researcher during the taped interview. School records indicated that she had attended the school since first grade, and she was the youngest of the $C A$ students. No history of family, social, or behavioral problems was found for this student. 